Georgia State University

ScholarWorks @ Georgia State University

8-12-2016

\title{
Measuring Caregiver Impact on Children's Violent News Media Exposure: Development and Initial Validation of the Caregiver Responses to Youth Media Exposure (CRYME)
}

Susanna Crowell McQuarrie

\section{Recommended Citation}

Crowell McQuarrie, Susanna, "Measuring Caregiver Impact on Children's Violent News Media Exposure: Development and Initial Validation of the Caregiver Responses to Youth Media Exposure (CRYME)." Thesis, Georgia State University, 2016. doi: https://doi.org/10.57709/8838034

This Thesis is brought to you for free and open access by the Department of Psychology at ScholarWorks @ Georgia State University. It has been accepted for inclusion in Psychology Theses by an authorized administrator of ScholarWorks@Georgia State University. For more information, please contact scholarworks@gsu.edu. 


\title{
MEASURING CAREGIVER IMPACT ON CHILDREN'S VIOLENT NEWS MEDIA EXPOSURE: DEVELOPMENT AND INITIAL VALIDATION OF THE CAREIVER RESPONSES TO YOUTH MEDIA EXPOSURE (CRYME)
}

by

\author{
SUSANNA CROWELL MCQUARRIE
}

Under the Direction of Nicole Caporino, $\mathrm{PhD}$

\begin{abstract}
Research has shown that media exposure to violence is positively correlated with anxiety and posttraumatic stress symptoms in children (Becker-Blease et al. 2008), and parents can influence children's responses to media (Otto et al. 2007). Few studies have examined specific parenting behaviors related to their children's response to violent news media exposure; which is further limited by the lack of available measures with adequate psychometric support (Comer \& Kendall, 2007). The current study addresses this gap by developing a measure of specific ways that caregivers may influence their children's exposure and reaction to violent news. Item content was generated based on a literature review and focus group interview with six parents. Using a sample of 702 participants recruited through Amazon Mechanical Turk, exploratory factor analysis was conducted on the initial 74-item measure of Caregiver Responses to Youth Media Exposure (CRYME). With a total of 35 items, a three-factor solution emerged.
\end{abstract}

INDEX WORDS: Violent news media, Parenting, Standardized measure 


\section{MEASURING CAREGIVER IMPACT ON CHILDREN'S VIOLENT NEWS MEDIA EXPOSURE: DEVELOPMENT AND INITIAL VALIDATION OF THE CAREIVER RESPONSES TO YOUTH MEDIA EXPOSURE (CRYME)}

by

\section{SUSANNA CROWELL MCQUARRIE}

A Thesis Submitted in Partial Fulfillment of the Requirements for the Degree of Master of Arts

in the College of Arts and Sciences

Georgia State University

2016 
Copyright by

Susanna Jane Crowell McQuarrie 2016 


\section{MEASURING CAREGIVER IMPACT ON CHILDREN'S VIOLENT NEWS MEDIA EXPOSURE: DEVELOPMENT AND INITIAL VALIDATION OF THE CAREIVER RESPONSES TO YOUTH MEDIA EXPOSURE (CRYME)}

by

SUSANNA CROWELL MCQUARRIE

Committee Chair: Nicole Caporino

Committee: Christopher Henrich

Robert Latzman

Electronic Version Approved:

Office of Graduate Studies

College of Arts and Sciences

Georgia State University

August 2016 


\section{DEDICATION}

To my husband, thank you for your never ending love and support. To my mother for believing in me and encouraging me to accomplish my dreams, no matter what. 


\section{ACKNOWLEDGEMENTS}

Thank you to Dr. Caporino for invaluable edits and contributions to this project. And thank you to Drs. Henrich and Latzman for ensuring the academic rigor of the project. 


\section{TABLE OF CONTENTS}

ACKNOWLEDGEMENTS $\mathbf{V}$

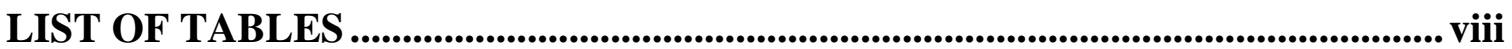

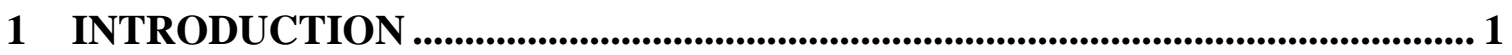

1.1 Immediate Impact of Childhood Media Exposure ........................................ 2

1.2 Long-Term Impact of Childhood Media Exposure ....................................... 4

1.3 Caregiver Influence on Child's Response to Media Exposure......................... 5

1.4 Current Recommendations for Caregivers................................................. 11

1.5 Limitations of Current Literature ..................................................................... 12

2 PRIMARY RESEARCH AIM: MEASURE DEVELOPMENT AND

PRELIMINARY EVALUATION .................................................................................... 13

2.1 Study 1: Qualitative Methods ............................................................... 13

2.2 Study 1: Qualitative Results .......................................................................... 19

2.3 Study 2: Quantitative Methods ......................................................................... 20

2.4 Study 2: Quantitative Results ............................................................................ 31

3 SECONDARY RESEARCH AIM: CRYME MEASURE RELATION TO AGE

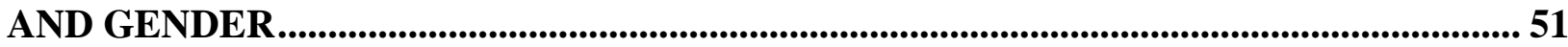

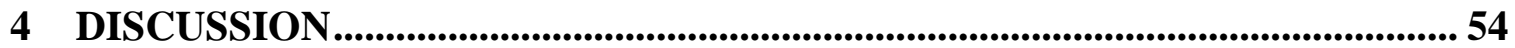

4.1 Limitations. ................................................................................................. 60

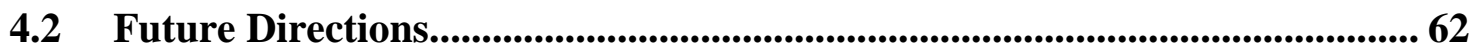


REFERENCES

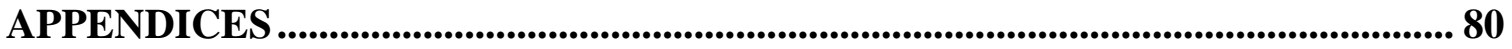

Appendix A: Caregiver's Response to Youth Media Exposure (CRYME) Initially

Proposed ................................................................................................................................................................ 80

Appendix B: Atlanta Major Neighborhood Demographics ......................................... 84

Appendix C: Discussion Questions for Caregiver Focus Group ............................... 85

Appendix D: Tong, Sainsbury, \& Craig (2007) Focus Group Checklist.................. 87

Appendix E: Themes Identified by Researchers ............................................................... 90

Appendix F: Consistency and Organization of Themes ................................................ 92

Appendix G: Evidence from Data Supporting Themes ................................................ 93

Appendix H: Caregiver's Response to Youth Media Exposure (CRYME) Pre-EFA

Appendix I: Insufficient Effort Response (IER) Items ............................................... 102

Appendix J: Frequency of Media Use .............................................................................. 103

Appendix K: Demographics Questions .............................................................................. 105

Appendix L: CRYME Item Frequencies ........................................................... 108

Appendix M: Caregiver's Response to Youth Media Exposure (CRYME) Post- 


\section{LIST OF TABLES}

Table 1 Sample Demographics 20

Table 2 National Demographic Information for U.S. Households with Children Aged 6-18 ...... 22

Table 3 Means and Standard Deviations of Child Media Exposure ........................................ 23

Table 4 CRYME items EFA (Promax Rotation) Factor Loadings First Analyses ..................... 32

Table 5 CRYME items EFA (Promax Rotation) Factor Loadings Final Analyses .................... 44

Table 6 CRYME Item Means and Standard Deviations .................................................... 47

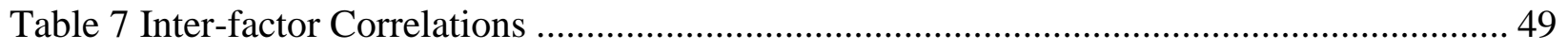

Table 8 Independent Samples t-test of Items by Gender ............................................... 51

Table 9 Independent Samples t-test Between Factor Scores and Gender............................... 53

Table 10 Correlations between Facotrs and Child Age in Years ............................................ 54 


\section{INTRODUCTION}

Children are exposed to many forms of media. In a recent study by the Pew Research Center (2013), 43\% of people polled indicated that using mobile devices (e.g., tablets; cell phones) has increased the amount of news that they consume. Childhood media exposure in general can influence mental health (Brown \& Bobowski, 2011). A child's exposure to violent news, in particular, has been positively associated with worry about similar events happening to him/her or to a relative (Becker-Blease, Finkelhor, \& Turner, 2008). A national survey of people not directly exposed to the September 11 terrorist attacks showed that $35 \%$ of children exhibited symptoms of posttraumatic stress disorder (PTSD) following media exposure (Schuster et al., 2001).

Parents may attempt to minimize their children's negative emotional responses to media by limiting exposure (Strasburger et al., 2010). However, restricting access to media is not always a successful strategy for reducing anxiety in children (Buijzen, van der Molen, \& Sondij, 2007). Additionally, completely limiting a child's exposure to media is not feasible. For instance, Sumiala and Tikka (2011) found that children were able to access videos of school shootings on YouTube while at school. Thus, it is important to investigate additional ways to influence a child's emotional response to violent media.

Given that violent news media exposure has been positively correlated with emotional and behavioral difficulties (e.g., anxiety symptoms) in children and that caregivers likely play a role in their children's responses to media (e.g., Becker-Blease, Finkelhor, \& Turner, 2008; Buijzen, van der Molen, \& Sondij, 2007), research is needed to identify optimal ways for caregivers to buffer the effects of violent news media on their children's mental health. The ideal strategies for caregivers to use may also differ by child age and gender. However, there currently 
does not exist any measure of specific ways that caregivers may influence their children's media exposure and response to violent news (Comer \& Kendall, 2007).

Primary Research Aim: To develop and explore the factor structure of a measure of specific ways that caregivers may influence their children's exposure and response to media coverage of violent events: the Caregiver Responses to Youth Media Exposure (CRYME).

Secondary Research Aim: To explore the relationships of child age and gender to caregiver responses to youth media exposure.

\subsection{Immediate Impact of Childhood Media Exposure}

Media exposure to violence (e.g., exposure time/frequency) is positively correlated with anxiety, posttraumatic stress symptoms, depression, separation anxiety, sleep problems, and aggressive behaviors in children (e.g., Becker-Blease, Finkelhor, \& Turner, 2008; Collimore et al., 2008; Johnson et al., 2002; see review by Comer \& Kendall, 2007; Owens et al., 1999). In a survey of family media habits, approximately $62 \%$ of parents of youth between 2 and 17 years old reported that their child had been frightened and anxious about media content at some point, and $31 \%$ reported that such anxiety was severe enough to interfere with the child's sleeping or eating habits and/or to result in thought disturbances or avoidance of similar situations (Gentile \& Walsh, 2002).

Most studies that have examined the impact of violent news events (versus fictional violence) have assessed children's responses to news coverage of the September 11 terrorist attacks (see review by Comer \& Kendall, 2007; Saylor et al., 2003, Lengua et al., 2005). Others have investigated the effects of exposure to media coverage of natural disasters on children's anxiety and posttraumatic symptoms (Fremont, 2004; Weems et al., 2012; Ortiz et al., 2011). For 
example, Ortiz et al. (2011) showed children either a neutral weather clip or a clip of a natural disaster (i.e., a hurricane). Children who watched the media clip of a hurricane had significantly higher state anxiety levels than the children who watched the neutral weather clip. The finding that exposure to violent news media is associated with negative mental health outcomes for children has been consistent regardless of the type of violence or trauma (e.g., man-made versus natural disasters; e.g., Comer \& Kendall, 2007; Lengua et al., 2005).

Given the potential for negative emotional impact, Comer and Kendall (2007) have referred to media exposure to violent news as a type of "second hand trauma" (i.e., trauma that does not involve being physically present during a life-threatening event). In support of the idea of "second hand trauma," a study completed following the events of September 11 showed that physical distance from the terrorist attack did not predict levels of anxiety and posttraumatic stress symptoms, suggesting that even children who were not in imminent physical danger may have experienced the exposure (e.g., via the media) as traumatic (Lengua et al., 2005).

Preexisting vulnerabilities, in addition to content of and time spent in contact with media, may put children at increased risk for internalizing problems following exposure to violent news, though findings are mixed. In a study of children's responses to a series of hurricanes, Weems et al. (2012) found that the association between television viewing of hurricane coverage and posttraumatic stress was stronger among children who had preexisting posttraumatic symptoms. Also, the relationship between television consumption and levels of perceived personal threat has been found to be stronger for children with greater anxiety (Comer et al., 2008a). A study evaluating the impact of a physiological risk factor, autonomic nervous system reactivity, suggested that degree of media exposure is less critical for youth at high risk - as they reliably show poorer outcomes following exposure (Busso, McLaughlin, \& Sheridan, 2014). The 
relationship between pretrauma autonomic nervous system reactivity and PTSD severity among adolescents (ages 14-19) two weeks after the Boston Marathon Bombings interacted with the degree of exposure to media coverage of the event to predict self-reported PTSD symptoms in children not present at the marathon. At low levels of pretrauma risk factors, media exposure was significantly and positively associated with the number of PTSD symptoms. However, this relationship was not significant at high levels of pretrauma risk factors. The mixed findings in regard to the relationship of media exposure, preexisting risk factors, and subsequent internalizing problems may differ due to the type of risk factor (i.e., physiological or emotional) studied and measurement of these risk factors.

There is clear evidence to support that there are immediate consequences to violent news media exposure for children. The specific caregiver behaviors that can mediate these negative consequences have not been adequately studied.

\subsection{Long-Term Impact of Childhood Media Exposure}

Some studies have suggested that the behavioral and physiological effects of media exposure can be relatively enduring, upwards of 15 years (Johnson et al., 2002; Harrison \& Cantor, 1999). Age at the time of media exposure does not protect against the negative effects of media on children's well-being and the effects of television viewing broadly can extend past the immediate viewing time (see review by Wilson, 2008 and Comer \& Kendall, 2007). In a retrospective study that sampled 138 college students, $26 \%$ of participants reported still feeling anxious about some sort of media viewed during childhood or adolescence (Harrison \& Cantor, 1999).

Even when the violent news event did not happen in close proximity to the child, there can be a lasting adverse impact of media coverage. Pfefferbaum et al. (2003) investigated the 
emotional responses of 88 sixth graders who attended school 100 miles from the Oklahoma City bombing and were not directly affected by the attack, two years following the event. In a regression analysis the amount of broadcast exposure and children's immediate emotional reaction to the broadcast coverage explained $26 \%$ of the variance in PTS symptoms two years after the event; the impact of children's amount of exposure on their PTSS was dependent upon the children's initial emotional reaction to the event. These findings highlight the potential for violent news media to negatively impact a child for years.

\subsection{Caregiver Influence on Child's Response to Media Exposure}

Studies have reliably shown that caregivers can influence the emotional impact of media exposure on children (Buijzen, van der Molen, \& Sondij, 2007), though it's unclear which caregiver strategies are optimal. Strategies that have been studied include active monitoring, restrictive parenting, deference, and explaining to the child the accuracy and other properties of media (Padilla-Walker et al., 2012; Buijzen, van der Molen, \& Sondij, 2007; Nathanson \& Yang, 2003). Previous research has revealed that some of these strategies (i.e., modeling coping thoughts, positively reinforcing children's use of coping thoughts, and helping children to better understand the media) are more beneficial to the child's emotional well-being than others (i.e., pointing out the positive aspects of the violent news media; for example, that there were helpers), though caregivers may not be aware of their children's responses to media (Saylor et al., 2003; Comer et al., 2008b; Nathanson \& Yang, 2003). The literature on caregiver restriction of childhood media exposure has been limited by the lack of a valid measure of relevant parenting behaviors. Some measures have been created for specific studies of media exposure effects and not validated; in other studies, questions were adapted from validated measures of related constructs (Owens et al., 1999; Padilla-Walker et al., 2012) 
Caregiver Perceptions of Child Responses. Caregivers' perceptions of how their child responds to specific forms of media may not be accurate, potentially limiting the caregivers' ability to positively influence their child's responses. For example, a study by Saylor et al. (2003) found that although parents perceived their child's exposure to positive media images (i.e., police/firefighters helping victims) as helpful in the aftermath of the September 11 terrorist attacks, analyses of actual viewing time suggested that children with greater exposure to media coverage, whether negative or positive, exhibited higher levels of posttraumatic symptoms. This result indicates that parents may not correctly perceive the impact of different aspects of violent news media exposure on their children. Thus, caregivers who deliberately employ strategies in an effort to minimize the negative emotional impact of this exposure may not achieve the effect they intended.

Active Strategies. Caregivers may attempt to protect their children from the emotional impact of media exposure by monitoring or restricting the time that children spend in contact with media. Despite limitations in measurement, strategies that have been studied, such as restrictive parenting, appear to influence child emotional responses (e.g., anxiety) to media exposure. In a study investigating the relative impact of various parenting strategies (Buijzen, van der Molen, \& Sondij, 2007), restrictive parenting was defined as simply limiting the child's exposure to media and active parenting was defined as talking with the child about what he/she had viewed in the media. The sample of 451 children living in the Netherlands completed an 8item measure of fear and worry specific to a well-known celebrity's brutal assassination, which had occurred two weeks prior. Parenting behaviors in response to media were assessed using five items that were adapted from a measure of parenting in regard to fictional media (Valkenberg et al., 1999). A hierarchical regression analysis showed that high levels of active parenting 
accounted for more variance in the impact of exposure to violent news media on children's fear and worry than did restrictive parenting, with active parenting negatively associated with child anxiety. A limitation of this study was that the specific content of parents' discussions with children about media was not assessed. Additionally, because the measure of parent behaviors was initially developed to study the impact of fictional media then adapted to nonfictional media content, it may not have addressed all of the potential parental responses to violent news media. In addition to restrictive parenting, certain types of caregiver and child discussions specific to violent news media have been found to be related to PTS symptom levels in children (Carpenter, Elkins, Kerns, Chou, Green, \& Comer, 2015). After the 2013 Boston Bombing, there was a unique opportunity to investigate caregiver-child discussions of the violent news media coverage of this event given the safety mandate for all residents of the city to stay in their homes. Researchers created items specifically for the study (e.g., "I informed my child about what happened; There were aspects of the attack that I did not discuss with my child, out of concern that it could unnecessarily frighten him/her; I expressed confidence to my child that he/she was safe; I monitored conversations about the attack that my child was exposed to, and was sure to end them if topics came up that I thought could frighten my child.”). Regression analyses revealed that caregiver conversation qualities like showing confidence in the family's safety and openly discussing the events of the violent news media with his/her child predicted lower child PTS symptoms.

To experimentally examine parental influence on children's emotional responses to violent news, Comer et al. (2008b) created a procedure for processing news information and images with children aimed at minimizing anxious response in a community sample of 90 children. These children were randomized to Discussion as Usual (DAU) and Coping Media 
Literacy (CML) conditions. The CML condition required that the mothers speak with the children about a televised media clip on the risk of future terrorist attacks using the following skills: modeling coping thoughts, positively reinforcing children's use of coping thoughts, and helping children to better understand the media (e.g., describing the disproportionately extreme violence presented in the news versus in reality). Mothers received prior training in these skills through a didactic presentation and role-play exercises. Children in the CML condition were less likely to feel threatened by the media information and images (measured by two child self-report items) than children in the DAU condition. Only $30 \%$ of mothers in the CML condition versus $90 \%$ of mothers in the DAU condition reported that their language was typical of daily interactions with their child. A limitation of this study is that the types of discussion and influence that the parents used in DAU were not assessed (Comer, et al., 2008b). Thus, it is unclear exactly how parents in the DAU condition were approaching discussions with their children differently from parents in CML.

Other strategies that may reduce the negative impact of violent media exposure on youth have been studied in the context of fictional media. For example, while youth were viewing violent media (not news) clips, researchers either stated or questioned whether the media clip was 1) factually unrealistic or 2) socially unrealistic, during pauses in the clips (Nathanson \& Yang, 2003). The inserted statements or questions were supposed to simulate what parents could do outside of an experimental condition to respond to their child's media exposure. Results revealed age differences in the effect of mediation statements/questions on children's selfreported post-viewing orientation to violence; younger children (ages 5-8 years) benefited most from mediation statements whereas older children (ages 9-12 years) benefited more from mediation questions than statements or no mediation at all. This study suggests that parents can 
influence their children's interpretation of media content and that there may be age-related differences in the relative benefit of particular strategies; however, additional research is necessary to extend these findings to violent news (versus fictional) media.

Passive Strategies/Caregiver-Child Co-viewing. Previous studies have provided evidence that there are certain active strategies (e.g., behaviors, statements, discussions) that parents can use to mediate the influence of violent news media exposure on their children; another more passive strategy, co-viewing, has been identified as relatively common but not studied in relation to children's emotional responses to violent news. Specifically, a study conducted to test which mediational strategies parents use most with their children found co-viewing (of any television content) to be among three of the most used strategies their sample (Valkenburg et al., 1999). Another study of 179 students (ages 5-11 years) and their parents one month after the terrorist attacks on September 11 showed that $76 \%$ of the children sampled had co-viewed the coverage with their parents (Saylor et al., 2003). Given limitations of measures used in these studies, it is unclear whether co-viewing was coincidental/passive (e.g., due to shared living space) or a deliberate caregiver strategy for mediating their children's responses to media exposure.

Changes in Caregiver Strategies Over Time. Caregiver behaviors concerning their child's media exposure, such as restriction and monitoring, appear to change in frequency over the course of the child's development. Padilla-Walker et al. (2012) investigated change in parental media monitoring over three years, as children transitioned to adolescence. Based on prior research on parenting values, (Padilla-Walker and Thompson, 2005; Padilla-Walker, Christiansen, \& Day, 2011), they measured active monitoring (talking with children about media content), restrictive monitoring (limiting exposure to media content), and deference (actively choosing to make no response) in regard to their children's media exposure. Mothers recruited 
from the community completed a six-item questionnaire measuring restrictive monitoring (e.g., “How often do you restrict your child's exposure to television and Internet in an attempt to avoid negative influences before they occur?"), active monitoring (e.g., "How often do you talk to your child about what they see on television or the Internet in an attempt to avoid negative influences before they occur?"), and deference (e.g., "How often do you allow your child to choose their own television or Internet programs because you want your child to make choices and know you trust them?"). Results suggested that over a three-year period, mothers consistently used active parenting strategies most often for the first two years but the relative frequency of restrictive methods and deference changed. Over time, the mothers became less restrictive and exhibited more deference (with deference and active parenting strategies being used equally as often in the third year); however, researchers did not examine the impact of parental media monitoring on children or adolescents' mental health.

Family Factors Impacting Child Responses. Beyond parenting behaviors, researchers have examined the impact of psychopathology in the family level and general family functioning on youth responses to media exposure. Otto et al. (2007) identified risk factors for children's anxiety following media exposure to the September 11 terrorist attacks, including parent PTSD symptoms, family support, identifying with the victims, and viewing time. Parents' own PTSD symptoms were not significantly related to their children's PTSD symptoms, as rated by clinicians. However, there was a negative relationship between the degree to which family members generally discussed their feelings openly (according to a self-report family environment measure; Moos, Insel, \& Humphrey, 1974) and the children's PTSD symptoms. Therefore, family functioning following violent news media exposure may influence child responses more than parental psychopathology. Advances in measurement are required to 
examine whether or not parenting behaviors specific to children's media exposure mediate the relationship between general family functioning and child distress following violent news events.

Summary. Previous findings suggest that caregivers may need to: monitor more than just the frequency of their children's media exposure (Ortiz et al., 2011), recognize that imminent physical danger is not necessary to experience negative consequences of a violent event (Lengua et al., 2005), and attend to preexisting factors that may put their child at a higher risk for negative outcomes following media exposure to violent news (Weems et al., 2012; Busso, McLaughlin, \& Sheridan, 2014). Caregiver "meditational strategies" that have been suggested to reduce the negative impact of violent media exposure on youth include: using statements or questions that further the youth's understanding of the media content as factually or socially unrealistic (Nathanson \& Yang, 2003); modeling coping thoughts (Comer et al. 2008b); describing the disproportionately extreme violence presented in the news versus in reality (Comer et al. 2008b); and assuring the child of his/her safety (Carpenter, Elkins, Kerns, Chou, Green, \& Comer, 2015). Beyond these strategies and other general family interactions (Otto et al., 2007), the current measure (i.e., the CRYME) will enable researchers to investigate specific parenting behaviors that may influence children's responses to violent news.

\subsection{Current Recommendations for Caregivers}

Despite the relatively sparse empirical literature informing suggestions for caregivers, the National Association for School Psychologists (nasponline.org, 2006) has recommended minimizing the negative impact of violence exposure on children by reassuring them that they are safe, making time to talk, keeping explanations developmentally appropriate, reviewing safety procedures, observing children's emotional state, limiting television viewing of these events, and maintaining a normal daily routine. Similar suggestions have been made by other 
organizations, such as the National Child Traumatic Stress Network (NCTSN; nctsn.org, 2006) and the Substance Abuse and Mental Health Services Administration (SAMHSA; samhsa.gov, 2012). However, the efficacy of such guidelines for minimizing distress reactions to violent news has not been fully examined. Also, some caregivers may require more explicit instructions in order to implement these recommendations. The proposed scale will facilitate research aimed at better understanding how caregivers talk to their children about the violence to which they are exposed via media, and how caregiver behavior relates to children's emotional responses. Such research could better inform caregivers and teachers of how to best prevent or address "second hand trauma" from exposure to violence with children.

\subsection{Limitations of Current Literature}

Previous research has emphasized the need to identify the most effective parenting strategies for minimizing a child's negative responses to violent media exposure (Comer \& Kendall, 2007). Studies have used very general questions to assess a child's exposure to media and his/her parent's involvement in the media exposure (e.g., Padilla-Walker et al., 2012; Saylor et al., 2003). It is difficult to compare findings across studies due to limitations in the measurement of specific parenting behaviors (Owens et al., 1999; Padilla-Walker et al., 2012). The majority of the questionnaires used to measure the impact of violent news media exposure have been validated using small samples, have included subscales based on theory but not validated with factor analysis, have tapped a limited range of parenting behaviors (e.g., restrictive influence but not nature/content of parent-child discussions), have focused on fictional media, or have included only very general items (e.g., Padilla-Walker \& Coyne, 2011; Valkenburg, Kramar, Peeters, \& Marseille, 1999). 
The current measure (the CRYME) advances prior efforts to assess caregiver influences on children's responses to violent news by covering a range of specific parenting behaviors in addition to addressing multiple forms of media; namely, television, internet (e.g., news sites, blogs, etc.), social media (e.g., Facebook, Twitter, etc.), and print media (e.g., magazines, newspaper, etc.).

\section{PRIMARY RESEARCH AIM: MEASURE DEVELOPMENT AND PRELIMINARY EVALUATION}

\subsection{Study 1: Qualitative Methods}

Item Generation. Items were generated based on a review of the theoretical and empirical literatures, and results of a caregiver focus group. Themes that emerged from the literature on caregiver influences on child exposure and response to violent news in the media include: restricting, modeling coping thoughts, positively reinforcing children's use of coping thoughts, helping children to better understand the media (e.g., describing the disproportionately extreme violence presented in the news versus in reality), active monitoring of media exposure, identifying the positive aspects of the news/situation, and co-viewing (Comer et al., 2008b; Padilla-Walker et al., 2012; Buijzen, van der Molen, \& Sondij, 2007; Nathanson \& Yang, 2003; Saylor et al., 2003). For each theme that emerged from the literature review and focus group, four to nine items were generated to cover the full range of potential strategies or behaviors that caregivers may exhibit in relation to their child's interaction with violent news media (see Appendix H).

Caregiver Focus Group. Participants. Participants were recruited through the use of GSU SONA and flyers in public posting areas (e.g., on campus; in grocery stores). This purposive sampling method was intended to maximize the diversity of the sample. Flyers were 
posted in at least one area from each of the seven major neighborhoods in Atlanta:

Downtown/Midtown, Buckhead, Northwest, West Midtown, Northeast, Southwest, Southeast (see Appendix $B$ for a breakdown of demographic information; U.S. Census, 2010 and trulia.com). These neighborhoods of Atlanta are widely diverse with regard to race/ethnicity and socioeconomic status (U.S. Census, 2010; trulia.com).

Six primary caregivers of children ages 6-17 years were included in this preliminary study. This age range was selected to sample parents of youth who are both attending school (where there may be increased opportunity for exposure to violent news) and living with their family of origin. The average age of the participants' children was 11 years $(\mathrm{SD}= \pm 3.6$; range 614 years). Participants were excluded if they did not speak English fluently, as it was important that they were able to understand and be understood in the focus group discussion. It was anticipated that the sample would be representative of the population of caregivers living in the U.S. with regard to gender, race, ethnicity, education level, and socioeconomic status (SES). However, despite efforts to recruit a diverse sample, the focus group participants all selfidentified as Black/African American and all but one were female. The participants' average age was 33 years (range $24-40$ years; $\mathrm{SD}= \pm 6.55$ ).

Procedure. Six caregivers (along with the primary researcher) gathered as a group for 2 hours to discuss their involvement in their children's interactions with multiple types of media: television, internet (e.g., news sites, blogs, etc.), social media (e.g., Facebook, Twitter, etc.), and print media (e.g., magazines, newspaper, etc.). Eight participants signed up for the study and were screened in advance by phone; two participants did not show up for the study for reasons unknown to the researcher. 
The focus group discussion was completed in one visit, conducted in a private room located in the GSU Psychology Clinic, and videotaped with primary and back-up recording devices; no field notes were taken. Following the informed consent procedure, the caregivers discussed strategies that they have used or considered using to influence their child's exposure and responses to violent news media.

The number of participants is in line with best practice guidelines (i.e., 4-12 is appropriate for encouraging discussion; Tong, Sainsbury, \& Craig, 2007). Focus group duration of one to two hours has been recommended (Rabiee, 2004) and provided ample time for data saturation in a relatively straightforward discussion among participants. Data saturation was seen through the repetition of ideas/comments during the focus group and each participant had at least two opportunities to speak and share his/her viewpoints. It is likely that all participants were able to voice their opinions and answers to discussion prompts without leaving any ideas/thoughts/opinions unaddressed (Rabiee, 2004). The structure of the focus group was based on the phenomenology methodological orientation because it promotes an atmosphere in which the researcher allows findings to emerge, rather than guiding the data to any particular hypothesis. Attention was paid to all items on the "checklist" for reporting focus group data suggested by Tong et al. (Tong, Sainsbury, \& Craig, 2007; see Appendix D).

Aside from the phone screen to ensure that eligibility criteria were met, no contact with the researcher took place prior to meeting in person for the focus group. There was a brief introduction of the study and the researcher's background (i.e., second-year clinical psychology graduate student interested in how caregivers interact with their children in response to viewing violent news in the media) during the consent process. The introduction of the researcher was 
kept brief and relatively vague, intentionally, to fit the "structured eavesdropping" environment suggested by Kitzenger (1995).

The researcher facilitated the discussion by asking follow-up questions as needed but for the most part, the discussion was generated and guided by the caregivers (see Appendix $C$ for specific questions that were used to start the discussion). As suggested by Ritchie and Lewis (2003) and Kitzinger (1994), the researcher acted as the facilitator in order to make sure that all participants had an opportunity to speak and that the discussion stayed on the topic of the research questions. The researcher attempted to mirror the language of the participants and be as non-directive as possible in order to remove researcher bias and encourage the "natural" discussion. Also, the researcher aimed to create a comfortable, judgment-free environment in which all participants could be heard (Kitzinger, 1994); nobody aside from the six participants and researcher was present in the room during the focus group.

Qualitative Data Analysis. The recorded focus group discussion was transcribed and analyzed qualitatively using methods outlined by Braun and Clark (2006). These methods were selected based on the purpose of the focus group data collection: to identify ways that caregivers may influence children's response to violent news media that may not have been reported in the literature. Braun and Clark (2006) define a theme in qualitative data as something important that helps answer the research questions. Themes are not necessarily tied to frequency and quantity of participant comments, nor do they have to be deduced from theory. Rather, themes are linked directly to the data. To identify themes, the current study used the "inductive" or "bottom-up" process. The steps involved in the thematic analysis are as follows: familiarizing oneself with the data, searching for themes, reviewing themes, defining and naming themes, and producing a report. 
Other methods of qualitative data analysis that were considered include: Consensual Qualitative Research (CQR; Hill, Thompson, and Williams, 1997), Morse and colleagues' (2002) verification strategies for ensuring rigor in qualitative research, and the Framework Method of Analysis (Ritchie and Lewis, 2003).

The Consensual Qualitative Research method also aims to describe phenomena by using open-ended questions to collect data and multiple researchers to find consensus regarding core themes in the data (Hill, Thompson, and Williams, 1997). However, the CQR method is typically used to analyze individual semi-structured interviews and requires multiple auditors to check for consensus among members of a relatively large research team. The methods focus on 1) composing research teams, 2) training for consistency across researchers, 3) rotating teams of researchers, and 4) cross-analyzing the same data. These elements were not necessary for the current study given the relatively small amount of data that the two-hour focus group generated. However, the concept of having multiple reviewers of the data was retained for the current study; specifically, there were two researchers who reviewed and generated themes and one primary auditor (i.e., the student principal investigator).

The Framework Method Analysis is a top-down method that involves using a set of themes and codes to reduce the data, making it more manageable in order to answer the particular research questions. Top-down processing, which refers to taking a theory or a framework and using it to guide interpretation of the qualitative data, would not have been optimal for the current study. Based on Clark and Watson's (1995) recommendation to have a broad content base when creating a new measure, the goal of the focus group was to generate any themes (i.e., parenting strategies for responding to youth viewing violent news in the media) that had not already been identified in the literature. With top-down approaches, such as the 
Framework Method, the researcher uses the current literature base to decide which themes from the data are most salient and important. Given that the purpose of the focus group was to expand on the current research, this method did not fit the needs of the study.

Finally, Morse et al. (2002) outlined the strategies that should be implemented in qualitative data analysis to ensure rigor; several suggestions from this article were used to enhance the Braun and Clark (2006) methods chosen for the current study. Specifically, important themes that were extracted were verified at every level of analysis (i.e., by looking back at the original data/transcription). That is, when a theme was identified, the researcher combed through the data again to ensure that the theme indeed fits the data. Also, in the consensus step taken by the auditor, each theme was not only verified against the other coder but also against the original data.

The common and/or critical elements in the previously discussed qualitative research methods are: having multiple researchers code for strong themes throughout the transcription and having a designated researcher resolve conflicting themes and/or generate a plan for reaching consensus among researchers' identified themes (Braun and Clark, 2006; Hill, Thompson, and Williams, 1997; Morse, Barrett, Mayan, Olson, and Spiers, 2002; Ritchie and Lewis, 2003). These critical elements are evident in the methods outlined by Braun and Clark (2006). For the purposes of the current study, Braun and Clark's (2006) methods were chosen because of the detailed description of how to extract themes and what constitutes a theme. Essentially, Braun and Clark's (2006) method is the most thorough and fits the purposes of this study.

Transcription of the focus group data was completed by the student principal researcher and double-checked for accuracy independently by an additional researcher. Transcripts of the 
focus group and themes identified were not returned to the participants from the focus group for review to protect data/participant confidentiality.

Two researchers independently viewed the entire two-hour focus group discussion. During a second viewing of the focus group, each researcher independently identified/coded themes throughout the transcription. Finally, each researcher viewed the focus group discussion a third time to ensure that no themes were missed. After each researcher identified the themes, he/she highlighted the evidence in the transcript for each theme identified. Each theme had at least two identifiable statements of supporting evidence. A third researcher (also called "the auditor" in some methods; e.g., Hill, Thompson, and Williams, 1997) had the role of resolving any discrepancies. The student principal researcher also identified themes within the transcript independently of the two researchers prior to resolving any discrepancies between the researchers' identified themes. See Appendix E and Appendix $G$ for a list of each researcher's identified themes and statements of supporting evidence.

\subsection{Study 1: Qualitative Results}

Within the data, the student principal researcher identified 12 narrow themes, the first assistant researcher identified eight broad themes, and the second assistant researcher identified seven broad themes. All themes but one were consistent among researchers, varying only by the scope of the theme (i.e., how broad/narrow). The one theme that was identified by only one researcher was media portrayal of only the most shocking or sensational material to interest viewers. Because this theme had already been identified in the literature, relevant items had already been generated. See Appendix $F$ for a table of the final consensus of the nine themes extracted from the qualitative data. 
After the themes and codes were identified and consensus reached, the student principal researcher transformed the themes into question format (about four to nine questions per theme) as items for the measure. The questions were returned to the two assistant researchers to ensure accuracy in the interpretation and transformation of themes into questions. Given that these themes were transformed into individual items, it was not necessary to develop a coding tree (otherwise known as a hierarchical coding system) to graphically depict how the themes relate to one another (Tong, Sainsbury, \& Craig, 2007).

The results of the focus group generally aligned with the literature review. Three themes (e.g., scaring to protect) that were novel were transformed into question form and added to the proposed items (see Appendix $H$ ). This broadened the scope of items submitted to the factor analysis, allowing excess/unnecessary items to be eliminated later based on quantitative results. A total of 74 items were generated as a result of the literature review and focus group. It was unnecessary to eliminate items prior to completing an exploratory factor analysis, which can be conducted with over 100 items (Floyd and Widaman, 1995).

\subsection{Study 2: Quantitative Methods}

Online Survey. Participants. Primary caregivers $(N=702)$ of children ages 6-17 years were recruited through the Amazon Mechanical Turk (MTurk) website. This age range was selected to sample caregivers of youth who are both attending school (where there may be increased opportunity for exposure to violent news) and living with their primary caregiver. See Table 1 for a breakdown of the demographic variables.

Table 1 Sample Demographics

\begin{tabular}{lccc}
\hline Age & N & Range & Mean \pm SD \\
\hline Caregiver's Age & 702 & $19-74$ & $35.44 \pm 8.67$
\end{tabular}




\begin{tabular}{|c|c|c|c|}
\hline Child's age & 702 & $6-17$ & $9.87 \pm 3.47$ \\
\hline Gender & $\mathrm{N}$ & Percentage Female & \\
\hline Caregiver Gender & 499 & 71 & \\
\hline Child Gender & 301 & 43 & \\
\hline Race & $\mathrm{N}$ & Percentage & \\
\hline American Indian/Native Alaskan & 30 & 4 & \\
\hline Asian & 76 & 11 & \\
\hline Black/African American & 56 & 8 & \\
\hline Native Hawaiian/Pacific Islander & 6 & 1 & \\
\hline White & 516 & 74 & \\
\hline Other & 18 & 3 & \\
\hline Ethnicity & $\mathrm{N}$ & Percentage & \\
\hline Hispanic & 78 & 11 & \\
\hline Not Hispanic & 624 & 89 & \\
\hline Education & $\mathrm{N}$ & Percentage & \\
\hline Grades 1-8 & 1 & 0 & \\
\hline Grades 9-11 & 6 & 1 & \\
\hline High School graduate or GED & 90 & 13 & \\
\hline College 1-3 years & 265 & 38 & \\
\hline College Graduate & 195 & 28 & \\
\hline Some Graduate school & 49 & 7 & \\
\hline Graduate degree & 96 & 14 & \\
\hline Employment & $\mathrm{N}$ & Percentage & \\
\hline
\end{tabular}




\begin{tabular}{lcl}
\hline Not working & 118 & 17 \\
Employed Part-time & 141 & 20 \\
Employed Full-time & 380 & 54 \\
Full-time student & 22 & 3 \\
Other & 41 & 6 \\
\hline Annual Household income & $\mathrm{N}$ & Percentage \\
\hline \$10,000 & 49 & 7 \\
$\$ 10,000-25,0000$ & 139 & 20 \\
$\$ 25,000-50,0000$ & 222 & 32 \\
$\$ 50,000-75,0000$ & 162 & 23 \\
$\$ 75,000-100,0000$ & 62 & 9 \\
$>\$ 100,000$ & 68 & 10
\end{tabular}

This sample was reasonably representative of the population of caregivers in the U.S. with regard to race, ethnicity, education level, and socioeconomic status (Table 2; U.S. Department of Education: National Center for Education Statistics, 2013).

Table 2 National Demographic Information for U.S. Households with Children Aged 618

Race Percentage

Asian 6

Black/African American $\quad 14$

White 59

Ethnicity Percentage


Not Hispanic $\quad 80$

\begin{tabular}{ll}
\hline Education & Percentage \\
\hline Grades 1-11 & 11 \\
High School graduate or GED & 19.5 \\
College 1-3 years & 22.6 \\
College Graduate & 28 \\
At least some graduate school & 36.3 \\
\hline Household Income (national) & Median $=\$ 51,400$ \\
\hline
\end{tabular}

Compared to the average U.S. household with children ages 6-18 years, the study's sample was slightly more educated and had a marginally lower income. Also, White and Asian participants were somewhat overrepresented in the current study relative to the national population.

Caregivers of multiple children were instructed to complete the measure with only one child in mind. At the beginning of the survey, the participants were asked for this child's age to further prompt them to think about a specific child. Caregivers reported their child's frequency of media exposure (see Table 3 for full results).

Table 3 Means and Standard Deviations of Child Media Exposure Days per Week Hours per Week

\begin{tabular}{ccccccc}
\hline Type of media & Range & $M$ & $S D$ & Range & $M$ & $S D$ \\
\hline TV & $0-7$ & 6.38 & \pm 2.19 & $0-90$ & 9.93 & \pm 9.41 \\
Internet & $0-7$ & 5.30 & \pm 2.76 & $0-90$ & 7.64 & \pm 10.44 \\
Social Media & $0-7$ & 3.65 & \pm 3.04 & $0-90$ & 4.38 & \pm 10.11
\end{tabular}



Print Media
$0-7$
3.70
$\pm 2.58$
$0-90$
$2.50 \quad \pm 5.05$

Television was the most frequent source of media used by children (caregiver reported; $M=6.38$ days per week, $S D= \pm 2.19$ ); the average number of hours reported per week that children are exposed to television media was $9.93(S D=9.41)$. Participants were excluded if they did not speak English fluently, as it was important that they fully understand all items on the CRYME.

Measures. Caregiver Responses to Youth Media Exposure. CRYME items were rated using a 0-4 Likert-type scale with the following options: never, rarely, sometimes, often, and almost always. (See Appendix $H$ for final list of items generated.) Having five response options is sufficient for maximizing item validity and enabled normal distribution of the data (Clark \& Watson, 1995).

Frequency of Media Use Questions. In line with prior studies (e.g., Comer et al., 2008b; Busso et al., 2014; Owens et al., 1999), six questions were included to measure type and frequency of media use (see Appendix J). In order to assess the use of multiple forms of media, caregivers indicated whether or not their child had access to: television, internet (e.g., news sites, blogs, etc.), social media (e.g., Facebook, Twitter, etc.), and print media (e.g., magazines, newspaper, etc.).

Lastly, insufficient effort response (IER) detection techniques were added to identify the participants who did not respond truthfully and thoughtfully to items on all measures (Huang et al., 2011). These techniques involve using multiple "check points" or unscored items inserted randomly throughout and/or at the end of the series of questionnaires in order to ensure that the participants are reading and carefully considering the items. Huang et al. (2011) tested additional 
strategies for reducing the effect of IER on data collected online, including self-report and page time. Based on their findings, the following items were added to the end of the online questionnaire in order to collect self-reported data on the participants' compliance with the study: "I didn't pay much attention to what the questions actually meant," "I filled out the questions without thinking about myself," "While completing this battery, I was distracted by other online/offline sources," and "I responded carelessly to the questions" (see Appendix I). Also, based on research, a two-second rule per item was implemented in order to test response time. All participants spent more than two seconds per item, indicating that they were likely reading and/or responding to the items carefully. For ease and efficiency, time spent per items was averaged per page and then compared against the two-second standard.

Procedure. All study procedures were approved by the GSU Institutional Review Board. A total of 702 caregivers completed the CRYME and other study measures online through Qualtrics (after being recruited through MTurk). Floyd and Widamen (1995) recommend collecting data from about 10 participants per item included in the factor analysis; therefore, the sample size of 702 was expected to provide sufficient power to factor analyze the 74 items of the CRYME. (Because results of the focus group yielded 20 additional items, the number of participants for quantitative data collection was increased from 500 to about 700.)

Measures were administered in this order: CRYME, frequency of media use, and demographics questionnaire (see Appendix $K$ ). Items on the CRYME were presented in a random order for each participant to reduce the likelihood that results would be impacted by item order. The average time required to respond to all items was 22 minutes. Participants were compensated $\$ 0.30$ for completing the questionnaires. This is well above the minimum and is average for comparable surveys administered through MTurk (amazon.com, 2013). Once 
participants selected the survey to complete within MTurk, they were directed to a link to Qualtrics (gsu.qualtrics.com, 2014). The consent form and survey questions were administered through Qualtrics, which provided added security for internet data collection and meets IRB standards for the protection of research participants.

Testing Construct Validity. Attention was paid to two components of construct validity: substantive and structural (Clark \& Watson, 1995). A broad scope of items (i.e., 74 total items covering nine themes) were initially included on the CRYME in order to ensure that the target construct was completely covered.

Substantive validity. The CRYME scale addressed the need for a standardized measure of the ways in which caregivers may influence their child's responses to violent news media exposure, and was based on the current literature. This well-established nomological network ensured that the measure was innovative and grounded in previous research (Cronbach \& Meehl, 1955).

Cronbach and Meehl (1955) stated that in order for a measure to have construct validity, the construct being assessed must have a well-established nomological network. Essentially, the nomological network is used to describe how the construct assessed through the CRYME is related to other similar constructs. Therefore, the construct of parental influence on their children's responses to violent news media exposure is a construct within a nomological network of other related constructs, including, (as previously described): parenting practices, parenting strategies, parenting behaviors, children's responses to violent news media, parents' responses to child PTS, etc. It is not feasible to assess a parent's actual influence on his/her child's response to violent news media through a self-report questionnaire. Thus, the CRYME will assess parents' behaviors, which are related to this broader nomological network. Specifically, a nomological 
network refers to the interconnected literatures that make up a theory. In the case of the current measure development, the studies previously mentioned provide clear examples of potential parenting behaviors that are included in the nomological network (e.g., restrictive parenting, active parenting, deference, Padilla-Walker et al., 2012; co-viewing, Saylor et al., 2003, etc.). The current literature contributes to the nomological network by providing a sampling of potential behaviors that, combined with the results from the focus group, provided grounding to create this measure. That is, the construct of interest is the set of potential parenting behaviors that were identified through the literature and the focus group.

Structural validity. Structural validity ensures that the items are internally correlated and that the internal correlations of items parallel the correlation with the appropriate external measures (Clark \& Watson, 1995).

Data Analysis. Exploratory factor analysis (EFA) was used to examine the factor structure of the CRYME. Exploratory factor analysis is a data reduction technique in which variables/items are reduced into clusters that hang together statistically, also called factors, in an effort to reveal the internal structure of the data. This type of analysis works from a theory that the data have a latent structure that can be revealed through the identification of shared variance within/among the factors. Traditionally, factor analysis can be used for the creation and refinement of measurement.

Other data reduction techniques that were considered for this study but weren't deemed appropriate are Principal Components Analysis (PCA) and Confirmatory Factor Analysis (CFA). PCA is not appropriate for the analysis of the data in this study because it is based on the orthogonal method of transformation; as will be discussed further, oblique is the best transformation method for the data. PCA also serves a slightly different purpose for data 
reduction in that it determines the variable(s) that account for the most variance in the dataset as the first component and subsequent components accounting for successive amounts of variance. Essentially, PCA reduces the data into components based on the amount of variance that each component accounts for in the entire dataset. EFA differs from PCA in that EFA reduces the data into factors accounting for common variance in the data rather than specifically the largest amount of variance in the data. CFA is more appropriate for a study or dataset with a testable hypothesis; due to the exploratory nature of this study (i.e., there was no hypothesized factor structure), EFA was the best choice.

Prior to the EFA, to confirm data were collected from a sufficient sample size, the Kaiser-Meyer-Olkin (KMO) measure of sampling adequacy was used. The KMO is a representation of the ratio of squared correlation between variables to the squared partial correlation between variables. The score result of this test ranges from 0 to 1 ; Hutcheson and Sofroniou (1999) advise that the KMO value must be above .5 to proceed with a factor analysis and suggest that a value of .7 or higher is a good standard.

Descriptive statistics were computed for all items and Pearson's Product Moment correlations were run, resulting in a correlation matrix that was used for further data checking procedures. Univariate descriptive statistics were computed to provide the means and standard deviations for each variable to examine the distribution of the data for normality. Item frequency distribution was also examined prior to the EFA. Kim (2013; citing West, Finch, Curran, 1995) recommends eliminating items with skewness higher than 2 or lower than -2 with sample sizes greater than 300. Items with kurtosis higher than 7 or lower than -7 should also eliminated.

To ensure that there is no multicollinearity (i.e., the variables are too highly correlated and it is difficult to know if the variables are providing a unique contribution to the factors) in 
the data, it was necessary to check that the determinant of the R-matrix is greater than 0.00001 (Field, 2009). The determinant is similar to eigenvalues except that instead of describing the height and width of the data, it represents the overall area of the data plotted on the factor plot. The determinant of the R-matrix prior to conducting the EFA was checked in place of Bartlett's test of sphericity, which is highly dependent on sample size. Bartlett's test appeared significant at every step of the analysis; this was expected given the large sample, even when the correlations between variables are very small.

Factor scores (i.e., the composite score for each item on a particular factor) for the EFA were calculated using the regression method in SPSS (Field, 2009). This method is best for use when factors are likely to correlate. In the regression method, the initial correlations between items are taken into account when adjusting factor loadings. The factor loadings matrix is multiplied by the inverse of the original correlation matrix in order to accomplish what is typically done in a regression, which is estimating the beta values. The result is a matrix of factor score coefficients that represents the relationship between each variable and each factor. When estimating the number of factors to extract from the data, there are several proposed methods: Kaiser's criterion, Cattell's scree test, and parallel analysis. To further explain the strategy for how the number of factors that were extracted was determined, it is critical to define an eigenvalue. An eigenvalue essentially reflects the amount of variance represented by a factor. A scree plot shows the eigenvalues plotted against the potential number of factors. Typically, the researcher identifies the point of inflection (i.e., where the line on the graph begins to level off and appear horizontal), which suggests the number of factors to retain.

Because Kaiser's criterion and Cattell's scree test often (about $90 \%$ of the time) overestimate the number of factors, a parallel analysis of eigenvalues was conducted to 
determine the number of factors to extract (Hayton, Allen, \& Scarpello, 2004; Zwich \& Velicer, 1986). Through parallel analysis (using the program R; R Core Team, 2013), data collected were compared to a randomly generated dataset of the same size. When comparing the eigenvalues from the two datasets, only the factors with eigenvalues from the proposed dataset that exceed the factors with eigenvalues from the randomly generated dataset were retained.

The issue of missing data was also considered; within EFA the method of handling of missing data is not consequential to the analyses (Chen, Wang, \& Chen, 2012); therefore, the listwise method was chosen. Minimal data were missing from the sample; a total of $3 \%$ of the CRYME data were missing (0-2 observations across items; 0-4 observations across participants).

In EFA, reference axes are subjected to either an oblique or an orthogonal rotation in order to maximally load the variables onto only one factor (Fabrigar, Wegener, MacCallum, \& Strahan, 1999). If the items are relatively uncorrelated, an orthogonal rotation is the best option. Orthogonal rotation requires that the axes be perpendicular. Alternatively, oblique rotation allows the items to be correlated. An oblique rotation was selected for the current study because various parenting behaviors for each individual caregiver are thought to be correlated with each other. Oblique rotation allows for non-perpendicular axes and for the factors to correlate. For oblique rotation, there are two methods: promax and direct oblimin. The promax method of oblique rotation was used, as it is best for large data sets (Field, 2009).

Items that didn't load onto one of the factors extracted were eliminated. Specifically, items that didn't load onto any factor at .3 or above were dropped (Fabrigar, Wegener, MacCallum, \& Strahan, 1999). As a conservative estimate, in samples of 300, factor loadings should be greater than .298 and in samples of 600 , factor loadings should be greater than .21 to be significant (and therefore, statistically meaningful to retain; Stevens, 2002). Given the sample 
of 702 in this study, the .3 standard is sufficient and even conservative. In line with recommendations from Fabrigar et al. (1999), items with cross-factor loadings greater than .3 were assigned to the factor for which they had the highest loading. Additionally, items that the majority of participants answered similarly (i.e., that provide minimal variability) or that crossloaded onto multiple factors were eliminated, as they do not provide meaningful information. The resulting factors were named based on the items that loaded onto these factors.

After the factors were extracted, Cronbach's alpha was computed as an index of internal consistency for each of the factors, which was transitioned to subscales of the measure as a whole (Field, 2009). Cronbach's alpha considers the relationship between the variance within the item and the covariance between an item within the subscale and any other item in that same subscale. The value of alpha depends on the number of items within the subscale, as the number of items in the subscale increases, so does alpha. The general standard is that $\alpha>.7$ indicates good reliability of the scale (Field, 2009). Hotelling's T-square test was used to compare the central tendency of different items in the measure, and to see if there was overall similar distributional properties of the individual items.

\subsection{Study 2: Quantitative Results}

Primary Research Aim: To develop and explore the factor structure of a measure of specific ways that caregivers may influence their children's exposure and response to media coverage of violent events in the news: the Caregiver Responses to Youth Media Exposure (CRYME).

Prior to the EFA, the previously described data checking procedures were conducted. At each stage of the EFA, the KMO was above .9 , indicating an adequate sample for conducting the EFA (Hutcheson and Sofroniou, 1999). No items were eliminated from the data due to skewness 
or kurtosis. The determinant of the R-matrix prior to conducting the EFA was less than 0.00001 , indicating that multicollinearity may be a problem. Because multicollinearity was identified as a potential a problem, the correlation matrix was referenced to eliminate one item from any pair with an $r$-value of greater than .8 prior to the EFA. Inter-item correlations revealed that four items were correlated at .8 or higher (i.e., two of the four were eliminated). The four highly correlated items were related to the spirituality theme. They were: a) -use religion or spirituality to help your child make sense of the violent news? b) - use religion or spirituality to explain the violent news to your child? c) -use religion or spirituality to comfort your child in light of the violent news event? d) -point out something positive, using religion or spirituality, about the violent/tragic news (for example: God was present, a higher power protected the victims, etc.). Of these spirituality items, b) and d) were retained and submitted to the EFA.

The EFA was completed in a total of five stages, with four steps at each stage. At the first step, an exploratory factor analysis using the oblique rotation and promax method was used to calculate the eigenvalues needed for the parallel analysis. Next, a parallel analysis was conducted to determine the appropriate number of factors to extract. Then, the EFA was rerun forcing the number of factors determined by the previous parallel analysis (see Table 4 for initial EFA factor loadings).

Table 4 CRYME items EFA (Promax Rotation) Factor Loadings First Analyses

\begin{tabular}{|c|c|c|c|c|c|}
\hline & Factor 1 & Factor 2 & Factor 3 & Factor 4 & Factor 5 \\
\hline $\begin{array}{l}\text { try to help your child make sense } \\
\text { of the violent/tragic news by } \\
\text { talking to him/her in a way that } \\
\text { s/he can understand? }\end{array}$ & .761 & -.182 & -.002 & .217 & -.044 \\
\hline
\end{tabular}




\begin{tabular}{|c|c|c|c|c|c|}
\hline $\begin{array}{l}\text { explain the violent/tragic news in } \\
\text { a way that s/he can understand? }\end{array}$ & .729 & -.165 & -.043 & .157 & .003 \\
\hline $\begin{array}{l}\text { talk to your child about how this } \\
\text { news event affects him/her } \\
\text { personally? }\end{array}$ & .554 & .241 & -.073 & .008 & .024 \\
\hline $\begin{array}{l}\text { talk to your child about whether } \\
\text { or not this news event will } \\
\text { change his/her daily life? }\end{array}$ & .460 & .387 & .004 & -.066 & -.005 \\
\hline $\begin{array}{l}\text { help your child figure out how } \\
\text { this event will change his/her } \\
\text { daily life? }\end{array}$ & .353 & .343 & .017 & -.002 & .102 \\
\hline $\begin{array}{l}\text { describe how this news event } \\
\text { affects your child's } \\
\text { society/community? }\end{array}$ & .407 & .372 & -.055 & .011 & .065 \\
\hline $\begin{array}{l}\text { talk with your child about } \\
\text { aspects of the violent news that } \\
\text { bother him/her the most? }\end{array}$ & .674 & -.015 & -.059 & .154 & -.054 \\
\hline $\begin{array}{l}\text { change your visible reaction to } \\
\text { violent news in the media based } \\
\text { on how you think your child will } \\
\text { react? }\end{array}$ & .162 & .243 & .448 & .075 & .027 \\
\hline $\begin{array}{l}\text { change the way you talk to your } \\
\text { child about the violent/tragic }\end{array}$ & .072 & .473 & .363 & .035 & .019 \\
\hline
\end{tabular}




\begin{tabular}{|c|c|c|c|c|c|}
\hline $\begin{array}{l}\text { news in an effort to influence } \\
\text { his/her feelings about the news? }\end{array}$ & & & & & \\
\hline $\begin{array}{l}\text { point out something reassuring } \\
\text { about the violent/tragic news (for } \\
\text { example: no deaths, the } \\
\text { perpetrator was caught, etc.)? }\end{array}$ & .607 & .009 & .031 & .043 & .106 \\
\hline $\begin{array}{l}\text { explain why this violent/tragic } \\
\text { news was not as bad as it could } \\
\text { have been? }\end{array}$ & .307 & .330 & .010 & -.046 & .055 \\
\hline $\begin{array}{l}\text { explain ways in which the } \\
\text { government, police, or other } \\
\text { officials addressed the situation? }\end{array}$ & .558 & .105 & -.014 & .087 & .003 \\
\hline $\begin{array}{l}\text { reassure your child that you } \\
\text { (his/her caregiver) are safe in } \\
\text { spite of the violent/tragic news? }\end{array}$ & .725 & -.292 & .150 & .110 & -.013 \\
\hline $\begin{array}{l}\text { reassure your child that s/he is } \\
\text { safe in spite of the violent/tragic } \\
\text { news? }\end{array}$ & .741 & -.309 & .234 & .055 & -.033 \\
\hline $\begin{array}{l}\text { reassure your child that such a } \\
\text { violent/tragic event will not } \\
\text { happen to him/her? }\end{array}$ & .430 & -.001 & .351 & -.048 & -.032 \\
\hline $\begin{array}{l}\text { talk to your child about the } \\
\text { violent news in a neutral way, }\end{array}$ & .385 & .294 & .077 & -.047 & -.115 \\
\hline
\end{tabular}




\begin{tabular}{|l|l|l|l|l|l|}
\hline describing just the facts? & & & & & \\
\hline $\begin{array}{l}\text { teach your child that what s/he } \\
\text { sees in the news cannot control } \\
\text { how s/he lives his/her life? }\end{array}$ & .630 & -.021 & .119 & .007 & .000 \\
\hline $\begin{array}{l}\text { encourage your child not to let } \\
\text { the violent news change his/her } \\
\text { day-to-day actions? }\end{array}$ & .657 & -.106 & .141 & .000 & -.015 \\
\hline $\begin{array}{l}\text { explain how the media presents } \\
\text { events in an extreme way to } \\
\text { interest viewers? }\end{array}$ & .435 & .270 & .096 & -.098 & -.032 \\
\hline $\begin{array}{l}\text { explain how the media features } \\
\text { events that are uncommon to } \\
\text { interest viewers? }\end{array}$ & .402 & .341 & .079 & -.165 & -.032 \\
\hline $\begin{array}{l}\text { explain the likelihood of this } \\
\text { event happening again? } \\
\text { violent/tragic news? }\end{array}$ & .489 & .237 & .030 & .011 & .007 \\
\hline $\begin{array}{l}\text { explain the likelihood of this } \\
\text { explain to your child that you }\end{array}$ & .341 & .323 & .022 & .061 & .004 \\
\hline
\end{tabular}




\begin{tabular}{|l|l|l|l|l|l|}
\hline $\begin{array}{l}\text { show your child, through your } \\
\text { own actions, how he/she can } \\
\text { avoid being part of similar } \\
\text { violent/tragic situations? }\end{array}$ & .393 & .029 & .016 & .386 & .058 \\
\hline $\begin{array}{l}\text { explain to your child ways to } \\
\text { stay safe considering the } \\
\text { violent/tragic news? }\end{array}$ & .387 & -.027 & -.005 & .470 & .068 \\
\hline $\begin{array}{l}\text { teach your child how to spot } \\
\text { dangerous situations, like those } \\
\text { featured in the violent/tragic } \\
\text { news? }\end{array}$ & .390 & -.038 & -.033 & .539 & -.031 \\
\hline $\begin{array}{l}\text { point out something positive } \\
\text { about the violent/tragic news (for } \\
\text { example: humanity, sense of } \\
\text { community, heroism)? }\end{array}$ & .583 & -.054 & .056 & .010 & .121 \\
\hline $\begin{array}{l}\text { explain the potential motives of } \\
\text { the one who committed the } \\
\text { violent act or the reasons why } \\
\text { someone might act violently? } \\
\text { about the event even when s/he }\end{array}$ & .455 & .313 & -.066 & .017 & .040 \\
\hline $\begin{array}{l}\text { ask your child how s/he feels } \\
\text { abk your child if s/he thinks }\end{array}$ & .636 & .109 & -.118 & .048 & -.055 \\
\hline
\end{tabular}




\begin{tabular}{|c|c|c|c|c|c|}
\hline is not actively viewing it? & & & & & \\
\hline $\begin{array}{l}\text { ask your child if s/he has trouble } \\
\text { sleeping at night because of the } \\
\text { violent/tragic news? }\end{array}$ & .240 & .471 & .092 & -.120 & .031 \\
\hline $\begin{array}{l}\text { express that you are fearful or } \\
\text { worried about the violent/tragic } \\
\text { news when with your child? }\end{array}$ & -.077 & .637 & -.028 & .053 & .004 \\
\hline $\begin{array}{l}\text { talk to your child about how the } \\
\text { violent/tragic news media makes } \\
\text { you feel? }\end{array}$ & .429 & .347 & -.144 & -.006 & -.032 \\
\hline $\begin{array}{l}\text { express that you are angry or sad } \\
\text { about the violent/tragic news } \\
\text { when with your child? }\end{array}$ & .269 & .361 & -.152 & .071 & -.048 \\
\hline $\begin{array}{l}\text { openly, without restraint, express } \\
\text { your emotions about the } \\
\text { violent/tragic news around your } \\
\text { child? }\end{array}$ & .185 & .481 & -.169 & -.015 & -.084 \\
\hline $\begin{array}{l}\text { learn about the violent/tragic } \\
\text { news together because it is } \\
\text { important to know about such } \\
\text { events and keep your child } \\
\text { informed? }\end{array}$ & .303 & .437 & -.230 & .021 & -.020 \\
\hline
\end{tabular}




\begin{tabular}{|c|c|c|c|c|c|}
\hline $\begin{array}{l}\text { talk to your child about how the } \\
\text { violent/tragic news impacts your } \\
\text { personal safety? }\end{array}$ & .310 & .324 & -.102 & .190 & .035 \\
\hline $\begin{array}{l}\text { explain to your child how the } \\
\text { violent/tragic event could happen } \\
\text { to you or another person in a } \\
\text { close relationship to your child? }\end{array}$ & -.012 & .554 & -.042 & .120 & .082 \\
\hline $\begin{array}{l}\text { help your child understand who } \\
\text { to trust and not to trust in light of } \\
\text { the violence in the media? }\end{array}$ & .381 & -.072 & .018 & .428 & .014 \\
\hline $\begin{array}{l}\text { explain to your child how to } \\
\text { avoid situations like the ones in } \\
\text { the violent/tragic news? }\end{array}$ & .362 & .000 & -.020 & .528 & .013 \\
\hline $\begin{array}{l}\text { talk to your child about how to } \\
\text { handle situations that are similar } \\
\text { to the violent news events? }\end{array}$ & .430 & .078 & -.036 & .431 & .004 \\
\hline $\begin{array}{l}\text { make a point to discuss the } \\
\text { violent/tragic news with your } \\
\text { child? }\end{array}$ & .355 & .404 & -.206 & .049 & -.027 \\
\hline $\begin{array}{l}\text { inform your child of } \\
\text { violent/tragic news that you have } \\
\text { learned about from the media, } \\
\text { that s/he hasn't seen or asked }\end{array}$ & -.053 & .606 & -.261 & -.057 & .121 \\
\hline
\end{tabular}




\begin{tabular}{|c|c|c|c|c|c|}
\hline about? & & & & & \\
\hline $\begin{array}{l}\text { use the violent/tragic news to } \\
\text { teach your child about safety? }\end{array}$ & .137 & .194 & -.073 & .495 & -.010 \\
\hline $\begin{array}{l}\text { use the violent/tragic news to } \\
\text { teach your child about other } \\
\text { potential dangers? }\end{array}$ & .182 & .305 & -.025 & .457 & -.041 \\
\hline $\begin{array}{l}\text { talk to your child about how to } \\
\text { prepare for potential violence, } \\
\text { such as the events s/he has seen } \\
\text { in the media? }\end{array}$ & .261 & .244 & -.020 & .369 & .045 \\
\hline $\begin{array}{l}\text { use the violent/tragic news as a } \\
\text { way to teach your child to fear } \\
\text { similar situations? }\end{array}$ & -.227 & .683 & .117 & .321 & -.016 \\
\hline $\begin{array}{l}\text { use the violent/tragic news to } \\
\text { scare your child away from } \\
\text { participating in dangerous } \\
\text { activities? }\end{array}$ & -.278 & .712 & .205 & .268 & -.058 \\
\hline $\begin{array}{l}\text { scare your child into being } \\
\text { cautious in similar situations? }\end{array}$ & -.298 & .650 & .201 & .276 & -.146 \\
\hline $\begin{array}{l}\text { use the violent/tragic news to } \\
\text { scare your child with the purpose } \\
\text { of protecting him/her from }\end{array}$ & -.362 & .751 & .169 & .214 & .007 \\
\hline
\end{tabular}




\begin{tabular}{|c|c|c|c|c|c|}
\hline harm? & & & & & \\
\hline $\begin{array}{l}\text { emphasize that violent/tragic } \\
\text { news is a reality in an effort to } \\
\text { protect your child from harm? }\end{array}$ & .084 & .407 & .002 & .249 & .080 \\
\hline $\begin{array}{l}\text { leave out details of the } \\
\text { violent/tragic news when } \\
\text { discussing it with your child to } \\
\text { protect him/her? }\end{array}$ & .248 & -.064 & .647 & -.043 & -.059 \\
\hline $\begin{array}{l}\text { purposefully leave out details of } \\
\text { the violent/tragic news when } \\
\text { discussing it with your child? }\end{array}$ & .173 & .008 & .646 & -.040 & -.127 \\
\hline $\begin{array}{l}\text { avoid talking to your child about } \\
\text { the violent/tragic news? }\end{array}$ & -.173 & .223 & .613 & -.107 & -.077 \\
\hline $\begin{array}{l}\text { interrupt your child's exposure to } \\
\text { the media (for example, by } \\
\text { telling him/her to turn off the } \\
\text { TV)? }\end{array}$ & -.041 & .015 & .698 & .037 & .047 \\
\hline $\begin{array}{l}\text { interrupt your child's exposure to } \\
\text { the media because it's not } \\
\text { appropriate for his/her age? }\end{array}$ & .159 & -.071 & .761 & .048 & -.009 \\
\hline $\begin{array}{l}\text { ask your child to leave the room } \\
\text { when violent/tragic news is }\end{array}$ & -.056 & .074 & .721 & -.074 & .070 \\
\hline
\end{tabular}




\begin{tabular}{|c|c|c|c|c|c|}
\hline displayed in the media? & & & & & \\
\hline $\begin{array}{l}\text { keep your child from learning } \\
\text { about violent/tragic news you } \\
\text { believe would scare or worry } \\
\text { your child? }\end{array}$ & .070 & .000 & .784 & -.072 & .016 \\
\hline $\begin{array}{l}\text { encourage your child not to } \\
\text { discuss the violent/tragic news } \\
\text { with peers at school? }\end{array}$ & .017 & .378 & .434 & -.079 & .049 \\
\hline $\begin{array}{l}\text { forbid your child to watch certain } \\
\text { programs, avoid certain Internet } \\
\text { sites, or read certain print } \\
\text { material (for example: books, } \\
\text { magazines, newspapers) } \\
\text { regarding violent/tragic news? }\end{array}$ & .020 & -.094 & .694 & .099 & .042 \\
\hline $\begin{array}{l}\text { specify in advance the TV } \\
\text { programs, Internet sites, or } \\
\text { specific print media your child } \\
\text { can view/use in order to limit } \\
\text { access to violent/tragic news? }\end{array}$ & .195 & -.038 & .691 & .062 & .046 \\
\hline $\begin{array}{l}\text { set parental controls on devices } \\
\text { in your home that enable } \\
\text { blocking certain TV channels, }\end{array}$ & .061 & -.014 & .623 & .011 & .086 \\
\hline
\end{tabular}




\begin{tabular}{|l|l|l|l|l|l|}
\hline $\begin{array}{l}\text { Internet sites, etc. to limit access } \\
\text { to violent/tragic news? }\end{array}$ & & & & & \\
\hline $\begin{array}{l}\text { allow your child to watch or } \\
\text { view the violent/tragic news only } \\
\text { when you are with him/her? }\end{array}$ & .368 & .192 & .247 & .009 & -.093 \\
\hline $\begin{array}{l}\text { watch or view the violent/tragic } \\
\text { news together? }\end{array}$ & .242 & .370 & -.323 & -.019 & -.028 \\
\hline $\begin{array}{l}\text { watch or view the news with } \\
\text { your child so that you can } \\
\text { monitor the content? }\end{array}$ & .408 & .160 & .235 & -.076 & -.042 \\
\hline $\begin{array}{l}\text { watch or view the violent/tragic } \\
\text { news together because of a } \\
\text { shared curiosity? }\end{array}$ & .130 & .543 & -.238 & .005 & -.062 \\
\hline $\begin{array}{l}\text { use religion or spirituality to } \\
\text { victims, etc.)? } \\
\text { explain the violent news to your } \\
\text { about the violent/tragic news (for } \\
\text { child? }\end{array}$ & -.011 & .104 & .081 & -.001 & .774 \\
\hline $\begin{array}{l}\text { point out something positive, } \\
\text { ving religion or spirituality, }\end{array}$ & .002 & -.007 & .002 & .028 & .877 \\
\hline
\end{tabular}




\begin{tabular}{|l|l|l|l|l|l|}
\hline $\begin{array}{l}\text { wait to see if your child brings } \\
\text { up violent/tragic news? }\end{array}$ & .177 & .092 & .203 & -.010 & -.018 \\
\hline $\begin{array}{l}\text { let your child bring up the } \\
\text { violent/tragic news to you, } \\
\text { instead of starting a conversation } \\
\text { yourself? }\end{array}$ & .199 & .148 & .229 & -.035 & -.002 \\
\hline $\begin{array}{l}\text { handle your child's response to } \\
\text { violent/tragic news in the } \\
\text { moment without thinking about } \\
\text { how to handle it in advance? }\end{array}$ & .050 & .378 & .091 & -.034 & -.014 \\
\hline $\begin{array}{l}\text { let someone else talk to your } \\
\text { child about the violent/tragic } \\
\text { news so you don't have to? }\end{array}$ & -.257 & .721 & .188 & -.209 & .057 \\
\hline
\end{tabular}

The final step in each stage of the analyses consisted of eliminating low- or cross-loading items. The four steps were repeated five times until a clean factor structure resulted, meaning all remaining items loaded onto only one factor with a coefficient of .3 or greater.

The final parallel analysis indicated that three factors would best fit the data. That is, there would be multiple factors (with items loading on various constructs) rather than unidimensionality (i.e., all items loading onto that single construct). The first of the three factors extracted through the EFA contains 14 items pertaining to an open dialogue between caregivers and children about the reality of violent news in the media along with attempts to reassure the child of safety; this factor was named "Reassuring Realistically." The second factor contains 11 
items addressing parental control of their children's access to the violent news in the media; this factor was named "Controlling Contact." The third factor was named "Scaring to Protect" and comprises 10 items related to caregivers purposefully scaring their child with the intention of protecting them from future harm. The amount of variance accounted for by each factor is as follows: Reassuring Realistically (22.13\%), Controlling Contact (14.71\%), and Scaring for Safety $(9.01 \%)$. The total variance accounted for by the three factors combined is $45.85 \%$. Table 5 presents factor loadings for the final solution.

Table 5 CRYME items EFA (Promax Rotation) Factor Loadings Final Analyses

\begin{tabular}{|c|c|c|c|}
\hline Item & Factor 1 & Factor 2 & Factor 3 \\
\hline $\begin{array}{l}\text { try to help your child make sense of the violent/tragic } \\
\text { news by talking to him/her in a way that s/he can } \\
\text { understand? }\end{array}$ & .795 & -.015 & -.068 \\
\hline $\begin{array}{l}\text { explain the violent/tragic news in a way that s/he can } \\
\text { understand? }\end{array}$ & .768 & -.055 & -.071 \\
\hline $\begin{array}{l}\text { talk with your child about aspects of the violent news that } \\
\text { bother him/her the most? }\end{array}$ & .707 & -.085 & .067 \\
\hline $\begin{array}{l}\text { reassure your child that you (his/her caregiver) are safe in } \\
\text { spite of the violent/tragic news? }\end{array}$ & .712 & .136 & -.189 \\
\hline $\begin{array}{l}\text { reassure your child that } \mathrm{s} / \text { he is safe in spite of the } \\
\text { violent/tragic news? }\end{array}$ & .713 & .206 & -.225 \\
\hline $\begin{array}{l}\text { explain to your child that you personally feel safe despite } \\
\text { the violent/tragic news? }\end{array}$ & 689 & .138 & -.108 \\
\hline ask your child how s/he feels about the violent/tragic & .644 & -.158 & .128 \\
\hline
\end{tabular}




\begin{tabular}{|c|c|c|c|}
\hline news? & & & \\
\hline $\begin{array}{l}\text { encourage your child not to let the violent news change } \\
\text { his/her day-to-day actions? }\end{array}$ & .626 & . 107 & -.052 \\
\hline $\begin{array}{l}\text { teach your child that what s/he sees in the news cannot } \\
\text { control how s/he lives his/her life? }\end{array}$ & .614 & .084 & .023 \\
\hline $\begin{array}{l}\text { point out something reassuring about the violent/tragic } \\
\text { news (for example: no deaths, the perpetrator was caught, } \\
\text { etc.)? }\end{array}$ & .625 & .029 & .093 \\
\hline $\begin{array}{l}\text { explain ways in which the government, police, or other } \\
\text { officials addressed the situation? }\end{array}$ & .581 & -.037 & .164 \\
\hline $\begin{array}{l}\text { talk to your child about how this news event affects } \\
\text { him/her personally? }\end{array}$ & .567 & -.101 & .271 \\
\hline $\begin{array}{l}\text { point out something positive about the violent/tragic news } \\
\text { (for example: humanity, sense of community, heroism)? }\end{array}$ & .585 & .058 & .029 \\
\hline explain the likelihood of this event happening again? & .498 & -.017 & .238 \\
\hline $\begin{array}{l}\text { interrupt your child's exposure to the media because it's } \\
\text { not appropriate for his/her age? }\end{array}$ & .124 & .778 & -.014 \\
\hline $\begin{array}{l}\text { keep your child from learning about violent/tragic news } \\
\text { you believe would scare or worry your child? }\end{array}$ & .015 & .775 & .013 \\
\hline $\begin{array}{l}\text { ask your child to leave the room when violent/tragic news } \\
\text { is displayed in the media? }\end{array}$ & -.094 & .734 & .103 \\
\hline $\begin{array}{l}\text { forbid your child to watch certain programs, avoid certain } \\
\text { Internet sites, or read certain print material (for example: }\end{array}$ & .032 & .730 & -.007 \\
\hline
\end{tabular}




\begin{tabular}{|c|c|c|c|}
\hline $\begin{array}{l}\text { books, magazines, newspapers) regarding violent/tragic } \\
\text { news? }\end{array}$ & & & \\
\hline $\begin{array}{l}\text { interrupt your child's exposure to the media (for example, } \\
\text { by telling him/her to turn off the TV)? }\end{array}$ & -.044 & .723 & .065 \\
\hline $\begin{array}{l}\text { specify in advance the TV programs, Internet sites, or } \\
\text { specific print media your child can view/use in order to } \\
\text { limit access to violent/tragic news? }\end{array}$ & .185 & .705 & .049 \\
\hline $\begin{array}{l}\text { leave out details of the violent/tragic news when } \\
\text { discussing it with your child to protect him/her? }\end{array}$ & .194 & .617 & -.055 \\
\hline $\begin{array}{l}\text { purposefully leave out details of the violent/tragic news } \\
\text { when discussing it with your child? }\end{array}$ & .117 & .595 & -.025 \\
\hline $\begin{array}{l}\text { set parental controls on devices in your home that enable } \\
\text { blocking certain TV channels, Internet sites, etc. to limit } \\
\text { access to violent/tragic news? }\end{array}$ & .040 & 649 & .049 \\
\hline avoid talking to your child about the violent/tragic news? & -.228 & .558 & .143 \\
\hline $\begin{array}{l}\text { use the violent/tragic news to scare your child with the } \\
\text { purpose of protecting him/her from harm? }\end{array}$ & -.216 & .147 & .807 \\
\hline $\begin{array}{l}\text { use the violent/tragic news to scare your child away from } \\
\text { participating in dangerous activities? }\end{array}$ & -.129 & .171 & .774 \\
\hline $\begin{array}{l}\text { use the violent/tragic news as a way to teach your child to } \\
\text { fear similar situations? }\end{array}$ & -.505 & .093 & .731 \\
\hline scare your child into being cautious in similar situations? & -.179 & .152 & .687 \\
\hline express that you are fearful or worried about the & .006 & -.048 & .614 \\
\hline
\end{tabular}




\begin{tabular}{|l|l|l|l|}
\hline violent/tragic news when with your child? & & & \\
\hline $\begin{array}{l}\text { explain to your child how the violent/tragic event could } \\
\text { happen to you or another person in a close relationship to } \\
\text { your child? }\end{array}$ & .095 & -.045 & $\mathbf{. 5 6 7}$ \\
\hline $\begin{array}{l}\text { watch or view the violent/tragic news together because of } \\
\text { a shared curiosity? }\end{array}$ & .179 & -.283 & $\mathbf{. 4 6 8}$ \\
\hline $\begin{array}{l}\text { emphasize that violent/tragic news is a reality in an effort } \\
\text { to protect your child from harm? }\end{array}$ & .227 & .008 & $\mathbf{. 5 0 2}$ \\
\hline $\begin{array}{l}\text { ask your child if s/he thinks about the event even when } \\
\text { s/he is not actively viewing it? }\end{array}$ & .251 & -.092 & $\mathbf{. 4 5 1}$ \\
\hline $\begin{array}{l}\text { ask your child if s/he has trouble sleeping at night } \\
\text { because of the violent/tragic news? }\end{array}$ & .234 & .039 & $\mathbf{. 4 2 9}$ \\
\hline $\begin{array}{l}\text { openly, without restraint, express your emotions about the } \\
\text { violent/tragic news around your child? }\end{array}$ & .202 & -.214 & $\mathbf{. 3 9 1}$ \\
\hline
\end{tabular}

Item means and standard deviations are reported for the final remaining items in the measure. See Table 6 for full results.

Table 6 CRYME Item Means and Standard Deviations 


\begin{tabular}{|c|c|c|c|}
\hline Item & $M$ & $S D$ & $N$ \\
\hline 1 & 3.67 & 1.06 & 702 \\
\hline 2 & 3.69 & 1.02 & 702 \\
\hline 3 & 3.44 & 1.00 & 701 \\
\hline 4 & 3.80 & 0.99 & 701 \\
\hline 5 & 3.83 & 1.03 & 702 \\
\hline 6 & 3.59 & 1.06 & 702 \\
\hline 7 & 3.33 & 1.05 & 702 \\
\hline 8 & 3.50 & 1.09 & 701 \\
\hline 9 & 3.39 & 1.05 & 700 \\
\hline 10 & 3.33 & 1.04 & 702 \\
\hline 11 & 3.29 & 1.05 & 700 \\
\hline 12 & 3.20 & 1.02 & 702 \\
\hline 13 & 3.32 & 1.07 & 701 \\
\hline 14 & 3.12 & 0.98 & 701 \\
\hline 15 & 3.18 & 1.19 & 702 \\
\hline 16 & 2.88 & 1.19 & 702 \\
\hline 17 & 2.72 & 1.22 & 702 \\
\hline 18 & 3.17 & 1.32 & 702 \\
\hline 19 & 3.05 & 1.12 & 702 \\
\hline 20 & 3.26 & 1.28 & 702 \\
\hline 21 & 2.99 & 1.08 & 702 \\
\hline 22 & 3.01 & 1.09 & 702 \\
\hline 23 & 3.08 & 1.46 & 702 \\
\hline 24 & 2.46 & 1.13 & 701 \\
\hline 25 & 2.12 & 1.10 & 701 \\
\hline 26 & 2.36 & 1.15 & 701 \\
\hline 27 & 2.50 & 1.09 & 702 \\
\hline 28 & 2.13 & 1.10 & 702 \\
\hline 29 & 2.39 & 1.09 & 702 \\
\hline 30 & 2.63 & 1.09 & 702 \\
\hline
\end{tabular}




$\begin{array}{llll}31 & 2.65 & 1.13 & 702 \\ 32 & 2.90 & 1.06 & 702 \\ 33 & 2.65 & 1.12 & 702 \\ 34 & 2.63 & 1.14 & 702 \\ 35 & 2.76 & 1.10 & 702\end{array}$

Inter-factor correlations were examined. All three factors were significantly related to the CRYME total score. Reassuring Realistically and Scaring for Safety also have a moderate significant correlation $(r=.41, p<.001)$. Controlling Contact was not significantly correlated to either Reassuring Realistically $(r=.07, p=.05)$ or Scaring for Safety $(r=-.02, p=.7)$. All factors are highly and significantly $(p<.001)$ correlated with the CRYME total score: Reassuring Realistically, $r=.78$; Controlling Contact, $r=.53$; Scaring for Safety, $r=.67$. See Table 7 for complete inter-factor correlations.

Table 7 Inter-factor Correlations

$\begin{array}{lll}\text { Factor } 1 & \text { Factor } 2 & \text { Factor } 3\end{array}$

\section{Factor 1}

Factor 2

.07

Factor 3

$.41^{* *}$

.02

CRYME Total

$$
.78^{* *}
$$

$.53^{* *}$

$.67^{* *}$

Score

Note. ${ }^{* *} p<.001$

Cronbach's alpha was calculated for each scale and fell above .7, indicating good internal consistency (Field, 2009). Cronbach's alpha for Reassuring Realistically, Controlling Contact, and Scaring for Safety was $.91, .90$, and .86 , respectively. For the full scale, Cronbach's alpha 
was .90 . For each factor, Hotelling's T-square was significant, indicating that there are significant differences (between items within the scale).

Item-total statistics were also analyzed to further check reliability. In a reliable scale, all items should correlate with the total score (Field, 2009). An item-total correlation of below .3 may mean that the item does not fit well with the overall scale; this did not occur within any factor on the CRYME. It was important to also look at "Cronbach's Alpha if Item Deleted" to see if the overall alpha would increase if that specific item were eliminated. Two items were removed because the items either decreased the overall reliability of the scale or kept the alpha the same; one item was removed from Controlling Contact and one from Scaring for Safety. After removing these two items, the EFA was rerun to ensure that the factor structure still held; the same three factors emerged.

Relative means were also compared to explore the frequency of caregiver behaviors by factor. The mean for each factor (i.e., sum across items divided by number of items on the factor) was calculated for each participant and a repeated measures analysis of variance (ANOVA) was conducted to compare the means of each factor. Mauchly's test indicated that the assumption of sphericity had been violated, $\chi^{2}(2)=132.86, \mathrm{p}<0.001$, therefore Greenhouse-Geisser corrected tests are reported $(\varepsilon=.85)$. The results show there are statistically significant differences in scores by factor (Wilks' Lambda $=.40, F(2,700)=518.85, p<0.001$, multivariate partial eta squared $=.60)$. Post hoc comparisons using a $t$-test with Bonferroni correction revealed that the mean score for Reassuring Realistically $(M=3.47, S D=0.71)$ was significantly greater than the mean score for Controlling Contact $(M=2.98, S D=0.87)$, which was significantly greater than the mean score for Scaring for Safety $(M=2.52, S D=0.72)$ strategies. 


\section{SECONDARY RESEARCH AIM: CRYME MEASURE RELATION TO AGE AND GENDER}

Secondary Research Aim: To explore the relationships of child age and gender to caregiver responses to youth media exposure.

Data Analysis. The relationship between child age (in years) and caregiver behaviors as measured by three factors (i.e., Reassuring Realistically, Controlling Contact, Scaring for Safety) was investigated using Pearson Product Moment correlation coefficients. Pearson's Product Moment correlations divide the covariance of two variables by the product of their standard deviations. These correlational analyses allow for a better understanding of which factors are more frequent or apparent with age.

Second, independent samples t-tests were conducted using the factor scores to examine the relationship between the factors that emerged from the EFA and child gender. See Tables 8 $\& 9$ for full results.

Table 8 Independent Samples t-test of Items by Gender

\begin{tabular}{|c|c|c|c|c|c|}
\hline & \multicolumn{2}{|c|}{ Female } & \multicolumn{2}{|c|}{ Male } & \multirow[t]{2}{*}{ T-test } \\
\hline Item & $M$ & $S D$ & $M$ & $S D$ & \\
\hline 1 & 3.72 & 1.10 & 3.64 & 1.01 & -0.99 \\
\hline 2 & 3.72 & 0.99 & 3.67 & 1.04 & -0.60 \\
\hline 3 & 3.46 & 1.06 & 3.43 & 0.96 & -0.38 \\
\hline 4 & 3.80 & 1.01 & 3.81 & 0.98 & 0.17 \\
\hline 5 & 3.88 & 1.01 & 3.80 & 1.02 & -0.98 \\
\hline 6 & 3.64 & 1.03 & 3.54 & 1.08 & -1.19 \\
\hline 7 & 3.33 & 1.03 & 3.32 & 1.05 & -0.09 \\
\hline
\end{tabular}




\begin{tabular}{|c|c|c|c|c|c|}
\hline 8 & 3.50 & 1.10 & 3.49 & 1.08 & -0.04 \\
\hline 9 & 3.39 & 1.10 & 3.39 & 1.01 & 0.01 \\
\hline 10 & 3.32 & 1.06 & 3.33 & 1.03 & 0.11 \\
\hline 11 & 3.32 & 1.05 & 3.27 & 1.05 & -0.62 \\
\hline 12 & 3.14 & 1.04 & 3.24 & 1.01 & 1.24 \\
\hline 13 & 3.34 & 1.05 & 3.30 & 1.08 & -0.49 \\
\hline 14 & 3.07 & 1.01 & 3.15 & 0.95 & 1.05 \\
\hline 15 & 3.17 & 1.18 & 3.19 & 1.19 & 0.24 \\
\hline 16 & 2.87 & 1.18 & 2.90 & 1.19 & 0.31 \\
\hline 17 & 2.63 & 1.17 & 2.78 & 1.24 & 1.64 \\
\hline 18 & 3.17 & 1.34 & 3.16 & 1.31 & -0.16 \\
\hline 19 & 2.98 & 1.12 & 3.11 & 1.12 & 1.48 \\
\hline 20 & 3.21 & 1.31 & 3.31 & 1.27 & 0.92 \\
\hline 21 & 2.99 & 1.11 & 2.99 & 1.07 & -0.07 \\
\hline 22 & 3.00 & 1.09 & 3.02 & 1.10 & 0.24 \\
\hline 23 & 2.93 & 1.51 & 3.19 & 1.41 & 2.32 \\
\hline 24 & 2.42 & 1.11 & 2.49 & 1.14 & 0.76 \\
\hline 25 & 2.00 & 1.07 & 2.20 & 1.12 & $2.30 *$ \\
\hline 26 & 2.27 & 1.14 & 2.41 & 1.14 & 1.61 \\
\hline 27 & 2.34 & 1.07 & 2.63 & 1.09 & $3.42 * * *$ \\
\hline 28 & 2.03 & 1.11 & 2.18 & 1.07 & 1.70 \\
\hline 29 & 2.23 & 1.03 & 2.49 & 1.11 & $3.17 * *$ \\
\hline 30 & 2.46 & 1.06 & 2.75 & 1.09 & $3.46 * * *$ \\
\hline
\end{tabular}




\begin{tabular}{llllll}
\hline 31 & 2.51 & 1.10 & 2.74 & 1.14 & $2.69^{* *}$ \\
32 & 2.83 & 1.08 & 2.94 & 1.03 & 1.32 \\
33 & 2.53 & 1.12 & 2.72 & 1.10 & $2.22^{*}$ \\
34 & 2.52 & 1.14 & 2.71 & 1.14 & $2.17^{*}$ \\
35 & 2.61 & 1.10 & 2.88 & 1.07 & $3.25^{* *}$ \\
\hline
\end{tabular}

Note. $N=702,{ }^{*} p<.05,{ }^{* *} p<.01,{ }^{* * *} p<.001$

Table 9 Independent Samples t-test Between Factor Scores and Gender

\begin{tabular}{lrrrrc}
\hline \multicolumn{5}{c}{ Female } & \multicolumn{3}{c}{ Male } & T-test \\
\hline & $M$ & $S D$ & $M$ & $S D$ & \\
\hline Factor 1 & 48.62 & 10.31 & 48.41 & 9.78 & -.29 \\
Factor 2 & 29.40 & 8.71 & 30.11 & 8.77 & 1.06 \\
Factor 3 & 26.37 & 7.57 & 28.73 & 8.00 & $3.96^{* * *}$ \\
\hline Note. $N=702, * p<.05, * * p<.01, * * * p<.001$ & & &
\end{tabular}

Note. $N=702, * p<.05,{ }^{* *} p<.01, * * * p<.001$

A t-test examines mean group differences to determine if the two groups being analyzed are statistically significantly different (Field, 2009). Therefore, the t-test subtracts the expected difference between population means from the observed difference between sample means and divides that by the estimated standard error of the difference between two sample means.

Results. Preliminary analyses were performed to ensure no violation of the assumptions of normality, linearity, and homoscedasticity. There was a small, positive correlation between Reassuring Realistically and age, indicating that the older the child, the more likely caregivers are to provide realistic reassurance in response to media exposure $(r=.14, N=702, p<.001)$. The same small, positive correlation was found between Scaring to Protect and age, indicating 
that caregivers use the content in the media to scare their children away from similar events/experiences more frequently as the child gets older $(r=.15, N=702, p<.001)$. A medium, negative correlation was found between Controlling Contact and age, indicating that the older the child, the less likely it is that caregivers control their children's access to violent news in the media $(r=-.43, N=702, p<.001)$. See Table 10 for complete correlation results.

\section{Table 10 Correlations between Facotrs and Child Age in Years}

\section{Age}

Factor 1

Factor $2 \quad-.43 * * *$

Factor $3 \quad .15 * * *$

Note. $N=702, * * * p<.001$, Age range $=6-17$ years

For each factor (i.e., Reassuring Realistically, Controlling Contact, Scaring for Safety), an independent samples t-test was conducted to compare male and female children's factor scores. There was no significant difference in scores for Reassuring Realistically between males $(M=48.41, S D=9.78)$ and females $(M=48.62, S D=10.31)$; nor was there a significant difference in scores for Controlling Contact between males $(M=30.11, S D=8.77)$ and females $(M=29.40, S D=8.71)$. There was a significant difference between males $(M=28.73, S D=$ 8.00) and females $(M=26.37, S D=7.57)$ for Scaring for Safety. Caregivers reported deliberately scaring male children more than female children with the intention of protecting them; this effect was small (Pearson's $r=.15$ ). See Table 9 for complete t-test results.

\section{DISCUSSION}

This study was the first to develop and examine the factor structure of a questionnaire specifically measuring caregiver behaviors in response to youth violent news media exposure. A 
three-factor structure emerged: Reassuring Realistically (factor one), Controlling Contact (factor two), and Scaring for Safety (factor three). The Reassuring Realistically factor is comprised of parenting behaviors that involve conversing with the child about the media in an open and realistic manner. The Controlling Contact factor measures parenting behaviors that involve limiting or restricting access to media. The Scaring for Safety factor assesses parenting behaviors that use the media content as a way to teach the child safety-promoting behaviors in spite of the violence in the media. The Reassuring Realistically and Controlling Contact factors are consistent with content of previous measures that have been used in studies of parental behaviors in response to media exposure (Owens et al., 1999; Padilla-Walker et al., 2012; Padilla-Walker \& Coyne, 2011; Valkenburg, Kramar, Peeters, \& Marseille, 1999). However, analysis of data from a focus group of caregivers generated additional items for the CRYME, evidenced by the Scaring for Safety factor. Internal consistency of each factor was good (George \& Mallery, 2003).

The resulting factors covered a range of unique parenting behaviors in response to children viewing violent news in the media. The measure as a whole had a Cronbach's alpha of .89; however, responses are better interpreted as scores for the individual scales rather than the total score. Although the factors were each highly and significantly associated with the CRYME total score, the CRYME may be measuring overall caregiver involvement in youth violent news media exposure. If a caregiver is extremely involved or attentive to this area of his/her child's life, he/she will likely score relatively high on all three factors. On the contrary, if violent news media is not of particular concern to the caregiver, he/she will likely score relatively low on all three factors. Each factor measures a set/pattern of parenting behaviors that is meaningfully distinct. 
Reassuring Realistically includes items that assess the parenting behaviors of reassuring the child of his/her safety, explaining the violent news events in a developmentally appropriate way, and/or encouraging the child to not let the violent news affect his/her daily life and routine. This factor is similar to a previously identified construct that involves educating the child about what is realistic about the event being portrayed in the media (i.e., introducing statements or questions that allow youth to question the inaccuracy or unrealistic content of violent media; Nathanson \& Yang, 2003). Other previously identified strategies similar to those captured by the Reassuring Realistically factor related media content to the child personally (e.g., modeling coping thoughts; Comer et al., 2008b) but did not include realistic reassurance of the child's loved ones' safety or discussion of impact on the child's daily life. In the current sample, caregivers exhibited these behaviors more frequently than Controlling Contact and Scaring for Safety behaviors.

Controlling Contact measures caregiver behavior related to limiting a child's access to the violent news media either before or during the exposure, limiting conversations with the child about the events, and/or sheltering the child from knowledge of the violent news events portrayed in the media. The Controlling Contact factor is consistent with strategies previously identified in the media monitoring literature (e.g., limiting access to specific media outlets, restricting media access when content seems inappropriate for child's specific developmental level; Owens et al., 1999; Padilla-Walker et al., 2012; Padilla-Walker \& Thompson, 2005; Padilla-Walker, Christiansen, \& Day, 2011). Specifically, some measures created for individual studies of media exposure effects included items inquiring about restriction and control of media access; however, these measures were not generated with a focus group or validated through factor analysis (Owens et al., 1999; Padilla-Walker et al., 2012). The Controlling Contact factor 
also parallels the literature on family accommodation of anxiety symptoms in that it includes parenting behaviors intended to limit a child's exposure to anxiety-provoking situations in the moment (Benito et al., 2015; Caporino et al., 2013). This strategy likely helps to reduce anxiety in the short term, situationally; but may increase anxiety in the long term by limiting the child's opportunities to learn coping strategies when exposed to anxiety-provoking content. Future studies should investigate the relationship of Controlling Contact to child state and trait anxiety.

Scaring for Safety assesses parenting behaviors related to using the violent news media as a teaching mechanism to prevent the child from engaging in dangerous activities or to instill fear of similar situations. This factor also includes items that assess a caregiver's tendency to share his/her own feelings of fear and worry about the event and explain that the event could happen again to the child or a loved one. While the items loading onto the Reassuring Realistically and Controlling Contact factors were generated from themes identified in the literature and through the focus group, the Scaring for Safety items were generated solely from the focus group data. Scaring for Safety appears to be related to a theme that has emerged in the community violence literature, for example, via reports of minority parents' attempts to balance teaching children to protect themselves from harm with realistic expectations of safety (Letiecq \& Koblinsky, 2004). Researchers suggested that some of the caregiver strategies might actually provoke fear in the children rather than empowering them with skills to be safe. On the contrary, "hypervigilant parental monitoring" has been associated with a decrease in exposure to community violence over a five-year period (Spano, Rivera, \& Bolland, 2011). Research is warranted to better understand the interaction of Scaring for Safety tactics and exposure to violence on children's mental health outcomes. 
Caregivers in this sample used the Reassuring Realistically strategies more frequently than Controlling Contact, which was used more frequently than Scaring for Safety behaviors. It may be that reassuring a child of his/her safety is easier for caregivers to implement than controlling their access to media or taking the time to scare their children away from engaging in dangerous circumstances. It is also possible that caregivers perceive Reassuring Realistically strategies to be more effective for protecting youth from distress than Controlling Contact or Scaring for Safety. Differences in the frequency with which these types of caregiver behaviors are endorsed might also reflect different goals that caregivers have for their children with regard to violent news media exposure. For example, Scaring for Safety strategies may have been used relatively infrequently because they reflect a less common goal (e.g., promoting cautious behavior) than the goal that likely motivates Realistic Reassurance (e.g., minimizing distress while promoting understanding). Further research is needed to better understand the reasons why the frequencies with which caregivers exhibit the behaviors reflected by the three factors differ.

Two of the factors were moderately correlated, while the third was not significantly correlated with any other factor. Specifically, Reassuring Realistically and Scaring for Safety were significantly positively correlated, but Controlling Contact stood alone. This finding makes sense in that strategies tapped by Reassuring Realistically and Scaring for Safety items involve discussing violent news with children to reduce its negative impact, whereas Controlling Contact involves restricting children's access to violent news (such that there is less to discuss). Caregiver-child discussions have not been well studied (Carpenter, Elkins, Kerns, Chou, Green, \& Comer, 2015). It's possible that caregivers who discuss violent news with their children use multiple strategies (e.g., reassuring children that they are safe; scaring them away from 
potentially dangerous activities) for influencing children's emotional responses depending on the context.

There were differences by age and gender in how caregivers respond to their children's exposure to violent news media. Caregivers in this study were more likely to use Reassuring Realistically and Scaring to Protect techniques with older children and Controlling Contact techniques with younger children. These age differences are generally consistent with those reported in previous studies (Fagot, 1978; Karraker, Vogel, \& Lake, 1995; Lott, 1997; PadillaWalker et al., 2012; Rosen, Cheever, \& Carrier, 2008) that suggested that over time, mothers become less restrictive of their children's media access. For example, parents have been shown to set different limits with regards to child use of social media websites depending on child age (Rosen, Cheever, \& Carrier, 2008). While age does not protect against the negative effects of media on children's well-being (see review by Wilson, 2008), caregivers may adjust their strategy for responding to youth media exposure based on the child's age.

In addition to showing expected differences in age, this study supported gender differences in strategies that caregivers use in response to their child viewing violent news in the media. There were no differences in the frequency of caregiver use of Reassuring Realistically and Controlling Contact by child gender; however, caregivers reported deliberately scaring male children more than female children in hopes of protecting them from harm (Scaring for Safety). Of note, the large sample size and small effect may mean that the observed gender differences are not critical for parenting intervention planning. These gender differences are in line with a replication of a classic gender study (Karraker, Vogel, \& Lake, 1995) in which babies perceived to be girls were treated more delicately than boys. Similar sex differences in parent-child interactions have been found in studies with older children as well (Fagot, 1978; Lott, 1997). It 
may be that caregivers in the current study are more likely to treat girls more delicately (i.e., scaring them less) than they treat boys.

Another possible reason why caregivers in the current study use Scaring for Safety strategies more frequently with male children than with female children is that caregivers accurately perceive boys to be more risk-taking than girls (Ginsburg, \& Miller, 1982; Harris, Jenkins, \& Glaser, 2006; Morrongiello, \& Rennie, 1998; Smokowski, Mann, Reynolds, \& Fraser, 2004). Adjusting parenting strategies to fit the risk-taking levels of males and females could be effective for keeping children safe. For example, conveying trust was most strongly associated with reductions in females' risk taking in a sample of African American adolescents compared to parental monitoring, which was most effective in reducing risky behavior for males only (Borawski, Ievers-Landis, Lovegreen, \& Trapl, 2003). Similarly, high parental control protected against risky sexual behavior in males while the opposite was true for females. In addition to selecting parenting strategies based on child gender with the goal of keeping children safe, caregivers may also have different goals for male versus female children. Qualitative analyses of mothers' statements towards their children in potentially risky situations showed higher rates of statements warning females of danger and encouraging risk-taking behavior in males (Morrongiello \& Dawber, 2000). In sum, it may be adaptive that the caregivers in this study use the Scaring for Safety tactics more frequently with males than females, though further investigation is needed.

\subsection{Limitations.}

This study had several limitations. First, the focus group intended to fill any gaps in the literature on how caregivers respond to their children's violent news media exposure was limited in racial diversity. Although the ideal sample size for conducting a focus group inherently limits 
generalizability of the findings, the sample for the current focus group was further limited in that it consisted only of African American caregivers, primarily mothers (83\%). On balance, minority populations have been underrepresented in prior research on this topic; thus, the focus group succeeded in filling a gap in the literature. Additionally, the racial homogeneity of the focus group may have allowed the participants to feel more comfortable, open, and free to share information (Kitzinger, 1994).

Second, the study relied on retrospective caregiver report. As with any self-report measure, the CRYME is limited by the extent to which caregivers have insight into their own behavior. Caregivers were not asked to monitor their behavior prior to answering the questions; therefore, responses may have been limited by memory and subject to recency effects. An alternative was to develop a multi-informant measure of caregiver behavior (i.e., also completed by other caregivers and the child); however, others may not be aware of the primary caregiver's behavior with regard to his/her child's media use and therefore may not be accurate reporters of behaviors tapped by the CRYME. Another option was to develop a behavioral task for directly observing caregiver behavior while/after their children viewed violent news in the media. Although behavioral tasks could be used in experimental designs to make causal inferences, a questionnaire is more feasible for use in a range of research and clinical settings in which it is likely useful to understand parental responses to their children's violent news media exposure.

Third, there were barriers (e.g., participant effort and honesty) to ensuring a valid administration online of the measures included in this study. To address this concern, as detailed in the methods, insufficient effort response (IER) detection techniques were used to identify the participants who did not respond truthfully and thoughtfully to items on all measures (Huang et al., 2011). Offsetting the potential disadvantages of online data collection, data collected online 
may have been less affected by impression management than data collected in person.

Anonymity online might encourage more truthful responses from participants who put forth genuine effort to interpret and respond to the questions.

Finally, the sample consisted only of primary caregivers because they would presumably have the most influence over the child's access and responses to media. The sample was also predominantly female (i.e., $71 \%$ ), which is not surprising given that a requirement of participation in the study was being a primary caregiver. In future studies, it will be important to recruit male caregivers to better understand if there are gender differences by caregiver and how the behavior of multiple caregivers might interact to influence child responses to violent news in the media.

Despite these limitations, this study makes a unique contribution to the current literature in that no other study has used such a large sample to develop and validate through factor analysis a measure parenting behaviors in response to children's violent news media exposure. Additionally, the data collected through the focus group allowed for the identification of a theme not previously reported in the literature: using the media as a means of educating or scaring a child away from participating in harmful/dangerous situations. The parenting behaviors identified through the focus group portion of the study that had not been assessed in prior research were: using the media as a teaching mechanism, using spirituality to cope, taking a child-led approach, and reassuring in a realistic way.

\subsection{Future Directions.}

Further validation. The EFA determined the factor structure of the CRYME and results provide preliminary support for the use of the subscales. Future studies should use bivariate correlational analyses to explore the common and unique associations of CRYME factors with 
theoretically relevant parenting and family constructs, including parental accommodation and family functioning, with the goal of assessing convergent and discriminant validity. Convergent validity would demonstrate that the CRYME scales are related to previously validated measures of similar constructs. Discriminant validity would show that the CRYME scales each measure something unique. Taken together, convergent and discriminant validity coefficients can demonstrate construct validity by showing that similar constructs are related and dissimilar constructs are not related. Study measures should be selected to cover a range of family constructs expected to be differentially related to various aspects of caregiver influence on child responses to media (measured by the CRYME).

Specifically, it is expected that the Controlling Contact factor would correlate more strongly with a measure of family accommodation (e.g., FASA; Lebowitz et al., 2012) than would Reassuring Realistically and Scaring for Safety, as Controlling Contact and family accommodation both involve limiting access to anxiety-provoking stimuli whereas Reassuring Realistically and Scaring for Safety involve discussion of potentially anxiety-provoking content. Given evidence that adults with elevated anxiety see value in their worry (e.g., rate it as useful for preparing for the worst and avoiding negative outcomes; Borkovec \& Roemer, 1995), caregiver self-reported anxiety symptoms (e.g., measured using the GAD-7; Spitzer, Kroenke, Williams \& Lowe, 2006) would likely be positively related to Scaring for Safety, which reflects instances in which caregivers are attempting to evoke anxiety in their children for the purpose of motivating cautious behavior. Caregiver self-reported anxiety is not expected to be associated with Reassuring Realistically, which may require tolerance of uncertainty that is uncharacteristic of adults with generalized anxiety (e.g., Ladouceur et al., 1999), or Controlling Contact, which may be motivated by a number of goals (e.g., preventing child aggression) unrelated to caregiver 
anxiety. Lastly, in order to show that the CRYME measures caregiver behavior beyond just discussions and involvement with their children, it is expected that CRYME items should not be strongly associated with items assessing involvement or communication on a measure of specific aspects of family functioning (e.g., FAM-III; Skinner, Steinhauer, \& Santa-Barbara, 1995).

In addition to convergent and discriminant validity, test-retest reliability of the CRYME should be assessed. Comparing CRYME scores to observation of caregivers' behavior while viewing a segment of violent news media with their children would allow for an assessment of how accurately caregivers self-report their behavior.

Advanced statistical methods may afford opportunities to improve the CRYME. The analyses of the CRYME conducted thus far are rooted in classical test theory and assume that each item loading on a given factor represents that factor equally as well as the other items loading on that factor, and that measurement precision is constant across the entire range of the latent construct or trait. However, Item Response Theory (IRT) analyses would help to better explore the "difficulty" of individual items (with a higher level of the latent construct required to endorse a more difficult item) as well as their "discrimination," or ability to differentiate among individuals in the trait range around the item's difficulty. Thus, IRT would allow for the selection of items that simultaneously cover the interested range of the latent construct with adequate precision and improve construct validity (With \& Edwards, 2007).

Measure adaptive caregiver strategies. Once the measure is further validated, it can be used to better understand which caregiver behaviors are related to positive and negative emotional outcomes for children after exposure to violent news media. Such research will inform the creation of trainings to allow caregivers to learn skills and strategies to use with their children to mitigate the negative impact of exposure to violent news media. This research could also 
inform recommendations disseminated to parents by professional organizations following a major disaster.

Given that the focus group consisted of all African American caregivers and subsequent data analysis revealed a parenting strategy previously unidentified in the literature, it's possible that this strategy is more highly utilized among African Americans than parents of other racial groups. The identities of race and gender interact in parenting (i.e., the more salient identity may be most influential) to shape parents' emphasis on values in areas of teaching, providing, and disciplining (Hill \& Sprague, 1999). Thus, it is important to consider the interaction of gender and race roles in relation to caregiver responses to youth media exposure assessed via the CRYME.

Also, there is evidence that adaptive and maladaptive parenting strategies may differ by race. For example, corporal punishment has been shown to be associated with negative outcomes (i.e., conduct problems, depression, etc.) in non-Hispanic White children but not necessarily in African American children (e.g., Dodge, Pettit, Bates, \& Valente, 1995; Simons, Simons, \& Su, 2013). Also, supportive parenting behaviors act as a buffer for the negative effects of discrimination, showing that specific parenting behaviors that are adaptive may be unique to different cultural experiences (Simons et al., 2006). Future studies should test the relationship between Scaring for Safety and child outcomes by race, controlling for socioeconomic status. Race may moderate the relationship between Scaring for Safety and negative outcomes (e.g., anxiety) in youth after exposure to violent news media.

Expanding use to populations with anxiety. Different youth populations have unique needs with regard to mental health (Drake \& Ginsburg, 2012) and thus may have unique needs 
regarding caregiver responses to violent news media exposure. One such population is children with preexisting risk factors for anxiety or trauma-related symptoms.

Parental responses to violent news could potentially exacerbate its negative impact on children with preexisting anxiety. Outside of the media research, studies have demonstrated that parental modeling of anxious and avoidant behaviors is associated with anxiety in children (see review by Drake \& Ginsburg, 2012). Anxious parents are more likely than non-anxious parents to interpret neutral stimuli as dangerous and influence their children's appraisals of and responses to such stimuli (Barrett et al., 1996; Lester et al., 2008). These findings are consistent with the idea that parents, through their responses to violent news, can reinforce or influence anxious thoughts and behaviors in their children.

Observed parental control (i.e., the encouragement of dependency on parents, which can lead to a lack of mastery or perceived control of the child's own environment) has also been linked to high levels of anxiety in children (e.g., Wood et al., 2003; van Brakel et al., 2006). Restrictive parenting in the context of violent news media exposure may have the same impact as parental overcontrol, contributing to child anxiety by communicating to children that they cannot cope independently with violent news. Parenting behaviors pinpointed by Controlling Contact items may minimize their child's immediate negative responses to media (Strasburger et al., 2010) but future studies should determine if in the long term, these strategies are as effective as processing violent news with children.

Additionally, anxiety is thought to be maintained or exacerbated when caregivers accommodate symptoms in order to reduce a child's distress in the short term (e.g., Caporino et al., 2012; Lebowitz et al., 2012). Restricting a child's media exposure or providing excessive reassurance that the child will not be affected by violent events in the news, for example, may 
reflect a broader pattern of family accommodation. Such caregiver/family accommodation includes facilitating avoidance of anxiety-provoking situations and providing repeated reassurance that feared outcomes will not occur. Accommodating behaviors may prevent habituation that results from exposure to feared situations (Foa \& Kozak, 1986) and limit a child's opportunities to learn that feared outcomes are unlikely (Storch, et al., 2007). The CRYME will allow for research on the context-specific impact of accommodating behaviors.

Another group of children with unique needs are children whose caregivers exhibit preexisting psychopathology. There is evidence to support that caregivers suffering from mental illness parent differently (Compas et al., 2001). It is important to understand the unique behaviors that these caregivers exhibit in response to their children's exposure to violent news media. Based on the larger body of research on parent psychopathology, it is likely that caregivers model maladaptive coping strategies but further investigation in the context of parentchild interactions around violent news is warranted (Aldridge, 2006; Compas et al., 2001; Barrett, et al. 2006).

There are many future uses for the CRYME. This timely measure of caregiver responses to youth media exposure is the first to offer distinct empirically-derived factors to better understand patterns in caregiver behaviors. It is hoped that the CRYME will enable further understanding of caregiver behaviors that attenuate the negative consequences of violent news media exposure on children. 


\section{REFERENCES}

Aldridge, J. (2006). The experiences of children living with and caring for parents with mental illness. Child abuse review, 15(2), 79-88.

Amazon.com (2013). Amazon Mechanical Turk, Artificial Artificial Intelligence.

Anderson, D. R., \& Hanson, K. G. (2009). Children, media, and methodology. American Behavioral Scientist, 52(8), 1204-1219.

Barrett, P. M., Rapee, R. M., Dadds, M. M., and Ryan, S. M. (1996). Family enhancement of cognitive style in anxious and aggressive children. Journal of Abnormal Child Psychology, 24(2), 187-203.

Becker-Blease, K. A., Finkelhor, D., \& Turner, H. (2008). Media exposure predicts children's reactions to crime and terrorism. Journal of Trauma \& Dissociation, 9(2), 225-248.

Borawski, E. A., Ievers-Landis, C. E., Lovegreen, L. D., \& Trapl, E. S. (2003). Parental monitoring, negotiated unsupervised time, and parental trust: The role of perceived parenting practices in adolescent health risk behaviors. Journal of Adolescent Health, 33(2), 60-70.

Borkovec, T. D., \& Roemer, L. (1995). Perceived functions of worry among generalized anxiety disorder subjects: Distraction from more emotionally distressing topics?. Journal of behavior therapy and experimental psychiatry,26(1), 25-30.

Braun, V. and Clarke, V. (2006). Using thematic analysis in psychology. Qualitative Research In Psychology, 7, 77-101.

Brown, J. D., \& Bobowski, P. S. (2011). Older and newer media: Patterns of use and effects on adolescents' health and well- being. Journal of Research on Adolescence, 21(1), 95113. 
Buijzen, M., van der Molen, J. H., \& Sondij, P. (2007). Parental mediation of children's emotional responses to violent news event. Communication Research, 34, 212-230.

Busso, D., McLaughlin, K., \& Sheridan, M. (2014). Media exposure and sympathetic nervous system reactivity predict PTSD symptoms after the Boston marathon bombings. Depression and Anxiety, 31, 551-558.

Carpenter, A. L., Elkins, R. M., Kerns, C., Chou, T., Green, J. G., \& Comer, J. S. (2015). Event-related household discussions following the Boston Marathon bombing and associated posttraumatic stress among area youth. Journal of Clinical Child \& Adolescent Psychology, 1-12.

Caporino, N. E., Morgan, J., Beckstead, J., Phares, V., Murphy, T. K., \& Storch, E. A. (2012). A structural equation analysis of family accommodation in pediatric obsessivecompulsive disorder. Journal of abnormal child psychology, 40(1), 133-143.

Caporino, N.E., Sakolsky, D., Brodman, D.B., Kendall, P.C., Albano, A.M., Sherrill, J....Walkup, J.T. (2014). Defining treatment response and remission in child anxiety: Signal detection analysis using the Screen for Child Anxiety Related Emotional Disorders (SCARED). Unpublished manuscript.

Chen, S. F., Wang, S., \& Chen, C. Y. (2012). A simulation study using EFA and CFA programs based the impact of missing data on test dimensionality. Expert Systems with Applications, 39(4), 4026-4031.

Clark, L. A. and Watson, D. (1995). Constructing validity: Basic issues in objective scale development. Psychological Assessment, 7(3), 309-319. 
Collimore, K. C., McCabe, R. E., Carleton, R. N., Asmundson, G. J. G. (2008). Media exposure and dimensions of anxiety sensitivity: Differential associations with PTSD symptom clusters. Journal of Anxiety Disorders, 22, 1021-1029.

Comer, J. S., Furr, J. M., Beidas, R. S., Babyar, H. M., \& Kendall, P. C. (2008a). Media use and children's perceptions of societal threat and personal vulnerability. Journal of Clinical Child and Adolescent Psychology, 37(3), 622-630.

Comer, J. S., Furr, J. M., Beidas, R. S., Werner, C. L., \& Kendall, P. C. (2008b). Children and terrorism-related news: Training parents in coping and media literacy. Journal of Consulting and Clinical Psychology, 76(4), 568-578.

Comer, J. S., \& Kendall, P. C. (2007). Terrorism: The psychological impact on youth. Clinical Psychology: Science and Practice, 14(3), 178-212.

Compas, B. E., Connor-Smith, J. K., Saltzman, H., Thomsen, A. H., \& Wadsworth, M. E. (2001). Coping with stress during childhood and adolescence: problems, progress, and potential in theory and research. Psychological Bulletin, 127(1), 87.

Cronbach, L. J. and Meehl, P. E. (1955). Construct validity in psychological tests. Psychological Bulletin, 52(4), 281-302.

Dodge, K. A., Pettit, G. S., Bates, J. E., \& Valente, E. (1995). Social information-processing patterns partially mediate the effect of early physical abuse on later conduct problems. Journal of abnormal psychology, 104(4), 632.

Drake, K. L. and Ginsburg, G. S. (2012). Family factors in the development, treatment, and prevention of childhood anxiety. Clinical Child and Family Psychological Review, 15, 144-162. 
Fabrigar, L. R., Wegener, D. T., MacCallum, R. C., \& Strahan E. J. (1999). Evaluating the use of factor analysis in psychological research. Psychological Methods, 4(3), 272-299.

Fagot, B. I. (1978). The influence of sex of child on parental reactions to toddler children. Child development, 459-465.

Field, A. (2009). Discovering Statistics Using IBM SPSS Statistics: 4 $^{\text {th }}$ Edition. London: SAGE Publications.

Floyd, F. J. and Widaman, K. F. (1995). Factor analysis in the development and refinement of clinical assessment instruments. Psychological Assessment, 7(3), 286-299.

Foa, E. B., \& Kozak, M. J. (1986). Emotional processing of fear: exposure to corrective information. Psychological bulletin, 99(1), 20.

Fremont, W. P. (2003). Child reactions to terrorism induced trauma: A review of the past 10 years. Journal of American Academy of Child and Adolescent Psychiatry, 43(4), 381393.

George, D., \& Mallery, P. (2003). SPSS for Windows step by step: A simple guide and reference. 11.0 update (4th ed.). Boston: Allyn \& Bacon.

Ginsburg, H. J., \& Miller, S. M. (1982). Sex differences in children's risk-taking behavior. Child development, 426-428.

Gentile, D. A. and Walsh, D. A. (2002). A normative study of family media habits. Applied Developmental Psychology, 23, 157-178.

Harris, C. R., Jenkins, M., \& Glaser, D. (2006). Gender differences in risk assessment: Why do women take fewer risks than men. Judgment and Decision Making, 1(1), 48-63. 
Harrison, K. and Cantor, J. (1999). Tales from the screen: Enduring fright reactions to scary media. Media Psychology, 1, 97-116.

Hayton, J. C., Allen, D. G., \& Scarpello, V. (2004). Factor retention decisions in exploratory factor analysis: A tutorial on parallel analysis. Organizational Research Methods, 7(2), 191-205.

Hill, S. A., \& Sprague, J. (1999). PARENTING IN BLACK AND WHITE FAMILIES The Interaction of Gender with Race and Class. Gender \& Society, 13(4), 480-502.

Hill, C. E., Thompson, B. J., \& Williams, E. N. (1997). A guide to conducting consensual qualitative research. The Counseling Psychologist, 25(4), 517-572.

Horowitz, M., Wilner, N., \& Alvarez, W. (1979). Impact of Event Scale: a measure of subjective stress. Psychosomatic Medicine, 41(3), 209-218.

Huang, J. L., Curran, P. G., Keeney, J., Poposki, E. M., and DeShon, R. P. (2011). Detecting and deterring insufficient effort responding to surveys. Journal of Business Psychology, $10,1-16$.

Hutcheson, G., \& Sofroniou, F. L. (1999). The multivariate social scientist. London: Sage.

Johnson, J. G., Cohen, P., Smailes, E. M., Kasen, S., and Brook, J. S. (2002). Television viewing and aggressive behavior during adolescence and adulthood. Science, 295, 2468-2473.

Karraker, K. H., Vogel, D. A., \& Lake, M. A. (1995). Parents' gender-stereotyped perceptions of newborns: The eye of the beholder revisited. Sex Roles, 33(9-10), 687-701.

Keresteš, G. (2006). Children's aggressive and prosocial behavior in relation to war exposure: Testing the role of perceived parenting and child's gender. International Journal of Behavioral Development, 30(3), 227-239. 
Kim, H. (2013). Statistical notes for clinical researchers: assessing normal distribution (2) using skewness and kurtosis. Restorative Dentistry \& Endodontics, 38(1), 52-54.

Kitzinger, J. (1994). The methodology of focus groups: The importance of interactions between research participants. Sociology of health and Illness, 16, 103-121.

Ladouceur, R., Dugas, M. J., Freeston, M. H., Rhéaume, J., Blais, F., Boisvert, J. M., ... \& Thibodeau, N. (1999). Specificity of generalized anxiety disorder symptoms and processes. Behavior Therapy, 30(2), 191-207.

Lebowitz, E. R., Woolston, J., Bar- Haim, Y., Calvocoressi, L., Dauser, C., Warnick, E., ... \& Leckman, J. F. (2012). Family accommodations in pediatric anxiety disorders. Depression and Anxiety, 30(1), 47-54.

Lebowitz, E. R., Scharfstein, L. A., \& Jones, J. (2014). Comparing family accommodation in pediatric obsessive-compulsive disorder, anxiety disorders, and nonanxious children. Depression and Anxiety.

Lengua, L. J., Long, A. C., Smith, K. I., \& Meltzoff, A. N. (2005). Pre-attack symptomatology and temperament as predictors of children's responses to the September 11 terrorist attacks. Journal of Child Psychology and Psychiatry, 46(6), 631-645.

Lester, K. J., Field, A. P., Oliver, S., \& Cartwright-Hatton, S. (2008). Do anxious parents interpretive biases towards threat extend into their child's environment? Behavior Research and Therapy, 47, 170-174.

Letiecq, B. L., \& Koblinsky, S. A. (2004). Parenting in Violent Neighborhoods African American Fathers Share Strategies for Keeping Children Safe.Journal of Family Issues, 25(6), 715-734. 
Lewis, J., \& Ritchie, J. (2003). Generalising from qualitative research. Qualitative research practice: A guide for social science students and researchers, 263-286.

McNaughton-Cassill, M. E. (2001). The news media and psychological distress. Anxiety, Stress \& Coping: An International Journal, 14(2), 193-211.

Moos, R. H., Insel, P. M., \& Humphrey, B. (1974). Preliminary manual for family environment scale, work environment scale, group environment scale. Psychometry, 46-50.

Morrongiello, B. A., \& Rennie, H. (1998). Why do boys engage in more risk taking than girls? The role of attributions, beliefs, and risk appraisals. Journal of Pediatric Psychology, 23(1), 33-43.

Morrongiello, B. A., \& Dawber, T. (2000). Mothers' responses to sons and daughters engaging in injury-risk behaviors on a playground: Implications for sex differences in injury rates. Journal of experimental child psychology,76(2), 89-103.

Morse, J. M., Barrett, M., Mayan, M., Olson, K., \& Spiers, J. (2008). Verification strategies for establishing reliability and validity in qualitative research. International Journal of Qualitative Methods, 1(2), 13-22.

Nathanson, A. I. and Yang, M. S. (2003). The effects of mediation content and form on children's responses to violent television. Human Communication Research, 29(1), 111134.

National Association for Media Literacy Education. (n.d.). Definitions. Retrieved from http://www.namle.net/ publications/media-literacy-definitions/

National Child Traumatic Stress Network. (2006). 
Ortiz, C. D., Silverman, W. K., Jaccard, J., \& La Greca, A. M. (2011). Children's state anxiety in reaction to disaster media cues: A preliminary test of a multivariate model. Psychological Trauma: Theory, Research, Practice, and Policy, 3(2), 157-164.

Otto, M. W., Henin, A., Hirshfeld-Becker, D. R., Pollack, M. H., Biederman, J., \& Rosenbaum, J. F. (2007). Posttraumatic stress disorder symptoms following media exposure to tragic events: Impact of 9/11 on children at risk for anxiety disorders. Journal of Anxiety Disorders, 21(7), 888-902.

Owens, J., Maxim, R., McGuinn, M., Nobile, C., Msall, M., \& Alario, A. (1999). Televisionviewing habits and sleep disturbances in school children. Pediatrics, 104, 1-8.

Padilla-Walker, L. M., Christensen, K. J., \& Day, R. D. (2011). Proactive parenting practices during early adolescence: A cluster approach. Journal of adolescence, 34(2), 203-214.

Paidilla-Walker, L. M. \& Coyne, S. M. (2011). “Turn that thing off!” parent and adolescent predictors of proactive media parenting. Journal of Adolescence, 34, 705-715.

Paidilla-Walker, L. M., Coyne, S. M., Fraswer, A. M., Dyer, J., \& Yorgason, J. B. (2012). Parents and adolescents growing up in the digital age: Latent growth curve analysis of proactive media monitoring. Journal of Adolescence, 35, 1153-1165.

Padilla- Walker, L. M., \& Thompson, R. A. (2005). Combating conflicting messages of values: A closer look at parental strategies. Social Development, 14(2), 305-323.

Pew Research Center (2013). Pewresearch.org.

Pfefferbaum, B., Seale, T. W., Brandt, E. N., Pfefferbaum, R. L., Doughty, D. E., \& Rainwater, S. M. (2003). Media exposure in children one hundred miles from a terrorist bombing. Annals of Clinical Psychiatry, 15(1), 1-8.

Qualtrics, LLC. (2014). Gsu.qualtrics.com. 
R Core Team (2013). R: A language and environment for statistical computing. R Foundation for Statistical Computing, Vienna, Austria. ISBN 3-900051-07-0, URL http://www.Rproject.org/.

Rabiee, F. (2004). Focus-group interview and data analysis. Proceedings of the Nutrition Society, 63(4), 655-660.

Rosen, L. D., Cheever, N. A., \& Carrier, L. M. (2008). The association of parenting style and child age with parental limit setting and adolescent MySpace behavior. Journal of Applied Developmental Psychology, 29(6), 459-471.

Ross, J., Zaldivar, A., Irani, L., Tomlinson, B. (2009). Who are the Turkers? Worker demographics in amazon mechanical turk. http://www.ics.uci.edu/ jwross/pubs/SocialCode-2009-01.pdf

Saylor, C. F., Cowart, B. L., Lipovsky, J. A., Jackson, C., and Finch, A. J. (2003). Media exposure to September 11. American Behavior Scientist, 46, 1622-1642.

Shapiro, D. N., Chandler, J., and Mueller, P. A. (2013). Using mechanical turk to study clinical populations. Clinical Psychological Science, 1-8.

Schuster, M. A., Stein, B. D., Jaycox, L. H., Collins, R. L., Marshall, G. N., Elliott, M. N.,...Berry, S. H. (2001). National survey of stress reactions after the September 11, 2001, terrorist attacks. New England Journal of Medicine, 345, 1507-1512.

Simons, R. L., Simons, L. G., Burt, C. H., Drummund, H., Stewart, E., Brody, G. H., ... \& Cutrona, C. (2006). Supportive parenting moderates the effect of discrimination upon anger, hostile view of relationships, and violence among African American boys. Journal of Health and Social Behavior, 47(4), 373-389. 
Simons, L. G., Simons, R. L., \& Su, X. (2013). Consequences of corporal punishment among African Americans: The importance of context and outcome. Journal of Youth and Adolescence, 42(8), 1273-1285.

Smokowski, P. R., Mann, E. A., Reynolds, A. J., \& Fraser, M. W. (2004). Childhood risk and protective factors and late adolescent adjustment in inner city minority youth. Children and Youth Services Review, 26(1), 63-91.

Snyder, T. D. \& Dillow, S. A. of U.S. Department of Education (2013). Digest of Education Statistics, National Center for Education Statistics, NCES 2015-011.

Spano, R., Rivera, C., \& Bolland, J. M. (2011). Does parenting shield youth from exposure to violence during adolescence? A 5-year longitudinal test in a high-poverty sample of minority youth. Journal of interpersonal violence,26(5), 930-949.

Spitzer, R. L., Kroenke, K., Williams, J. B., \& Löwe, B. (2006). A brief measure for assessing generalized anxiety disorder: the GAD-7. Archives of Internal Medicine, 166(10), 10921097.

Stevens, J. P. (2002). Applied multivariate statistics for the social sciences $\left(4^{\text {th }}\right.$ ed.). Hillsdale, NJ: Erlbaum.

Storch, E. A., Geffken, G. R., Merlo, L. J., Jacob, M. L., Murphy, T. K., Goodman, W. K., ... \& Grabill, K. (2007). Family accommodation in pediatric obsessive-compulsive disorder. Journal of Clinical Child and Adolescent Psychology, 36(2), 207-216.

Strasburger, V. C., Jordan, A. B., \& Donnerstein, E. (2010). Health effects of media on children and adolescents. Pediatrics, 125(4), 756-767.

Substance Abuse and Mental Health Services Administration. (2012). 
Sumiala, J. and Tikka, M. (2011). Imaging globalised fears: School shooting videos and circulation of violence on YouTube. Social Anthropology, 19(3), 254-267.

Tong, A., Sainsbury, P., and Craig, J. (2007). Consolidated criteria for reporting qualitative research (COREQ): A 32-item checklist for interviews and focus groups. International Journal of Quality in Health Care, 19(6), 349-357.

Trulia.com (2014). Trulia. Your Home for Real Estate.

U.S. Census. (2010). Summary Report: Neighborhood Planning. Retrieved from http://www.atlantaga.gov/modules/showdocument.aspx?documentid=3905

Valkenburg, P. M., Kramar, C., Peeters, A. L. \& Marseille, N. M. (1999). Developing a scale to assess three styles of television mediation: "Instructive mediation," "restrictive mediation," and "social coviewing." Journal of Broadcasting and Electronic Media, 43(1), 52-66.

van Brakel A. M. L., Muris, P., Bogels, S. M., and Thomassen, C. (2006). A multifactorial model for the etiology of anxiety in non-clinical adolescents: Main and interactive effects of behavioral inhibition, attachment and parental rearing. Journal of Child and Family Studies, 15, 569-579.

Weems, C.F., Scott, B. G., Banks, D. M., and Graham, R. A. (2012). Is TV traumatic for all youths? The role of preexisting posttraumatic-stress symptoms in the link between disaster coverage and stress. Psychological Sciences, 23, 1293-1298.

West, S.G., Finch, J.F., and Curran, P.J. Structural equation models with nonnormal variables: problems and remedies. In RH Hoyle (Ed.). Structural equation modeling: Concepts, issues and applications. Newbery Park, CA: Sage; 1995. p56-75. 
Wilson, B. J. (2008). Media and children's aggression, fear, and altruism. The Future of Children, 18(1), 87-118.

Wirth, R. J. and Edwards, M. C. (2007). Item factor analysis: Current approaches and future directions. Psychological Methods, 12(1), 58-79.

Wood, J. J., McLeod, B. D., Sigman, M., Hwang, W. C., and Chu, B. C. (2003). Parenting and childhood anxiety: Theory, empirical findings, and future directions. Journal of Child Psychology and Psychiatry, 44(1), 134-151.

Zwich, W. R., and Velicer, W. F. (1986). Comparison of five rules for determining the number of components to retain. Psychological Bulletin, 99(3), 432. 


\section{APPENDICES}

\section{Appendix A: Caregiver's Response to Youth Media Exposure (CRYME) Initially Proposed}

Please circle never, rarely, sometimes, often, or almost always for each of the following questions. All of the questions refer specifically to violent or tragic news in the media (terrorist attacks, school shootings, bombings, natural disasters, fires, etc.).

With regard to what your child sees on TV, the internet (news sites, social media, etc.), or in print media (magazines, newspapers, etc.), how often do you...

Never Rarely Sometimes Often Almost Always

1. try to help your child make sense of the violent or tragic news event by talking to him/her in a way that s/he can understand?

2. point out something positive about the violent or tragic news (e.g., no deaths, the perpetrator was caught, etc.)?

3. explain why this violent or tragic news event was not as bad as it could have been?

4. point out what was bad about the violent or tragic news (e.g., the act was illegal, there were many victims, etc.)?

5. explain why this violent or tragic news event was bad?

6. explain the potential motives of the perpetrator?

7. explain why this violent or tragic event may have happened?

8. explain ways in which the government, police, or other officials addressed the situation?

9. explain the outcome of the violent or tragic news event in a way that s/he can understand?

10. explain the violent or tragic news event in a developmentally appropriate way?

11. address whether or how this news event may affect your child personally?

12. help your child determine if/how this event will change how s/he lives daily? 
13. describe how this news event affects the society/community of which your child is a part?

14. explain how the media shows a disproportionate amount of negative or extreme news?

15. explain the likelihood of this event happening again?

16. explain the likelihood of this event happening to your child or his/her loved ones?

17. ask your child how s/he feels about viewing the violent or tragic news in the media?

18. ask your child if s/he feels less safe after viewing the violent or tragic news media?

19. ask your child if s/he thinks about the event even when s/he is not directly viewing the media?

20. ask your child if s/he has trouble sleeping at night because of the images in the media of the violent or tragic news event?

21. tell your child to turn off the TV, not visit that particular news site, or refrain from reading the print media?

22. interrupt your child's media viewing if it seems developmentally inappropriate for $\operatorname{him} /$ her?

23. ask your child to leave the room if violent or tragic news events are displayed in the media you are viewing?

24. encourage your child not to discuss the violent or tragic news events with peers at school?

25. set specific viewing times/hours for your child?

26. forbid your child to watch certain programs, avoid certain internet sites, or read certain print material regarding violent or tragic news?

27. restrict the amount of time your child spends viewing violent or tragic or tragic news in the media? 
28. specify in advance the TV programs, internet sites, or specific print media your child can view/use?

29. set parental controls on devices in your home that enable blocking certain TV channels, internet site, etc.?

30. keep your child from viewing violent or tragic media that you believe would scare or worry your child?

31. watch/view the violent or tragic news media together?

32. watch/view the violent or tragic news media with your child so that you can monitor the content?

33. allow your child to watch/view the violent or tragic news media only when you are with him/her?

34. watch/view the violent or tragic news media together because of a shared curiosity?

35. watch/view the violent or tragic news media together because it is important to know about these major events and keep your child informed?

36. share your feelings of fear or worry about the violent or tragic news media with your child?

37. talk to your child about how the violent or tragic news media makes you feel?

38. talk to your child about how what you viewed in the violent or tragic news impacts your safety?

39. explain to your child how the violent or tragic news could happen to you or another person in a close relationship to your child?

40. share your feelings of anger or sadness about the violent or tragic news media with your child? 
41. explain to your child that you personally feel safe even considering the violent or tragic news media?

42. explain to your child ways to stay safe considering the violent or tragic news media?

43. explain to your child how to spot dangerous situations, like the one featured in the violent or tragic news media?

44. help your child understand who to trust and not to trust in light of the violence in the media?

45. explain to your child how to avoid situations like the ones in the violent or tragic news media?

46. demonstrate through your own actions how your child can avoid situations like the ones in the violent or tragic news media?

47. purposefully avoid talking to your child about the violent or tragic news?

48. reassure your child that you are safe in spite of the violent or tragic news media you viewed?

49. reassure your child that s/he is safe in spite of the violent or tragic news media s/he viewed?

50. reassure your child that what s/he viewed in the violent or tragic news media will not happen to him/her?

51. explain the impact of the violent or tragic news even on all parties involved?

52. share feelings of sorrow for the victims involved in the violent or tragic news event?

53. share feelings of sorrow for the perpetrators involved in the violent or tragic news event?

54. Explain potential consequences for the perpetrator of the violent or tragic news event? 
Appendix B: Atlanta Major Neighborhood Demographics

\begin{tabular}{|l|l|l|l|l|l|}
\hline Major Neighborhood & White & Black & Asian & All & Hispanic \\
\hline Midtown (e.g., Old Fourth Ward) & $34.1 \%$ & $56.1 \%$ & $4.9 \%$ & $4.9 \%$ & $4.8 \%$ \\
\hline Buckhead (e.g., Paces) & $91.7 \%$ & $3.2 \%$ & $3.5 \%$ & $1.7 \%$ & $2.3 \%$ \\
\hline Northwest (e.g., Hunter Hills) & $9.1 \%$ & $88.5 \%$ & $0.4 \%$ & $2.0 \%$ & $1.9 \%$ \\
\hline West Midtown (e.g., Berkeley & $59.2 \%$ & $23.9 \%$ & $4.5 \%$ & $12.4 \%$ & $15.7 \%$ \\
\hline Park) & & & & & \\
\hline Northeast (e.g., Inman Park) & $79.9 \%$ & $13.2 \%$ & $2.7 \%$ & $4.2 \%$ & $4.2 \%$ \\
\hline Southwest (e.g., Collier Heights) & $2.2 \%$ & $94.1 \%$ & $0.1 \%$ & $3.6 \%$ & $4.2 \%$ \\
\hline Southeast (e.g., South Atlanta) & $14.3 \%$ & $80.6 \%$ & $0.4 \%$ & $4.7 \%$ & $9.2 \%$ \\
\hline
\end{tabular}

U.S. Census. (2010). Summary Report: Neighborhood Planning. Retrieved from http://www.atlantaga.gov/modules/showdocument.aspx?documentid=3905

\begin{tabular}{|l|l|}
\hline Major Neighborhood & Median Home List \\
\hline Midtown (e.g., Old Fourth Ward) & $\$ 200,000$ \\
\hline Buckhead (e.g., Paces) & $\$ 1,695,000$ \\
\hline Northwest (e.g., Hunter Hills) & $\$ 36,900$ \\
\hline West Midtown (e.g., Berkeley & $\$ 275,000$ \\
\hline Park) & \\
\hline Northeast (e.g., Inman Park) & $\$ 309,000$ \\
\hline Southwest (e.g., Collier Heights) & $\$ 54,500$ \\
\hline Southeast (e.g., South Atlanta) & $\$ 59,900$ \\
\hline
\end{tabular}

Trulia.com (2014). Trulia. Your Home for Real Estate. 


\section{Appendix C: Discussion Questions for Caregiver Focus Group}

Intro to questions: This parent focus group is gathered in order to better understand how parents interact with their children in response to their child's exposure to violent news in the media. For this focus group, violent news media refers to any real life violence that is displayed on TV, the radio, the internet, social networking sites (e.g., Facebook, Twitter, Instagram, etc.) and any other form of media to which your child may have access. Additionally, the word "response" can refer to anything verbal or nonverbal that you say or do to interact with your child after they have had exposure to violent news in the media. Violent news media refers to any real life violence that is displayed or reported in the media, for instance: school shootings, terrorist attacks, bombings, hurricanes, other natural disasters, kidnappings, etc.

[For prompting discussion, parents may be reminded of recent violent events that were displayed in the media such as: the school shooting at Sandy Hook elementary in Connecticut, the Boston Marathon Bombing, violence in Syria, and the mass shooting in the movie theatre in Colorado.]

1. In the past, how have you responded to your child being exposed to violent news in the media?

2. How have you seen other parents responding to their child's violent news media exposure?

3. How do you wish you had responded to your child being exposed to violent news in the media?

4. What kind of responses do you think are most helpful to your child after being exposed to violent news in the media? 
5. What kind of responses do you think are least helpful to your child after being exposed to violent news in the media?

6. Do you restrict your child's use of any particular media (e.g., Limiting hours, limiting internet sites/TV channels, etc.)?

7. How does your child respond to violent news media exposure (e.g., asking questions, interest, fear, etc.)?

[Based on parents' responses, follow-up questions may be asked to encourage discussion.] 


\section{Appendix D: Tong, Sainsbury, \& Craig (2007) Focus Group Checklist}

\section{Domain 1: research team and reflexivity}

\section{Personal Characteristics}

1. Interviewer/facilitator: Which author/s conducted the interview or focus group?

2. Credentials: What were the researcher's credentials? E.g. PhD, MD

3. Occupation: What was their occupation at the time of the study?

4. Gender: Was the researcher male or female?

5. Experience and training: What experience or training did the researcher have?

Relationship with participants

6. Relationship established: Was a relationship established prior to study commencement?

7. Participant knowledge of the interviewer: What did the participants know about the researcher? e.g. personal goals, reasons for doing the research

8. Interviewer characteristics: What characteristics were reported about the interviewer/facilitator? e.g. Bias, assumptions, reasons and interests in the research topic

\section{Domain 2: study design}

Theoretical framework

9. Methodological orientation and Theory: What methodological orientation was stated to underpin the study? e.g. grounded theory, discourse analysis, ethnography, phenomenology, content analysis

Participant selection

10. Sampling: How were participants selected? e.g. purposive, convenience, consecutive, snowball 
11. Method of approach: How were participants approached? e.g. face-to-face, telephone, mail, email

12. Sample size: How many participants were in the study?

13. Non-participation: How many people refused to participate or dropped out? Reasons? Setting

14. Setting of data collection: Where was the data collected? e.g. home, clinic, workplace 15. Presence of non-participants: Was anyone else present besides the participants and researchers?

16. Description of sample: What are the important characteristics of the sample? e.g. demographic data, date

\section{Data collection}

17. Interview guide: Were questions, prompts, guides provided by the authors? Was it pilot tested?

18. Repeat interviews: Were repeat interviews carried out? If yes, how many?

19. Audio/visual recording: Did the research use audio or visual recording to collect the data?

20. Field notes: Were field notes made during and/or after the interview or focus group?

21. Duration: What was the duration of the interviews or focus group?

22. Data saturation: Was data saturation discussed?

23. Transcripts returned: Were transcripts returned to participants for comment and/or correction?

\section{Domain 3: analysis and findings}

Data analysis

24. Number of data coders: How many data coders coded the data? 
25. Description of the coding tree: Did authors provide a description of the coding tree?

26. Derivation of themes: Were themes identified in advance or derived from the data?

27. Software: What software, if applicable, was used to manage the data?

28. Participant checking: Did participants provide feedback on the findings?

Reporting

29. Quotations presented: Were participant quotations presented to illustrate the themes / findings? Was each quotation identified? e.g. participant number

30. Data and findings consistent: Was there consistency between the data presented and the findings?

31. Clarity of major themes: Were major themes clearly presented in the findings?

32. Clarity of minor themes: Is there a description of diverse cases or discuss 


\section{Appendix E: Themes Identified by Researchers}

Principal Researcher/Auditor's Identified Themes:

1. Using spirituality to make sense, comfort, or explain media

2. Tailor the conversation to what is most bothering to the child

3. Let child come to you to tell you what is bothering him/her about the media

4. Use media as a learning opportunity to teach safety

5. Shield children from media (e.g., make sure they're not looking when you're on Facebook, etc.)

6. Reassure child and tell him/her everything is okay

7. Media only puts what's catching on the news, they make it seem worse than it really is

8. Know your child and what he/she can handle

9. Show how the violence on TV could apply to child

10. Teach child strategies for what to do if what happens on media happens to him/her

11. Take each situation as it comes, no planning on how to handle it

12. Teach child to not let media impact where he/she goes or view of world

First Assistant Researcher's Identified Themes:

1. How relevant the media information is to the child

2. Need to have the child be aware of the news event

3. Limiting exposure to the children

4. Using fear to adjust child behavior

5. The readiness of the child, and coping abilities of the child

6. Limiting child anxiety (different purpose than just limiting exposure) 
7. How relevant is the topic to your specific child, how will your specific child deal with it

8. Have you discussed how you interact with your child with other parents

Second Assistant Researcher's Identified Themes:

1. Sheltering your child in order to protect

2. Having an open dialogue, making your child aware, trying to educate with the open dialogue

3. Gender differences in how to talk to your child

4. Scare to protect, using this method to protect child from the events that happen in the media

5. Hands off approach, letting the children come to parents instead of volunteering it 6. Spirituality, not having control, a means of coping

7. Knowing your child, knowing how your child is going to cope and preparing for that 


\section{Appendix F: Consistency and Organization of Themes}

\begin{tabular}{|c|c|c|c|}
\hline Final Theme & $\begin{array}{l}\text { Principal } \\
\text { Researcher/Auditor }\end{array}$ & $\begin{array}{l}\text { First Assistant } \\
\text { Researcher }\end{array}$ & $\begin{array}{l}\text { Second Assistant } \\
\text { Researcher }\end{array}$ \\
\hline Scaring to protect & $4,9,10$ & 4 & 4 \\
\hline $\begin{array}{l}\text { Using spirituality to } \\
\text { comfort/explain }\end{array}$ & 1 & 6 & 6 \\
\hline $\begin{array}{l}\text { Taking a hands- } \\
\text { off/child led approach }\end{array}$ & 3,11 & 8 & 3,5 \\
\hline $\begin{array}{l}\text { Tailoring response to } \\
\text { child's needs }\end{array}$ & 2,8 & $1,5,7$ & $3,6,7$ \\
\hline Granting reassurance & 6,12 & 5,6 & 7 \\
\hline $\begin{array}{l}\text { Highlighting the } \\
\text { sensationalism of the } \\
\text { media }\end{array}$ & 7 & NA & NA \\
\hline $\begin{array}{l}\text { Active } \\
\text { monitoring/open } \\
\text { dialogue }\end{array}$ & 4,10 & 2 & 2 \\
\hline Raising awareness & 4,10 & 2 & 2 \\
\hline Restricting/sheltering & 5 & 3 & 1 \\
\hline
\end{tabular}




\section{Appendix G: Evidence from Data Supporting Themes}

\begin{tabular}{|c|c|}
\hline Theme & Evidence of theme from data \\
\hline Scaring to protect & $\begin{array}{l}\text { "Right, I try to use the media to scare her. 'You see } \\
\text { what happened to her? Then you shouldn't do this because } \\
\text { this can happen."' -participant \#1 }\end{array}$ \\
\hline $\begin{array}{l}\text { Using spirituality to } \\
\text { comfort/explain }\end{array}$ & $\begin{array}{l}\text { "My mom raised me in the church and I guess I've } \\
\text { just instilled in them, my children, well my children-my } \\
\text { daughter and I go to church every Sunday and my son works } \\
\text { on the weekends. But I've also instilled in my children that } \\
\text { we are all human that we honestly have no control...but at } \\
\text { the end of the day God already has a plan for us." - } \\
\text { participant \#5 }\end{array}$ \\
\hline $\begin{array}{l}\text { Taking a hands-off/child led } \\
\text { approach }\end{array}$ & $\begin{array}{l}\text { “...that's creating fear in him and think about things } \\
\text { like, you know, that he shouldn't be worried about. But if it } \\
\text { were something happen that while we were together and he } \\
\text { ask questions then I can relate and be like ok." -participant } \\
\text { \#6 }\end{array}$ \\
\hline $\begin{array}{l}\text { Tailoring response to child's } \\
\text { needs }\end{array}$ & $\begin{array}{l}\text { "So its also not only just, you know, dealing with the } \\
\text { violence and all of that on the news its also understanding } \\
\text { that you gotta have that relationships with your child to } \\
\text { know how is he going to handle this." -participant \#3 }\end{array}$ \\
\hline Granting reassurance & $\begin{array}{l}\text { "Then at that point, as a parent, I'm going to reassure } \\
\text { her. 'Okay, well, you know, not sure why this happen, but }\end{array}$ \\
\hline
\end{tabular}




\begin{tabular}{|c|c|}
\hline & $\begin{array}{l}\text { this is certain thing that we might want to look at that we } \\
\text { make sure its not going to happen to you." -participant \#3 } \\
\text { "I'm still going to make him realize don't worry } \\
\text { about it. Its not going to happen to me, its not going to } \\
\text { happen around here." - participant \#6 }\end{array}$ \\
\hline $\begin{array}{l}\text { Highlighting the } \\
\text { sensationalism of the media }\end{array}$ & $\begin{array}{l}\text { "I don't really watch the news as much 'cause I feel } \\
\text { like its gossip." -participant \#2 } \\
\text { "its propaganda. Like they want you to-" -participant } \\
\text { \#6 (in response to participant \#2) } \\
\text { "Yeh it is just to like get hyped up." -participant \#2 } \\
\text { (in response participant \#6) }\end{array}$ \\
\hline $\begin{array}{l}\text { Active monitoring/open } \\
\text { dialogue }\end{array}$ & $\begin{array}{l}\text { "I've always been that parent to just have real talk, } \\
\text { like I might not give you the big words that I would have } \\
\text { with an adult but I'm gonna give you real life convo." - } \\
\text { participant \#5 }\end{array}$ \\
\hline Raising awareness & "I just want her to be more aware." -participant \#1 \\
\hline Restricting/sheltering & $\begin{array}{l}\text { "But I am so terrified of the things that are happening } \\
\text { that that is my way of, I guess, protecting him right now } \\
\text { from things that are going on in the media... so my way of } \\
\text { protecting him is keeping him sheltered." - participant \#5 }\end{array}$ \\
\hline
\end{tabular}




\section{Appendix H: Caregiver's Response to Youth Media Exposure (CRYME) Pre-EFA}

Please circle never, rarely, sometimes, often, or almost always for each of the following questions. All of the questions refer specifically to violent/tragic news in the media (terrorist attacks, school shootings, bombings, natural disasters, hurricanes, floods, fires, etc.).

With regard to what your child sees on TV, the internet (news sites, social media, etc.), or in print media (magazines, newspapers, etc.), how often do you...

Never Rarely Sometimes Often Almost Always

*theme from literature

\# theme from focus group

*\# theme overlaps literature and focus group

*\#TAILORING RESPONSE TO CHILD'S NEEDS: help your child better understand the media, talk to your child in a developmentally appropriate way, make the discussion specific to your child's fears/concerns/needs.

1. try to help your child make sense of the violent/tragic news by talking to him/her in a way that s/he can understand?

2. explain the violent/tragic news in a way that s/he can understand?

3. talk to your child about how this news event affects him/her personally?

4. talk to your child about whether or not this news event will change his/her daily life?

5. help your child figure out how this event will change his/her daily life?

6. describe how this news event affects the society/community of which your child is a part?

7. talk with your child about aspects of the violent news that bother him/her the most? 
8. change your outward reaction to violent news in the media based on how you think your child will react?

9. change the way you talk to your child about the violent/tragic news in an effort to influence his/her feelings about the news?

*\#GRANTING REASSURANCE: helping your child see the positive aspects of the news/situation and/or reassuring your child of his/her safety and the safety of his/her loved ones.

10. point out something reassuring about the violent/tragic news (for example: no deaths, the perpetrator was caught, etc.)?

11. explain why this violent/tragic news was not as bad as it could have been?

12. explain ways in which the government, police, or other officials addressed the situation?

13. reassure your child that you (his/her caregiver) are safe in spite of the violent/tragic news ?

14. reassure your child that s/he is safe in spite of the violent/tragic news?

15. reassure your child that such violent/tragic event will not happen to him/her?

16. talk to your child about the violent news in a neutral way, describing just the facts?

*\#HIGHLIGHTING THE SENSATIONALISM OF THE MEDIA: explaining to your child the disproportionate nature of negativity or extremes in the news compared to reality and that the sensationalism in the media cannot dictate how one lives their life.

17. teach your child that what s/he sees in the news cannot determine how s/he lives his/her life?

18. encourage your child not to let the violent news change his/her day-to-day actions?

19. explain how the media presents events in an extreme way to interest viewers?

20. explain how the media features events that are not common to interest viewers?

21. explain the likelihood of this event happening again?

22. explain the likelihood of this event happening to your child or his/her loved ones? 
*MODELING COPING THOUGHTS: telling your child about your coping thoughts or shaping the discussion of the violent news media in a way to teach your child how to cope with their response.

23. explain to your child that you personally feel safe despite the violent/tragic news?

24. show you child, through your own actions, how he/she can avoid similar violent/tragic situations?

25. explain to your child ways to stay safe considering the violent/tragic news?

26. explain to your child how to spot dangerous situations, like those featured in the violent/tragic news?

27. point out something positive about the violent/tragic news (for example: humanity, sense of community, heroism)?

*\#ACTIVE MONITORING/OPEN DIALOGUE: monitoring your child's access to violent news media and having an open dialogue about it.

28. explain the potential motives of the perpetrator or the reasons why someone might act violently?

29. ask your child how s/he feels about the violent/tragic news?

30. ask your child if s/he thinks about the event even when s/he is not actively viewing it?

31. ask your child if s/he has trouble sleeping at night because of the violent/tragic news?

32. express that you are fearful or worried about the violent/tragic news with your child?

33. talk to your child about how the violent/tragic news media makes you feel?

34. express that you are angry or sad about the violent/tragic news with your child?

35. openly, without restraint, express your emotions about the violent/tragic news around your child? 
*\#RAISING AWARENESS: make your child aware of what's going on in society, use media to teach child about safety (in a positive manner-different from "scare to protect") or helping child relate it to their own life.

36. learn about the violent/tragic news together because it is important to know about such events and keep your child informed?

37. talk to your child about how the violent/tragic news impacts your own safety?

38. explain to your child how the violent/tragic event could happen to you or another person in a close relationship to your child?

39. help your child understand who to trust and not to trust in light of the violence in the media?

40. explain to your child how to avoid situations like the ones in the violent/tragic news?

41. talk to your child about how to handle situations that are similar to the violent news events?

42. purposefully discuss the violent/tragic news with your child?

43. inform your child of violent/tragic news that you have learned about from the media?

\#SCARING TO PROTECT: using the violent news in the media to instill fear in your child to avoid unsafe situations or events.

44. use the violent/tragic news to teach your child about safety?

45. use the violent/tragic news to teach your child about other potential dangers?

46. talk to your child about how to prepare for potential violence based on the events s/he in the media?

47. use the violent/tragic news as a way to teach your child to fear similar situations?

48. use the violent/tragic news to scare your child away from participating in dangerous activities?

49. scare your child into being cautious in similar situations? 
50. use the violent/tragic news to scare your child with the purpose of protecting him/her from harm?

51. emphasize that violent/tragic news is a reality in an effort to protect your child from harm?

*\#RESTRICTING/SHELTERING: limiting your child's ability to access violent/tragic news in the media, sheltering your child from knowing about violent news in the media, purposefully avoiding discussions with your child about violent/tragic news.

52. leave out details of the violent/tragic news when discussing it with your child to protect $\operatorname{him} /$ her?

53. purposefully leave out details of the violent/tragic news when discussing it with your child?

54. avoid talking to your child about the violent/tragic news?

55. Interrupt your child's exposure to the media (for example, by telling him/her to turn off the TV)?

56. interrupt your child's exposure to the media because it's not appropriate for his/her age?

57. ask your child to leave the room when violent/tragic news is displayed in the media?

58. keep your child from learning about violent/tragic news you believe would scare or worry your child?

59. encourage your child not to discuss the violent/tragic news with peers at school?

60. forbid your child to watch certain programs, avoid certain internet sites, or read certain print material regarding violent/tragic news?

61. specify in advance the TV programs, internet sites, or specific print media your child can view/use to limit access to violent/tragic news?

62. set parental controls on devices in your home that enable blocking certain TV channels, internet site, etc. to limit access to violent/tragic news? 
*COVIEWING: accessing the media with your child in order to protect, monitor, or because of a shared interest.

63. allow your child to watch/view the violent/tragic news only when you are with him/her?

64. watch/view the violent/tragic news together?

65. watch/view the violent/tragic news with your child so that you can monitor the content?

66. watch/view the violent/tragic news together because of a shared curiosity?

\#USING SPIRITUALITY TO COMFORT/EXPLAIN: using religion or other

spiritual means to help your child make sense of the violent news media, comfort for your child after viewing violent news in the media, or to reassure your child of safety due to concerns of viewing violent news in the media.

67. use religion or other spiritual means to help your child make sense of the violent news?

68. use religion or other spiritual means to explain the violent news to your child?

69. use religion or other spiritual means to comfort your child in light of the violent news event?

70. point out something positive, using religion or other spiritual means, about the violent/tragic news (for example: God was present, God protected the victims, etc.)?

\#TAKING A HANDS-OFF/CHILD LED APPROACH: allowing your child to bring up their own feelings or questions about the violent news they were exposed to before you do. Taking each situation on a case-by-case basis, no preplanning or forethought for how to handle your child's violent news exposure.

71. wait until your child comes to you to talk about violent/tragic news, rather than bringing it up yourself?

72. let your child bring up the violent/tragic news to you, rather than you bring it up to your child? 
73. wait until each situation comes up with the violent/tragic news and handle it in the moment without thinking about how to handle it in advance?

74. letting someone else talk to your child about the violent/tragic news so you don't have to? 


\section{Appendix I: Insufficient Effort Response (IER) Items}

Please answer the following items honestly.

1. I paid careful attention to what the questions actually meant.

\section{Never Rarely Sometimes Often Almost Always}

2. While filling out the questions I thought about myself or my child and our typical behavior.

\section{Never Rarely Sometimes Often Almost Always}

3. While completing this survey, I was distracted by other online/offline sources.

Never Rarely Sometimes Often Almost Always

4. I responded carelessly to the questions.

\section{Never Rarely Sometimes Often Almost Always}

5. I have been to the planet Mars.

\section{Never Rarely Sometimes Often Almost Always}

6. I need oxygen to live.

\section{Never Rarely Sometimes Often Almost Always}

7. I have been awake while completing this questionnaire.

Never Rarely Sometimes Often Almost Always




\section{Appendix J: Frequency of Media Use}

Considering the various forms of media that your child accesses, please answer the following:

1. How many days each week does your child have contact with media?

- television

- internet (e.g., news sites, blogs, etc.)

- $\quad$ social media (e.g., Facebook, Twitter, etc.)

- $\quad$ print media (e.g., magazines, newspaper, etc.) (number of days) (number of days) (number of days) (number of days)

2. How many hours per week does your child spend using/viewing media?

- television

- $\quad$ internet (e.g., news sites, blogs, etc.)

- $\quad$ social media (e.g., Facebook, Twitter, etc.)

- $\quad$ print media (e.g., magazines, newspaper, etc.) (number of hours) (number of hours) (number of hours) (number of hours)

3. How many hours per week does your child have access to media that might show/expose violent news?

- television

- internet (e.g., news sites, blogs, etc.)

- $\quad$ social media (e.g., Facebook, Twitter, etc.)

- $\quad$ print media (e.g., magazines, newspaper, etc.) (number of hours) (number of hours) (number of hours) (number of hours)

4. What is the most frequent type of media that your child uses? Please rank $1-4,1$ being the most highly used and 4 being the least frequently used.

- television

- internet (e.g., news sites, blogs, etc.) (number 1 - 4)

(number 1 - 4) 
- social media (e.g., Facebook, Twitter, etc.) (number 1 - 4)

- print media (e.g., magazines, newspaper, etc.) (number 1 - 4)

5. How often do you place restrictions on your child's media use?

- television

\section{Never Rarely Often Almost Always}

- internet (e.g., news sites, blogs, etc.)

\section{Never Rarely Often Almost Always}

- social media (e.g., Facebook, Twitter, etc.)

\section{Never Rarely Often Almost Always}

- print media (e.g., magazines, newspaper, etc.)

\section{Never Rarely Often Almost Always}




\section{Appendix K: Demographics Questions}

1. How old are you? years old

2. Do you currently reside in the United States?
a. Yes
b. No

3. Do you spend more than $75 \%$ of the year living in the United States?
a. Yes
b. No

4. Which of the following best describes you:
a. American Indian or Native Alaskan
b. Asian
c. Black or African American
d. Native Hawaiian or Pacific Islander
e. White
f. Other, please specify:

5. Which of the following best describes you:
a. Hispanic
b. Not Hispanic

6. How many children do you have? number of children

7. What are the age (s) of your children? 
8. What is the age of the child that you had in mind when answering the questions in this survey?

9. Is at least one of your children between the ages 6 and 17 ?
a. Yes
b. No

10. Are you a primary caregiver to the child(ren) that you listed above?
a. Yes
b. No

11. Are you fluent in written and spoken English?
a. Yes
b. No

12. What is the highest level of education you have completed?
a. Never attended school or only attended kindergarten
b. Grades 1 through 8 (elementary/middle school)
c. Grades 9 through 11 (some high school)
d. Grade 12 or GED (high school graduate)
e. College 1 year to 3 years (some college or technical school)
f. College 4 years (college graduate)
g. Some graduate school (post college)
h. Graduate school degree (JD, MD, PhD, etc.)

13. Which of the following best describes you:
a. Male 
b. Female

c. Genderqueer/Androgynous

d. Intersex

e. Transgender

f. Transsexual

g. Cross-dresser

h. FTM (female-to-male)

i. MTF (male-to-female)

j. Other, please specify: 


\section{Appendix L: CRYME Item Frequencies}

Frequency of Responses for Item 1

-try to help your child make sense of the violent/tragic news by talking to him/her in a way that s/he can understand?

\begin{tabular}{llll}
\hline & Frequency & Percent & Cumulative Percent \\
Never & 31 & 4.4 & 4.4 \\
Rarely & 55 & 7.8 & 12.3 \\
Sometimes & 195 & 27.8 & 40 \\
Often & 254 & 36.2 & 76.2 \\
Almost Always & 167 & 23.8 & 100 \\
Total & 702 & 100 &
\end{tabular}

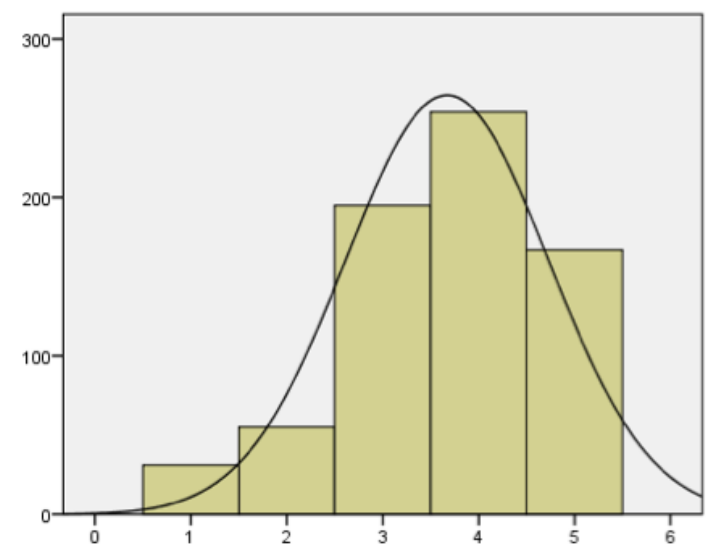


Frequency of Responses for Item 2

-explain the violent/tragic news in a way that s/he can understand?

\begin{tabular}{llll}
\hline & Frequency & Percent & Cumulative Percent \\
\hline Never & 20 & 2.8 & 2.8 \\
Rarely & 65 & 9.3 & 12.1 \\
Sometimes & 192 & 27.4 & 39.5 \\
Often & 260 & 37 & 76.5 \\
Almost Always & 165 & 23.5 & 100 \\
Total & 702 & 100 &
\end{tabular}

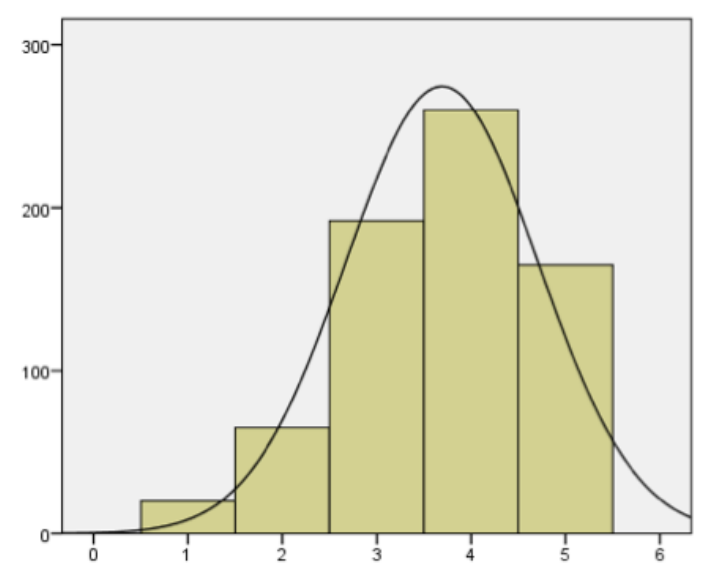


Frequency of Responses for Item 3

-talk with your child about aspects of the violent news that bother him/her the most?

\begin{tabular}{lllll}
\hline & & Frequency & Percent & Cumulative Percent \\
\hline & Never & 31 & 4.4 & 4.4 \\
& Rarely & 71 & 10.1 & 14.6 \\
& Sometimes & 257 & 36.6 & 51.2 \\
& Often & 242 & 34.5 & 85.7 \\
& Almost Always & 100 & 14.2 & 100 \\
& Total & 701 & 99.9 & \\
Missing & System & 1 & 0.1 & \\
Total & & 702 & 100 &
\end{tabular}

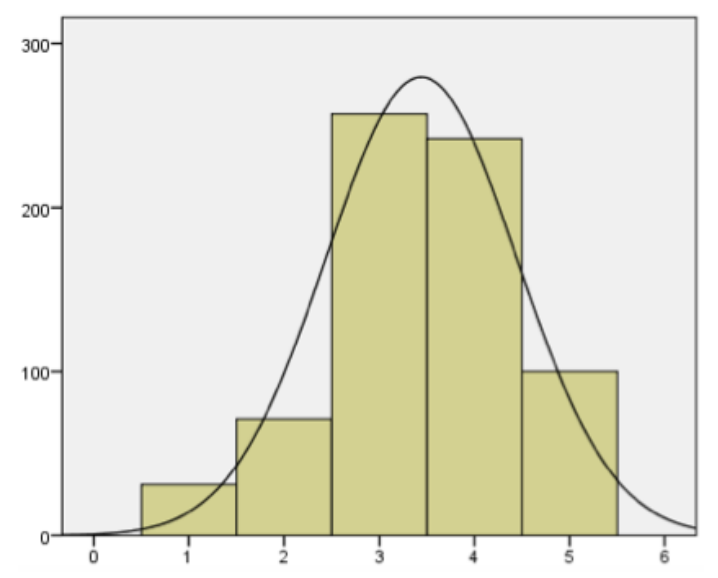


Frequency of Responses for Item 4

-reassure your child that you (his/her caregiver) are safe in spite of the violent/tragic news?

\begin{tabular}{lllll}
\hline & & Frequency & Percent & Cumulative Percent \\
\hline & Never & 15 & 2.1 & 2.1 \\
& Rarely & 48 & 6.8 & 9 \\
& Sometimes & 192 & 27.4 & 36.4 \\
& Often & 252 & 35.9 & 72.3 \\
& Almost Always & 194 & 27.6 & 100 \\
& Total & 701 & 99.9 & \\
Missing & System & 1 & 0.1 & \\
Total & & 702 & 100 &
\end{tabular}

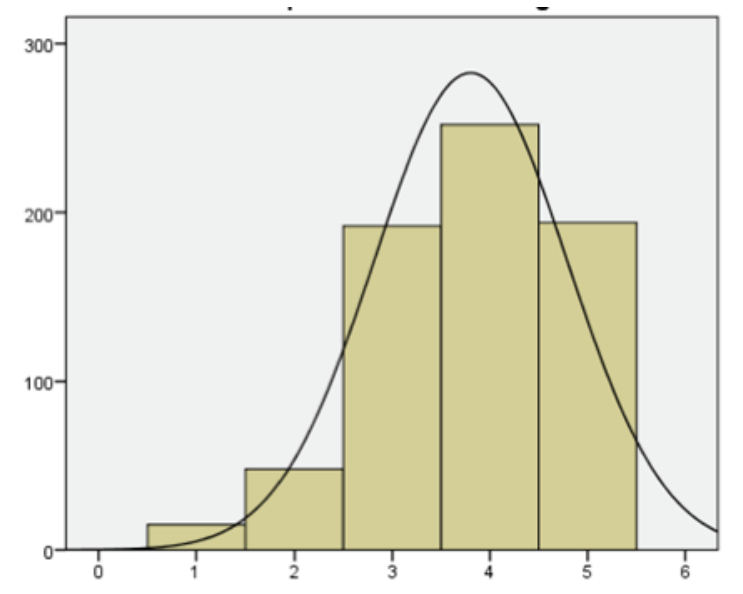


Frequency of Responses for Item 5

-reassure your child that $\mathrm{s} / \mathrm{he}$ is safe in spite of the violent/tragic news?

\begin{tabular}{llll}
\hline & Frequency & Percent & Cumulative Percent \\
\hline Never & 20 & 2.8 & 2.8 \\
Rarely & 51 & 7.3 & 10.1 \\
Sometimes & 165 & 23.5 & 33.6 \\
Often & 257 & 36.6 & 70.2 \\
Almost Always & 209 & 29.8 & 100 \\
Total & 702 & 100 &
\end{tabular}

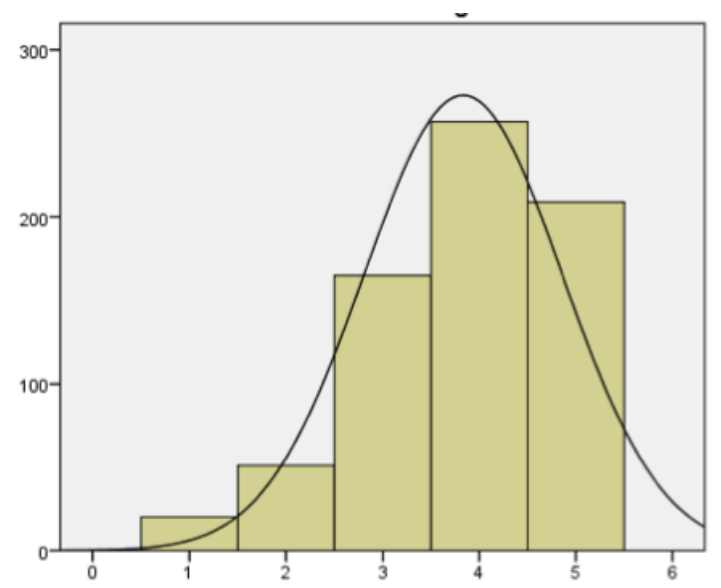


Frequency of Responses for Item 6

-explain to your child that you personally feel safe despite the violent/tragic news?

\begin{tabular}{llll}
\hline & Frequency & Percent & Cumulative Percent \\
\hline Never & 33 & 4.7 & 4.7 \\
Rarely & 62 & 8.8 & 13.5 \\
Sometimes & 215 & 30.6 & 44.2 \\
Often & 244 & 34.8 & 78.9 \\
Almost Always & 148 & 21.1 & 100 \\
Total & 702 & 100 &
\end{tabular}

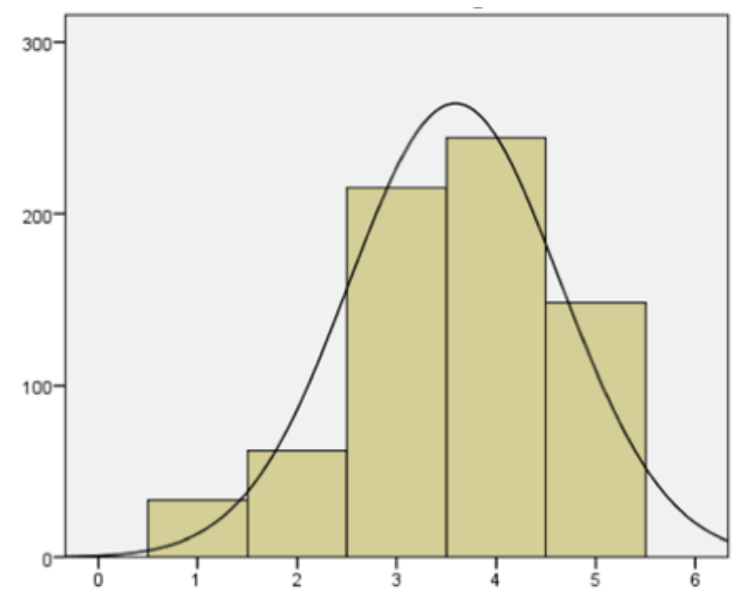


Frequency of Responses for Item 7

-ask your child how s/he feels about the violent/tragic news?

\begin{tabular}{llll}
\hline & Frequency & Percent & Cumulative Percent \\
\hline Never & 33 & 4.7 & 4.7 \\
Rarely & 108 & 15.4 & 20.1 \\
Sometimes & 258 & 36.8 & 56.8 \\
Often & 203 & 28.9 & 85.8 \\
Almost Always & 100 & 14.2 & 100 \\
Total & 702 & 100 &
\end{tabular}

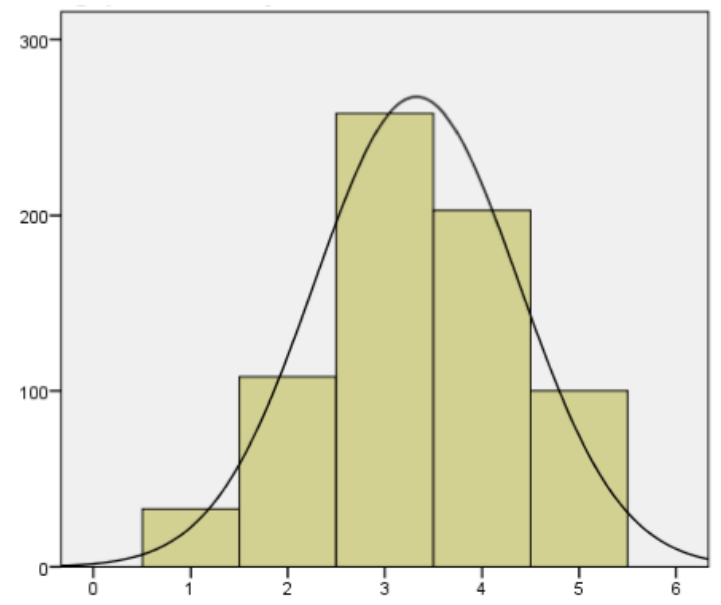


Frequency of Responses for Item 8

-encourage your child not to let the violent news change his/her day-to-day actions?

\begin{tabular}{lllll}
\hline & & Frequency & Percent & Cumulative Percent \\
\hline & Never & 38 & 5.4 & 5.4 \\
& Rarely & 88 & 12.5 & 18 \\
& Sometimes & 188 & 26.8 & 44.8 \\
& Often & 261 & 37.2 & 82 \\
& Almost Always & 126 & 17.9 & 100 \\
& Total & 701 & 99.9 & \\
Missing & System & 1 & 0.1 & \\
Total & & 702 & 100 &
\end{tabular}

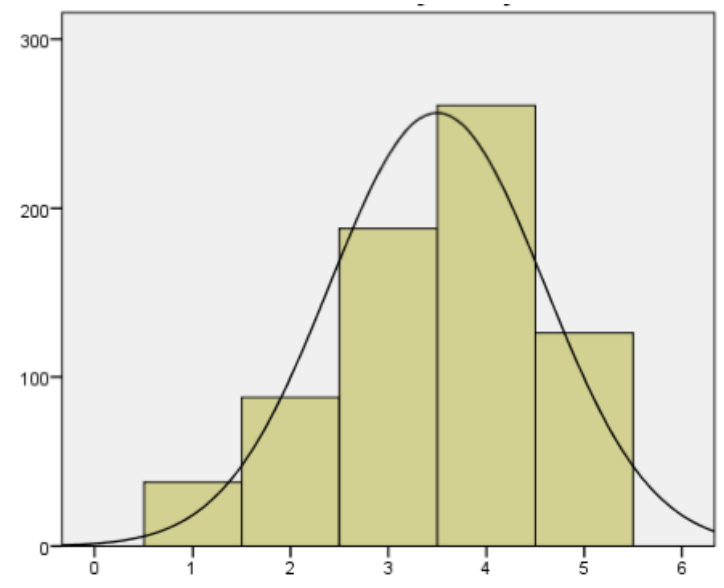


Frequency of Responses for Item 9

-teach your child that what s/he sees in the news cannot control how s/he lives his/her life?

\begin{tabular}{lllll}
\hline & & Frequency & Percent & Cumulative Percent \\
\hline \multirow{4}{*}{ Never } & 40 & 5.7 & 5.7 \\
& Rarely & 84 & 12 & 17.7 \\
& Sometimes & 236 & 33.6 & 51.4 \\
& Often & 242 & 34.5 & 86 \\
& Almost Always & 98 & 14 & 100 \\
& Total & 700 & 99.7 & \\
Missing & System & 2 & 0.3 & \\
Total & & 702 & 100 &
\end{tabular}

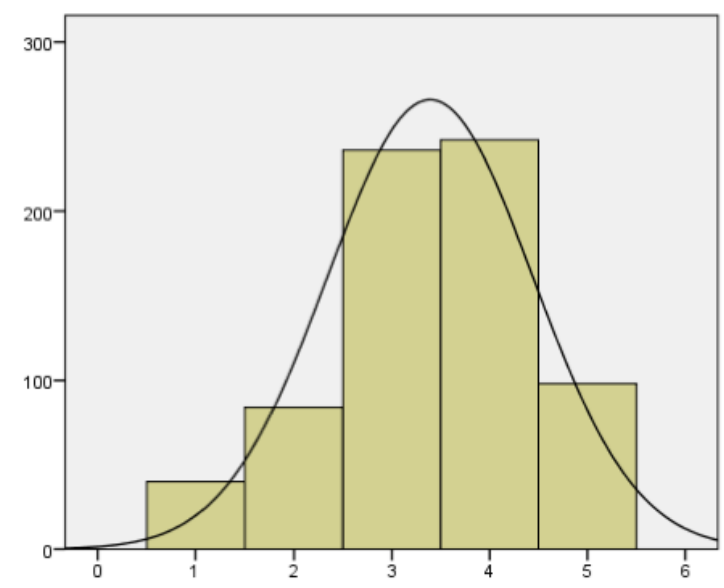


Frequency of Responses for Item 10

-point out something reassuring about the violent/tragic news (for example: no deaths, the perpetrator was caught, etc.)?

\begin{tabular}{llll}
\hline & Frequency & Percent & Cumulative Percent \\
\hline Never & 44 & 6.3 & 6.3 \\
Rarely & 84 & 12 & 18.2 \\
Sometimes & 261 & 37.2 & 55.4 \\
Often & 225 & 32.1 & 87.5 \\
Almost Always & 88 & 12.5 & 100 \\
Total & 702 & 100 &
\end{tabular}

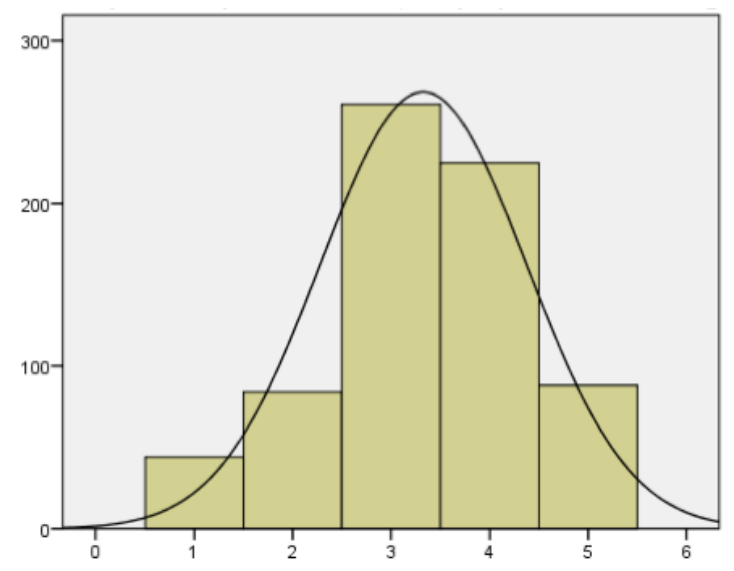


Frequency of Responses for Item 11

-explain ways in which the government, police, or other officials addressed the situation?

\begin{tabular}{lllll}
\hline & & Frequency & Percent & Cumulative Percent \\
\hline \multirow{4}{*}{ Never } & 44 & 6.3 & 6.3 \\
& Rarely & 94 & 13.4 & 19.7 \\
& Sometimes & 262 & 37.3 & 57.1 \\
& Often & 213 & 30.3 & 87.6 \\
& Almost Always & 87 & 12.4 & 100 \\
& Total & 700 & 99.7 & \\
Missing & System & 2 & 0.3 & \\
Total & & 702 & 100 &
\end{tabular}

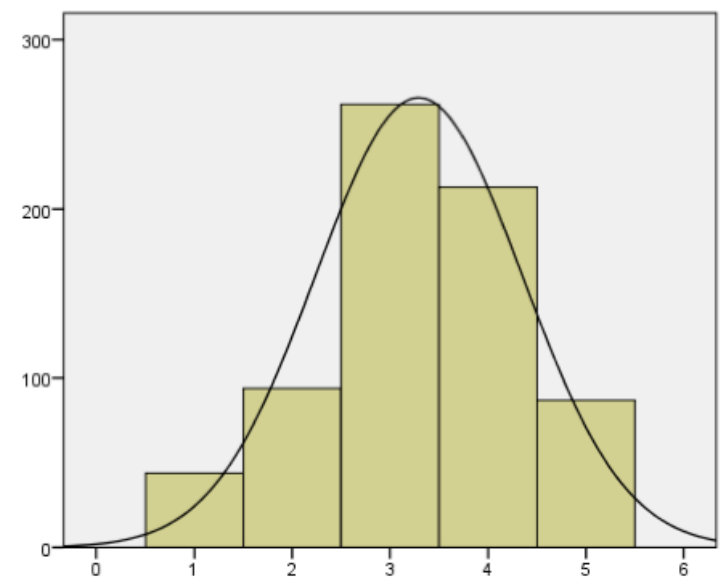


Frequency of Responses for Item 12

-talk to your child about how this news event affects him/her personally?

\begin{tabular}{llll}
\hline & Frequency & Percent & Cumulative Percent \\
\hline Never & 44 & 6.3 & 6.3 \\
Rarely & 104 & 14.8 & 21.1 \\
Sometimes & 294 & 41.9 & 63 \\
Often & 187 & 26.6 & 89.6 \\
Almost Always & 73 & 10.4 & 100 \\
Total & 702 & 100 &
\end{tabular}

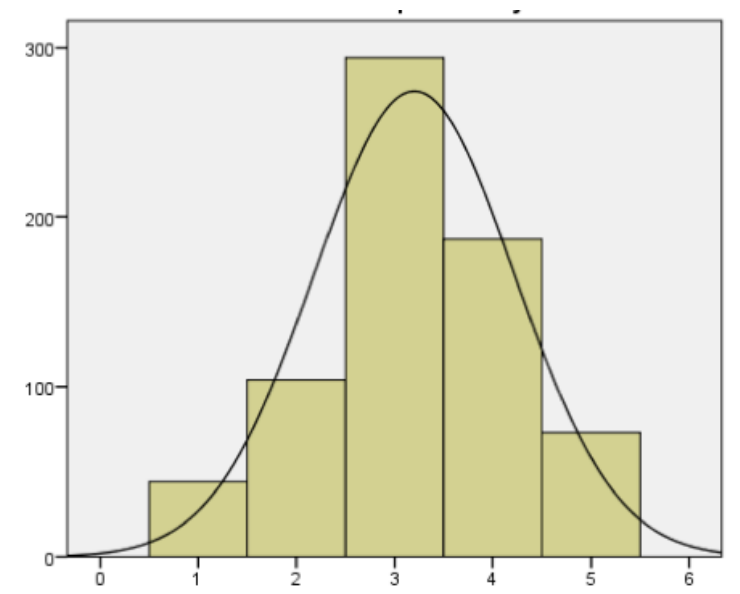


Frequency of Responses for Item 13

-point out something positive about the violent/tragic news (for example: humanity, sense of community, heroism)?

\begin{tabular}{lllll}
\hline & & Frequency & Percent & Cumulative Percent \\
\hline & Never & 48 & 6.8 & 6.8 \\
& Rarely & 81 & 11.5 & 18.4 \\
& Sometimes & 275 & 39.2 & 57.6 \\
& Often & 195 & 27.8 & 85.4 \\
& Almost Always & 102 & 14.5 & 100 \\
& Total & 701 & 99.9 & \\
Missing & System & 1 & 0.1 & \\
Total & & 702 & 100 &
\end{tabular}

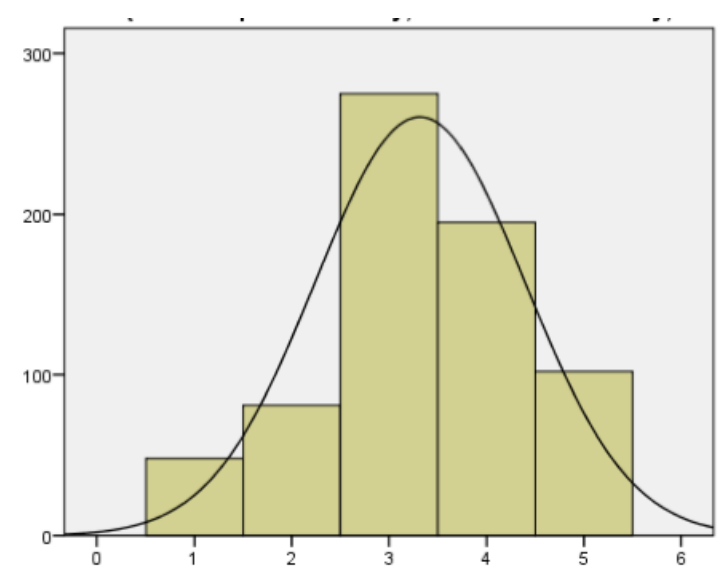


Frequency of Responses for Item 14

-explain the likelihood of this event happening again?

\begin{tabular}{lllll}
\hline & & Frequency & Percent & Cumulative Percent \\
\hline & Never & 44 & 6.3 & 6.3 \\
& Rarely & 109 & 15.5 & 21.8 \\
& Sometimes & 321 & 45.7 & 67.6 \\
& Often & 170 & 24.2 & 91.9 \\
& Almost Always & 57 & 8.1 & 100 \\
& Total & 701 & 99.9 & \\
Missing & System & 1 & 0.1 & \\
Total & & 702 & 100 &
\end{tabular}

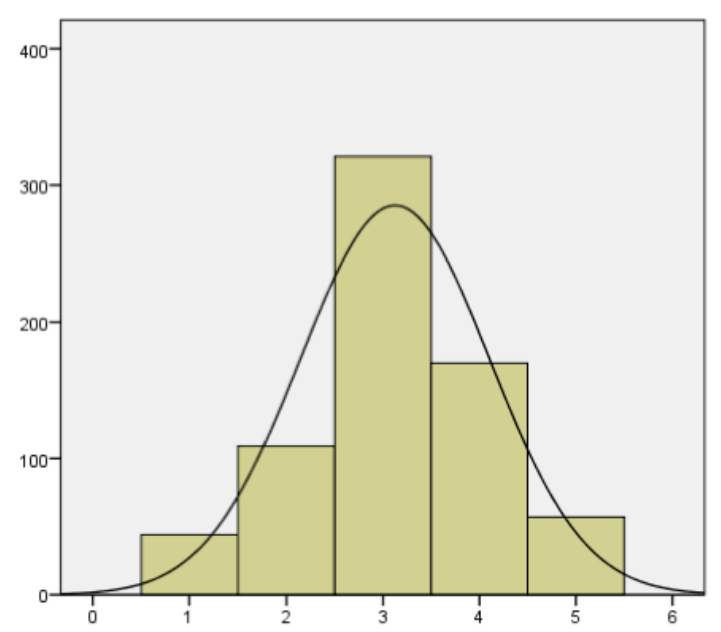


Frequency of Responses for Item 15

-interrupt your child's exposure to the media because it's not appropriate for his/her age?

\begin{tabular}{llll}
\hline & Frequency & Percent & Cumulative Percent \\
\hline Never & 70 & 10 & 10 \\
Rarely & 122 & 17.4 & 27.4 \\
Sometimes & 231 & 32.9 & 60.3 \\
Often & 167 & 23.8 & 84 \\
Almost Always & 112 & 16 & 100 \\
Total & 702 & 100 &
\end{tabular}

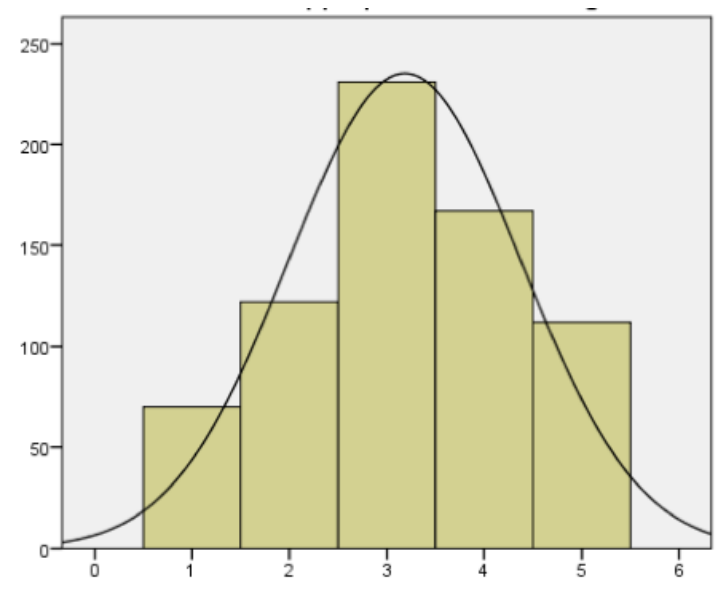


Frequency of Responses for Item 16

-keep your child from learning about violent/tragic news you believe would scare or worry your child?

\begin{tabular}{llll}
\hline & Frequency & Percent & Cumulative Percent \\
\hline Never & 93 & 13.2 & 13.2 \\
Rarely & 187 & 26.6 & 39.9 \\
Sometimes & 208 & 29.6 & 69.5 \\
Often & 140 & 19.9 & 89.5 \\
Almost Always & 74 & 10.5 & 100 \\
Total & 702 & 100 &
\end{tabular}

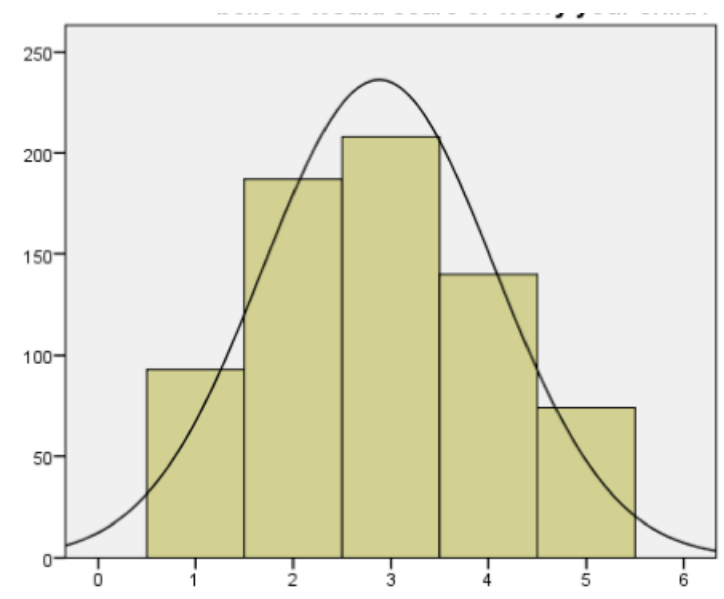




\section{Frequency of Responses for Item 17}

-ask your child to leave the room when violent/tragic news is displayed in the media?

\begin{tabular}{llll}
\hline & Frequency & Percent & Cumulative Percent \\
\hline Never & 136 & 19.4 & 19.4 \\
Rarely & 172 & 24.5 & 43.9 \\
Sometimes & 212 & 30.2 & 74.1 \\
Often & 117 & 16.7 & 90.7 \\
Almost Always & 65 & 9.3 & 100 \\
Total & 702 & 100 &
\end{tabular}

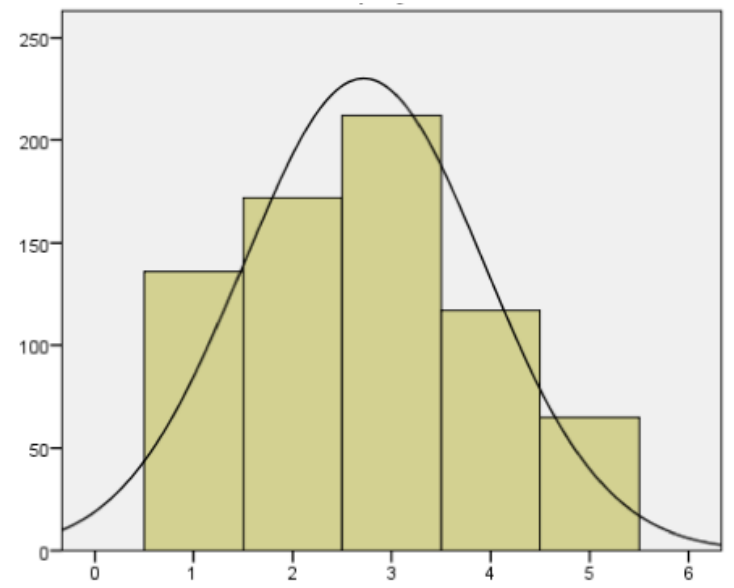


Frequency of Responses for Item 18

-forbid your child to watch certain programs, avoid certain Internet sites, or read certain print material (for example: books, magazines, newspapers) regarding violent/tragic news?

\begin{tabular}{llll}
\hline & Frequency & Percent & Cumulative Percent \\
\hline Never & 96 & 13.7 & 13.7 \\
Rarely & 130 & 18.5 & 32.2 \\
Sometimes & 186 & 26.5 & 58.7 \\
Often & 142 & 20.2 & 78.9 \\
Almost Always & 148 & 21.1 & 100 \\
Total & 702 & 100 &
\end{tabular}

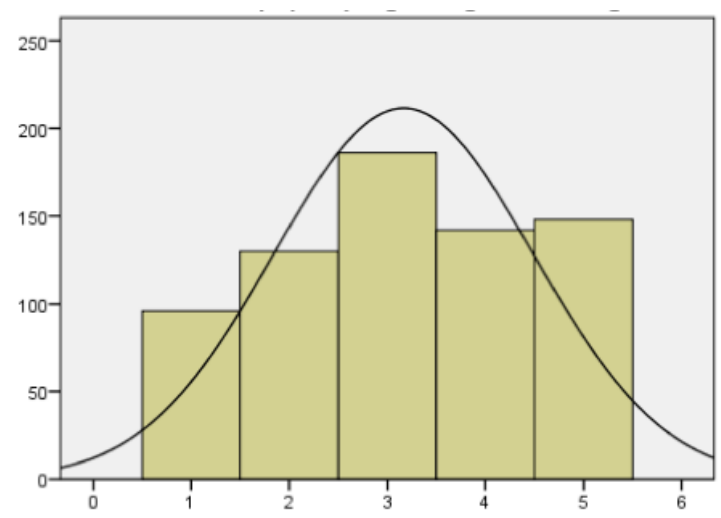


Frequency of Responses for Item 19

-interrupt your child's exposure to the media (for example, by telling him/her to turn off the TV)?

\begin{tabular}{llll}
\hline & Frequency & Percent & Cumulative Percent \\
\hline Never & 69 & 9.8 & 9.8 \\
Rarely & 134 & 19.1 & 28.9 \\
Sometimes & 272 & 38.7 & 67.7 \\
Often & 145 & 20.7 & 88.3 \\
Almost Always & 82 & 11.7 & 100 \\
Total & 702 & 100 &
\end{tabular}

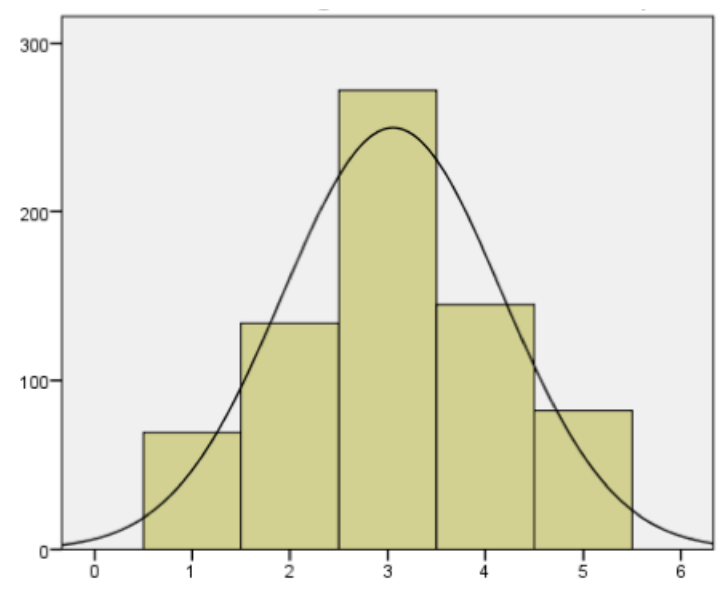


Frequency of Responses for Item 20

-specify in advance the TV programs, Internet sites, or specific print media your child can view/use in order to limit access to violent/tragic news?

\begin{tabular}{llll}
\hline & Frequency & Percent & Cumulative Percent \\
\hline Never & 79 & 11.3 & 11.3 \\
Rarely & 129 & 18.4 & 29.6 \\
Sometimes & 168 & 23.9 & 53.6 \\
Often & 182 & 25.9 & 79.5 \\
Almost Always & 144 & 20.5 & 100 \\
Total & 702 & 100 &
\end{tabular}

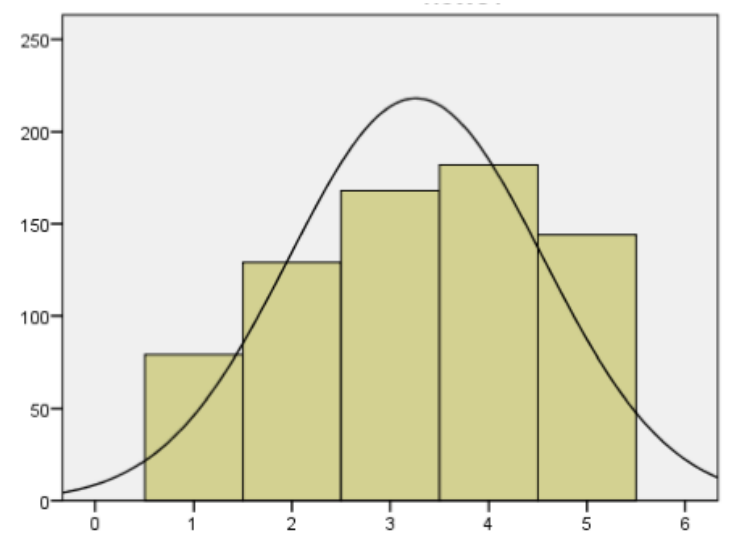


Frequency of Responses for Item 21

-leave out details of the violent/tragic news when discussing it with your child to protect $\operatorname{him} /$ her?

\begin{tabular}{llll}
\hline & Frequency & Percent & Cumulative Percent \\
\hline Never & 68 & 9.7 & 9.7 \\
Rarely & 150 & 21.4 & 31.1 \\
Sometimes & 270 & 38.5 & 69.5 \\
Often & 151 & 21.5 & 91 \\
Almost Always & 63 & 9 & 100 \\
Total & 702 & 100 &
\end{tabular}

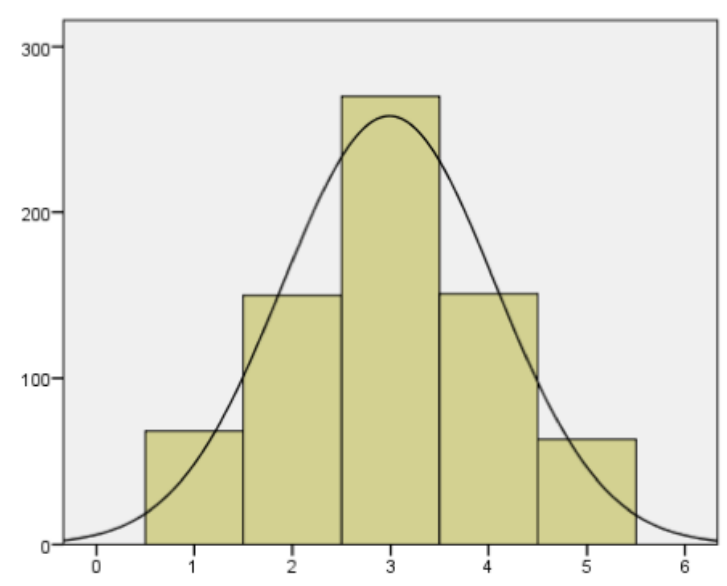


Frequency of Responses for Item 22

-purposefully leave out details of the violent/tragic news when discussing it with your child?

\begin{tabular}{llll}
\hline & Frequency & Percent & Cumulative Percent \\
\hline Never & 73 & 10.4 & 10.4 \\
Rarely & 134 & 19.1 & 29.5 \\
Sometimes & 271 & 38.6 & 68.1 \\
Often & 161 & 22.9 & 91 \\
Almost Always & 63 & 9 & 100 \\
Total & 702 & 100 &
\end{tabular}

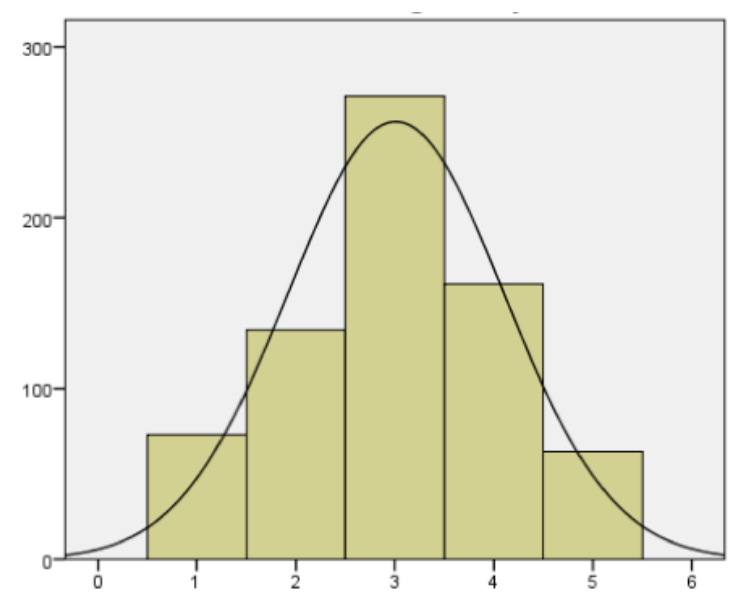


Frequency of Responses for Item 23

-set parental controls on devices in your home that enable blocking certain TV channels, Internet sites, etc. to limit access to violent/tragic news?

\begin{tabular}{llll}
\hline & Frequency & Percent & Cumulative Percent \\
\hline Never & 151 & 21.5 & 21.5 \\
Rarely & 107 & 15.2 & 36.8 \\
Sometimes & 135 & 19.2 & 56 \\
Often & 150 & 21.4 & 77.4 \\
Almost Always & 159 & 22.6 & 100 \\
Total & 702 & 100 &
\end{tabular}

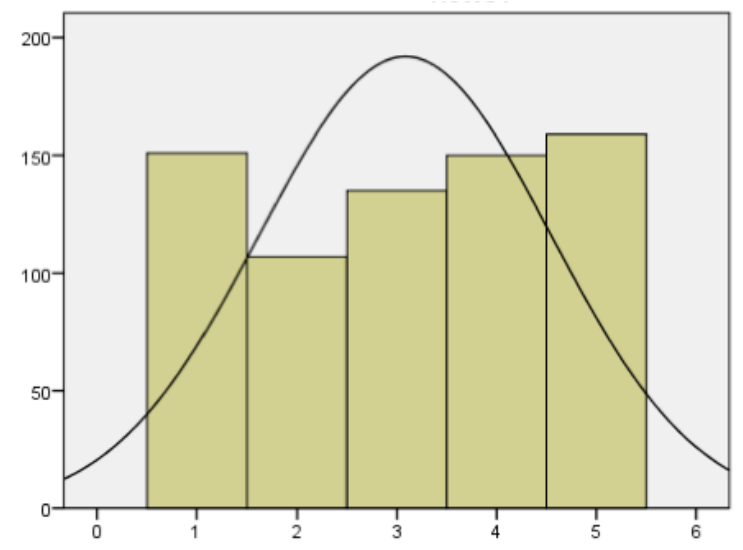


Frequency of Responses for Item 24

-avoid talking to your child about the violent/tragic news?

\begin{tabular}{lllll}
\hline & & Frequency & Percent & Cumulative Percent \\
\hline \multirow{4}{*}{ Never } & 159 & 22.6 & 22.7 \\
& Rarely & 227 & 32.3 & 55.1 \\
& Sometimes & 184 & 26.2 & 81.3 \\
& Often & 95 & 13.5 & 94.9 \\
& Almost Always & 36 & 5.1 & 100 \\
& Total & 701 & 99.9 & \\
Missing & System & 1 & 0.1 & \\
Total & & 702 & 100 &
\end{tabular}

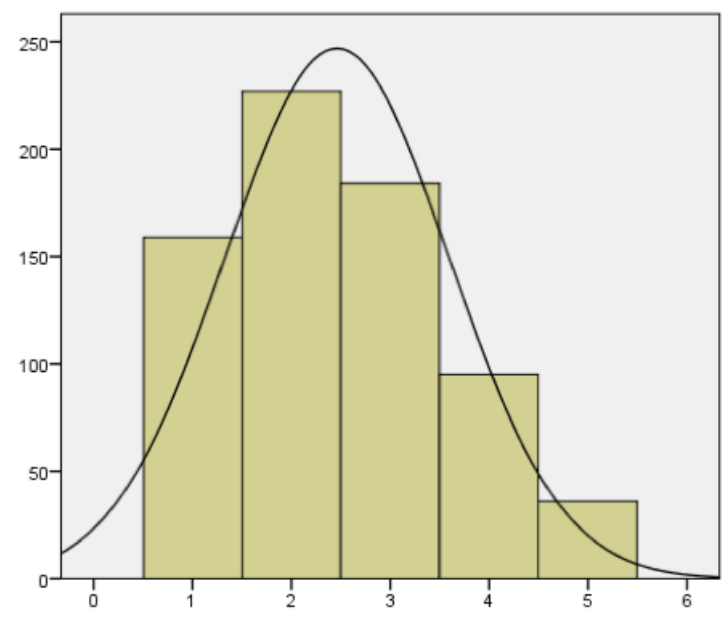


Frequency of Responses for Item 25

-use the violent/tragic news to scare your child with the purpose of protecting him/her from harm?

\begin{tabular}{lllll}
\hline & & Frequency & Percent & Cumulative Percent \\
\hline & Never & 271 & 38.6 & 38.7 \\
& Rarely & 175 & 24.9 & 63.6 \\
& Sometimes & 175 & 24.9 & 88.6 \\
& Often & 62 & 8.8 & 97.4 \\
& Almost Always & 18 & 2.6 & 100 \\
& Total & 701 & 99.9 & \\
Missing & System & 1 & 0.1 & \\
Total & & 702 & 100 &
\end{tabular}

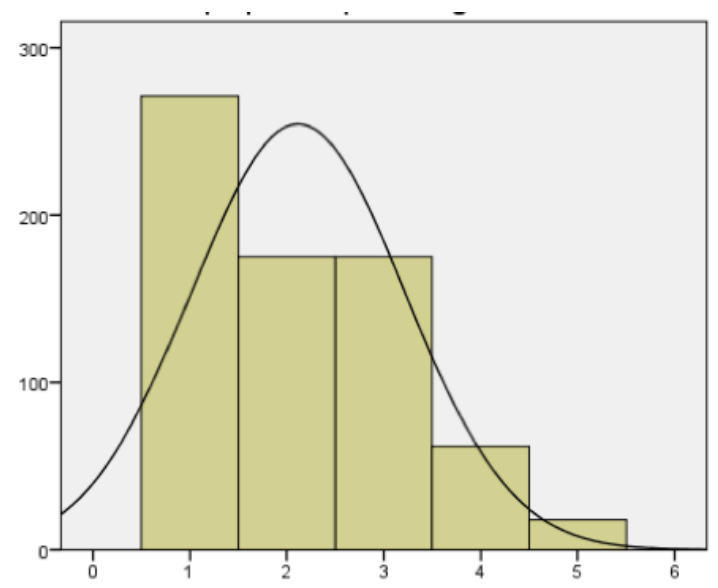


Frequency of Responses for Item 26

-use the violent/tragic news to scare your child away from participating in dangerous activities?

\begin{tabular}{lllll}
\hline & & Frequency & Percent & Cumulative Percent \\
& Never & 201 & 28.6 & 28.7 \\
& Rarely & 195 & 27.8 & 56.5 \\
& Sometimes & 193 & 27.5 & 84 \\
& Often & 79 & 11.3 & 95.3 \\
& Almost Always & 33 & 4.7 & 100 \\
& Total & 701 & 99.9 & \\
Missing & System & 1 & 0.1 & \\
Total & & 702 & 100 &
\end{tabular}

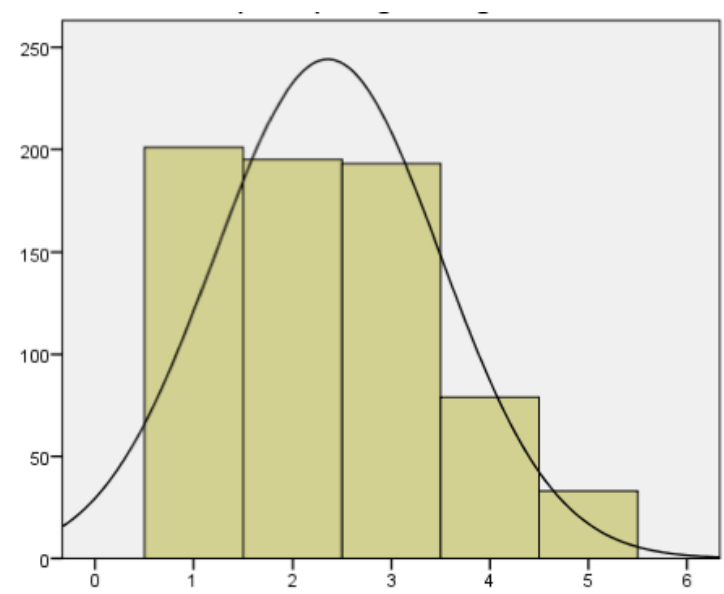


Frequency of Responses for Item 27

-use the violent/tragic news as a way to teach your child to fear similar situations?

\begin{tabular}{llll}
\hline & Frequency & Percent & Cumulative Percent \\
\hline Never & 152 & 21.7 & 21.7 \\
Rarely & 193 & 27.5 & 49.1 \\
Sometimes & 237 & 33.8 & 82.9 \\
Often & 93 & 13.2 & 96.2 \\
Almost Always & 27 & 3.8 & 100 \\
Total & 702 & 100 &
\end{tabular}

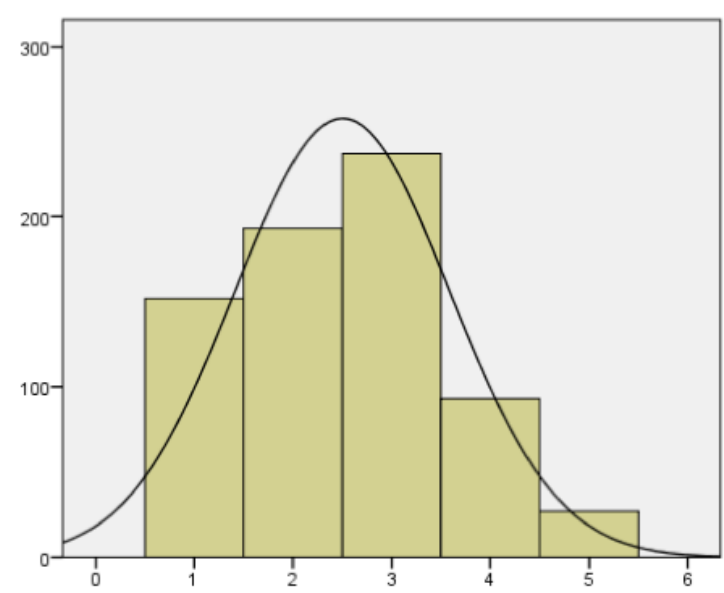


Frequency of Responses for Item 28

-scare your child into being cautious in similar situations?

\begin{tabular}{llll}
\hline & Frequency & Percent & Cumulative Percent \\
\hline Never & 261 & 37.2 & 37.2 \\
Rarely & 197 & 28.1 & 65.2 \\
Sometimes & 159 & 22.6 & 87.9 \\
Often & 65 & 9.3 & 97.2 \\
Almost Always & 20 & 2.8 & 100 \\
Total & 702 & 100 &
\end{tabular}

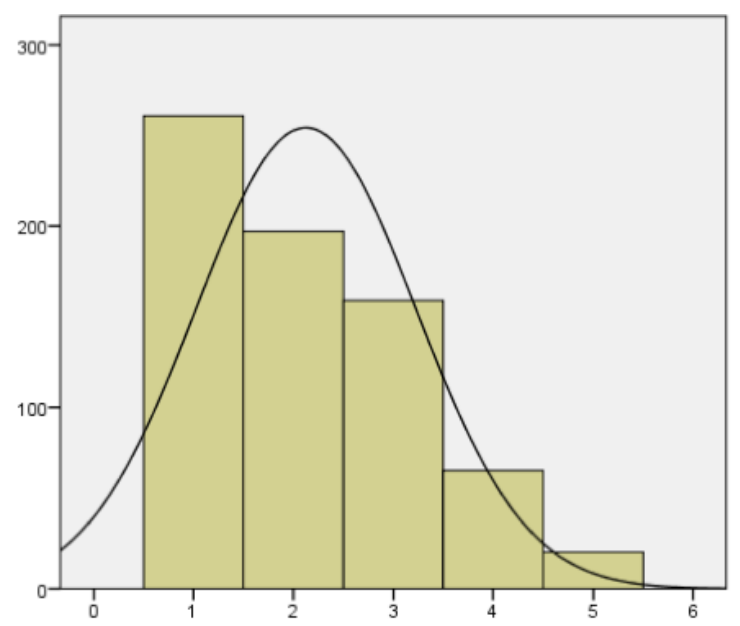


Frequency of Responses for Item 29

-express that you are fearful or worried about the violent/tragic news when with your child?

\begin{tabular}{llll}
\hline & Frequency & Percent & Cumulative Percent \\
\hline Never & 169 & 24.1 & 24.1 \\
Rarely & 226 & 32.2 & 56.3 \\
Sometimes & 198 & 28.2 & 84.5 \\
Often & 83 & 11.8 & 96.3 \\
Almost Always & 26 & 3.7 & 100 \\
Total & 702 & 100 &
\end{tabular}

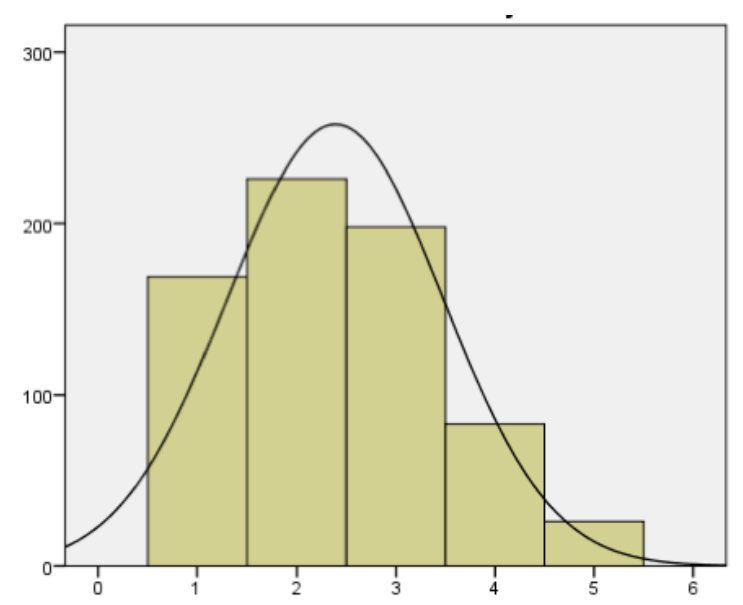


Frequency of Responses for Item 30

-explain to your child how the violent/tragic event could happen to you or another person in a close relationship to your child?

\begin{tabular}{llll}
\hline & Frequency & Percent & Cumulative Percent \\
\hline Never & 113 & 16.1 & 16.1 \\
Rarely & 213 & 30.3 & 46.4 \\
Sometimes & 233 & 33.2 & 79.6 \\
Often & 105 & 15 & 94.6 \\
Almost Always & 38 & 5.4 & 100 \\
Total & 702 & 100 &
\end{tabular}

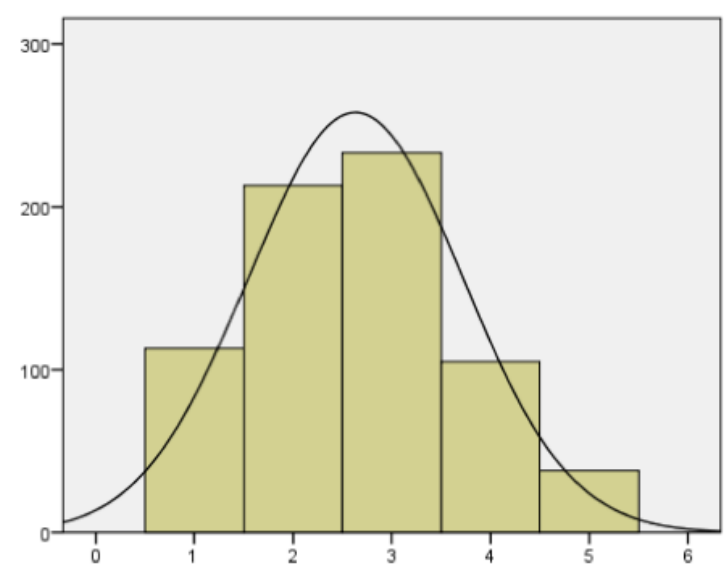


Frequency of Responses for Item 31

-watch or view the violent/tragic news together because of a shared curiosity?

\begin{tabular}{lccc}
\hline & Frequency & Percent & Cumulative Percent \\
\hline Never & 134 & 19.1 & 19.1 \\
Rarely & 176 & 25.1 & 44.2 \\
Sometimes & 230 & 32.8 & 76.9 \\
Often & 126 & 17.9 & 94.9 \\
Almost Always & 36 & 5.1 & 100 \\
Total & 702 & 100 &
\end{tabular}

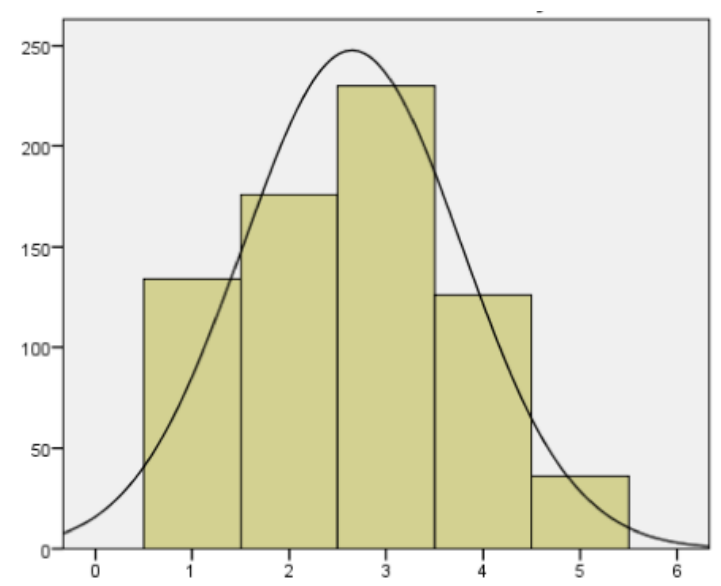


Frequency of Responses for Item 32

-emphasize that violent/tragic news is a reality in an effort to protect your child from harm?

\begin{tabular}{llll}
\hline & Frequency & Percent & Cumulative Percent \\
\hline Never & 78 & 11.1 & 11.1 \\
Rarely & 155 & 22.1 & 33.2 \\
Sometimes & 276 & 39.3 & 72.5 \\
Often & 148 & 21.1 & 93.6 \\
Almost Always & 45 & 6.4 & 100 \\
Total & 702 & 100 &
\end{tabular}

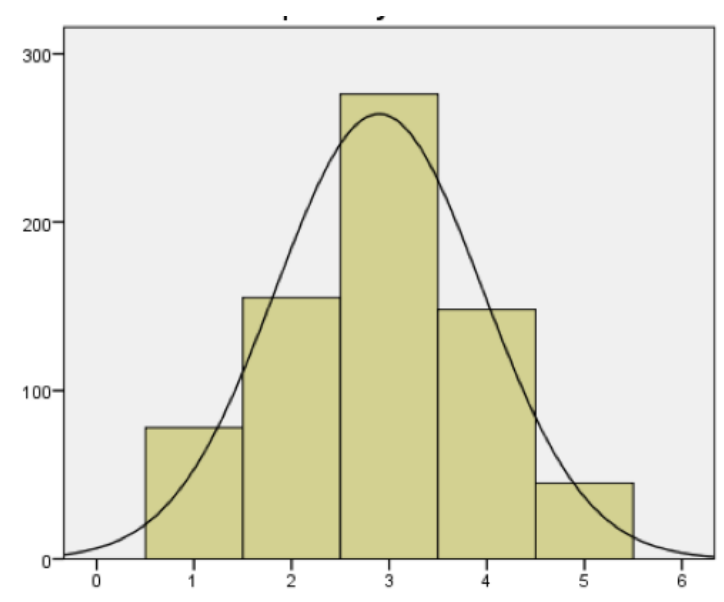


Frequency of Responses for Item 33

-ask your child if s/he thinks about the event even when s/he is not actively viewing it?

\begin{tabular}{llll}
\hline & Frequency & Percent & Cumulative Percent \\
\hline Never & 124 & 17.7 & 17.7 \\
Rarely & 191 & 27.2 & 44.9 \\
Sometimes & 233 & 33.2 & 78.1 \\
Often & 114 & 16.2 & 94.3 \\
Almost Always & 40 & 5.7 & 100 \\
Total & 702 & 100 &
\end{tabular}

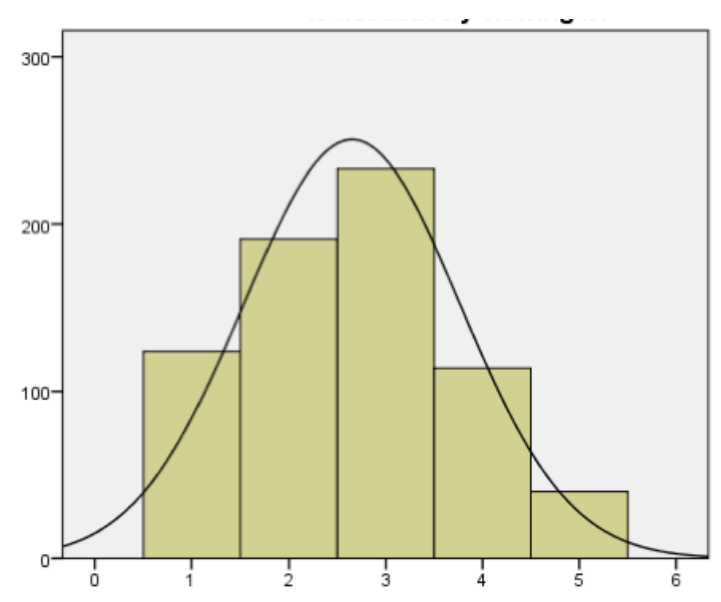


Frequency of Responses for Item 34

-ask your child if s/he has trouble sleeping at night because of the violent/tragic news?

\begin{tabular}{lccc}
\hline & Frequency & Percent & Cumulative Percent \\
\hline Never & 142 & 20.2 & 20.2 \\
Rarely & 169 & 24.1 & 44.3 \\
Sometimes & 238 & 33.9 & 78.2 \\
Often & 112 & 16 & 94.2 \\
Almost Always & 41 & 5.8 & 100 \\
Total & 702 & 100 &
\end{tabular}

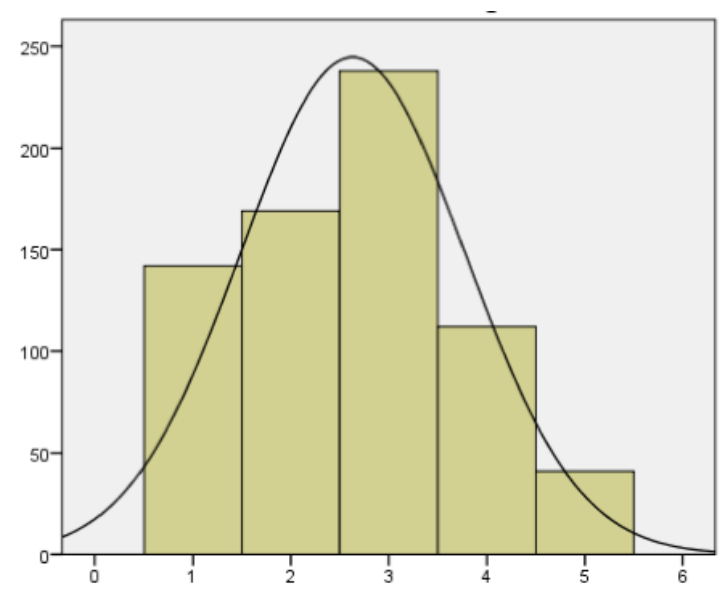


Frequency of Responses for Item 35

-openly, without restraint, express your emotions about the violent/tragic news around your child?

\begin{tabular}{llll}
\hline & Frequency & Percent & Cumulative Percent \\
\hline Never & 96 & 13.7 & 13.7 \\
Rarely & 185 & 26.4 & 40 \\
Sometimes & 259 & 36.9 & 76.9 \\
Often & 112 & 16 & 92.9 \\
Almost Always & 50 & 7.1 & 100 \\
Total & 702 & 100 &
\end{tabular}

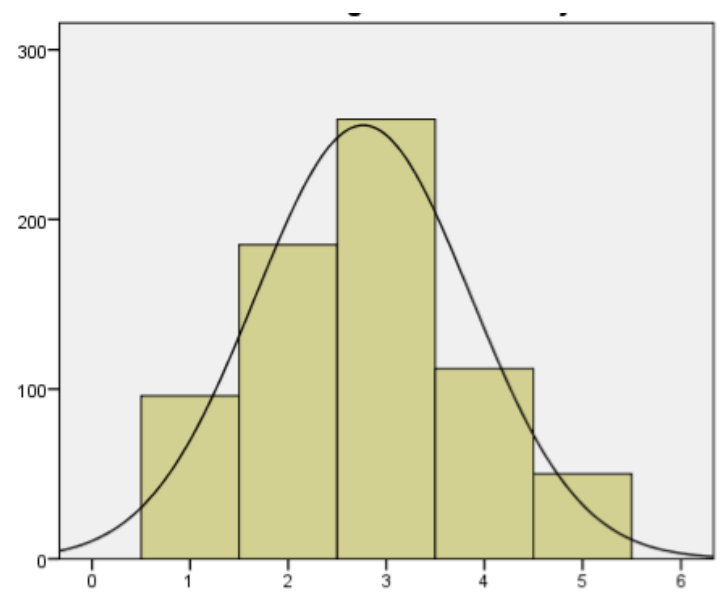




\section{Appendix M: Caregiver's Response to Youth Media Exposure (CRYME) Post-EFA}

Please circle never, rarely, sometimes, often, or almost always for each of the following questions. All of the questions refer specifically to violent/tragic news in the media (terrorist attacks, school shootings, bombings, natural disasters, hurricanes, floods, fires, etc.).

With regard to what your child sees on TV, the internet (news sites, social media, etc.), or in print media (magazines, newspapers, etc.), how often do you...

\section{Never Rarely Sometimes Often Almost Always}

1. try to help your child make sense of the violent/tragic news by talking to him/her in a way that s/he can understand?

2. Explain the violent/tragic news in a way that s/he can understand?

3. Talk with your child about aspects of the violent news that bother him/her the most?

4. Reassure your child that you (his/her caregiver) are safe in spite of the violent/tragic news?

5. Reassure your child that s/he is safe in spite of the violent/tragic news?

6. Explain to your child that you personally feel safe despite the violent/tragic news?

7. Ask you child how s/he feels about the violent/tragic news?

8. Encourage your child not to let the violent news change his/her day-to-day actions?

9. Teach you child that what s/he sees in the news cannot control how s/he lives his/her life?

10. Point out something reassuring about the violent/tragic news (for example: no deaths, the perpetrator was caught, etc.)?

11. Explain ways in which the government, police, or other officials addressed the situation?

12. Talk to your child about how this news event affects him/her personally? 
13. Point out something positive about the violent/tragic news (for example: humanity, sense of community, heroism)?

14. Explain the likelihood of this event happening again?

15. Interrupt your child's exposure to the media because its not appropriate for his/her age?

16. Keep your child from learning about violent/tragic news you believe would scare or worry your child?

17. Ask your child to leave the room when violent/tragic news is displayed in the media?

18. Forbid your child to watch certain programs, avoid certain internet sites, or read certain print material (for example: books, magazines, newspapers) regarding violent/tragic news?

19. Interrupt your child's exposure to the media (for example, by telling him/her to turn off the TV)?

20. Specify in advance the TV programs, Internet sites, or specific print media your child can view/use in order to limit access to violent/tragic news?

21. Leave out details of the violent/tragic news when discussing it with your child to protect $\operatorname{him} /$ her?

22. Purposefully leave out details of the violent/tragic news when discussing it with your child?

23. Set parental controls on devices in your home that enable blocking certain TV channels, Internet sites, etc. to limit access to violent/tragic news?

24. Avoid talking to your child about the violent/tragic news?

25. Use the violent/tragic news to scare your child with the purpose of protecting him/her from harm? 
26. Use the violent/tragic news to scare your child away from participating in dangerous activities?

27. Use the violent/tragic news as a way to teach your child to fear similar situations?

28. scare your child into being cautious in similar situations?

29. Express that you are fearful or worried about the violent/tragic news when with your child?

30. Explain to your child how the violent/tragic news event could happen to you or another person in a close relationship with your child?

31. Watch or view the violent/tragic news together because of a shared curiosity?

32. Emphasize that violent/tragic news is a reality in an effort to protect your child from harm?

33. Ask your child if s/he thinks about the event even when s/he is not actively viewing it?

34. Ask your child if s/he has trouble sleeping at night because of the violent/tragic news?

35. Openly, without restraint, express your emotions about that violent/tragic news around your child? 